NBER WORKING PAPER SERIES

\title{
LOCATION CHOICE, PORTFOLIO CHOICE
}

\author{
Ioannis Branikas \\ Harrison Hong \\ Jiangmin $\mathrm{Xu}$
}

Working Paper 23040

http://www.nber.org/papers/w23040

\author{
NATIONAL BUREAU OF ECONOMIC RESEARCH \\ 1050 Massachusetts Avenue \\ Cambridge, MA 02138 \\ January 2017
}

We thank Ulrich Mueller, Mark Watson, Chris Sims, Bo Honore, Kirill Evdokimov, Motohiro Yogo, Atif Mian, Jakub Kastl, and participants at Econometrics and Finance seminars at Princeton University, University of Toronto, Johns Hopkins University, 2016 LACEA/LAMES Conference, the 2016 China Five-Star Workshop in Finance, and the 2016 NYU Shanghai Volatility Institute Conference for helpful comments. The views expressed herein are those of the authors and do not necessarily reflect the views of the National Bureau of Economic Research.

NBER working papers are circulated for discussion and comment purposes. They have not been peer-reviewed or been subject to the review by the NBER Board of Directors that accompanies official NBER publications.

(C) 2017 by Ioannis Branikas, Harrison Hong, and Jiangmin Xu. All rights reserved. Short sections of text, not to exceed two paragraphs, may be quoted without explicit permission provided that full credit, including $\left({ }^{\circ}\right.$ notice, is given to the source. 
Location Choice, Portfolio Choice

Ioannis Branikas, Harrison Hong, and Jiangmin $\mathrm{Xu}$

NBER Working Paper No. 23040

January 2017

JEL No. G02,G11,R2,R22

\begin{abstract}
$\underline{\text { ABSTRACT }}$
Households hold nondiversified stock portfolios of firms headquartered near their city of residence. Explanations assign a causal role for proximity, either in generating an informational advantage or a familiarity bias. Empirical analyses assume households locate randomly, even though they optimally select a city. This selection is important since latent location factors might be correlated with latent demand for local stocks. Building on location choice models from urban economics, we develop a Heckman (1977)-style model to account for the effect of location choices on portfolio choices. Adjusting for selection significantly reduces local bias and the performance of local stock picks.
\end{abstract}

Ioannis Branikas

Economics Department

Princeton University Fisher Hall, Room 001

Princeton, NJ 08544

branikas@princeton.edu

Harrison Hong

Department of Economics

Columbia University

1022 International Affairs Building

Mail Code 3308

420 West 118th Street

New York, NY 10027

and NBER

hh2679@columbia.edu
Jiangmin Xu

Department of Finance

Guanghua School of Management

Peking University

jiangminxu@gsm.pku.edu.cn 


\section{Introduction}

A long-standing puzzle in financial economics is that households hold undiversified stock portfolios tilted toward firms headquartered near where they reside. Contrary to a valueweighted market portfolio prescription of the CAPM (Sharpe (1964)), households load on local stocks regardless of their market value. In canonical regressions of household stockportfolio weights on demographic and stock characteristics, distance from household residence to firm headquarters emerges as a key explanatory variable. This local-bias appears in many countries. ${ }^{1}$ This phenomenon is even more puzzling in some ways than its betterknown cousin, the international home-bias puzzle, where households in different countries tilt toward stocks in their own country (French and Poterba (1991)). In the international setting, portfolio costs or restrictions at least seem plausible impediments toward diversification.

Given the potentially high costs of under-diversification for households, many theories have been given for this local bias in the literature. ${ }^{2}$ There are two influential interpretations for local bias, and both revolve around the causal role of proximity. The first is that proximity confers an informational advantage to investors due to costly information acquisition. ${ }^{3}$ Households' investments in local stocks should offer higher expected returns compared to their non-local positions under this theory. The second is that proximity breeds familiarity or cognitive bias, whereby local positions mostly lead to under-diversification without necessarily being compensated with expected returns. ${ }^{4}$ There is evidence that the local stock picks of households out-perform their distant stock picks but there are still debates as to

\footnotetext{
${ }^{1}$ Prominent studies include the US (Zhu (2002)), Finland (Grinblatt and Keloharju (2001)), and China (Feng and Seasholes (2008)) to name a few.

${ }^{2}$ There is a sizeable literature examining the potential costs of under-diversification in stock portfolios and financial mistakes or literacy more generally (see, e.g., Campbell (2006), Bayer, Bernheim, and Scholz (2009), Agarwal, Driscoll, Gabaix, and Laibson (2009), Lusardi and Mitchell (2007)). Many households around the world have concentrated local stock holdings and little diversification through other investment vehicles (see, e.g., Keloharju, Knupfer, and Rantapuska (2012)). The costs of foregone diversification would seem to be large unless their local stock picks can significantly outperform the market.

${ }^{3}$ Coval and Moskowitz (2001) find such an informational advantage in the local trades of mutual funds managers. The proximity as informational advantage story is often promoted to retail investors with the phrase coined by Peter Lynch in the 80s, "invest in what you know".

${ }^{4}$ For instance, Huberman (2001) argues that such a bias is present using the holdings of households in their local electric utility companies.
} 
whether households can earn high enough returns on their local stock picks to overcome the costs of under-diversification (see, e.g., Odean (1999), Ivković and Weisbenner (2005)).

We point out in this paper that extant empirical tests of these explanations subtly but crucially assume that households locate randomly, which is likely to be counterfactual. Notably, in endogenous location choice models from the literature on urban and real estate economics, agents optimally locate in cities that provide them with the highest utility (e.g. Bajari and Kahn (2005) and Bayer, Ferreira, and McMillan (2007)). This sorting or selfselection depends on the congruence of city characteristics and household demographics as well as on factors that are unobservable to the econometrician (i.e. latent factors). Such optimal spatial sorting models are consistent with migration patterns that one sees in the US (e.g. Bishop (2007), Kennan and Walker (2011), Kaplan and Schulhofer-Wohl (2012), Diamond (2016)).

Latent factors of this location selection might then naturally be correlated with unobservable preferences for local stocks. For instance, given its demographics, a household optimally chooses to live in an urban center like NYC or Silicon Valley. Yet, its actual decision to reside in NYC but not in Silicon Valley might be motivated by a job offer as an investment banker instead of a job offer as a computer scientist, or by a fondness for investment bankers over computer scientists as friends. Such preferences are very likely to be correlated with an inclination towards finance stocks instead of technology stocks, independent of proximity. ${ }^{5}$ In other words, to what extent does proximity play a causal role in local bias and to what extent does it simply reflect selection bias? As a thought experiment, if we were to randomly locate households in different cities, would they still exhibit the same degree of local bias and how would their local stock picks perform?

In this paper we develop a methodology to account for the effect of endogenous location decisions as a form of selection bias on household portfolio choice. In particular, we introduce

\footnotetext{
${ }^{5} \mathrm{~A}$ more extreme version of local bias is the tendency of employees to invest in their own company's stock (see, e.g., Benartzi (2001)). This under-diversification might again be attributed to proximity, but could as well be interpreted as an endogenous selection; employees work for the companies that they like, but these preferences might be correlated with the purchase of company shares.
} 
optimal location choice on top of investment decisions. We start by using a location choice model from urban economics in which households choose their residence based on a match between their own demographics (e.g., age and family status) and the demographics of the location (e.g., urban vs. rural). We subsequently consider location decisions which could potentially also depend on the aggregate financial characteristics of local stocks (e.g., related to the presence of equity investment opportunities in the area). Our model eventually leads to an extended Heckman (1977) correction for location selection in standard portfolio-weight regressions, in which the adjustment takes into account both the over-weighting of local stocks as well as the under-weighting of distant stocks.

Our first and baseline model implicitly assumes that households first choose their location for reasons other than stock investments. A priori, this model is reasonable, since most households are unlikely to factor in current or prospective stock portfolio choices when they decide where to reside. ${ }^{6}$ The second model allows for more sophisticated households that might also take into account equity trading opportunities. Both models yield very similar conclusions as we show below.

The location selection bias is ultimately an omitted-variables problem, whereby unobservable location factors correlated with investment demand shocks are ignored, violating the strict exogeneity assumption on distance in a standard portfolio weights regression. Our optimal location choice model allows us to recover the expected location utility of a household in a city and hence the probability that it locates there. Similar to Heckman (1977), these location probabilities can then be added in the portfolio weights regression as extra covariates that capture unobserved locational shocks. To the extent that there is no location selection bias, introducing these probabilities should not affect the estimate of the coefficient on distance. On the other hand, any resulting correction in the distance coefficient might be interpreted as a more conservative contribution of the cognitive or information cost argument to the local bias, given a household's residence choice.

\footnotetext{
${ }^{6}$ On the other hand, investment funds and firms are expected to be more strategic in their headquarters choice (e.g. Strauss-Kahn and Vives (2009)).
} 
Based on the above procedure, a household's portfolio weight can potentially depend on the location probabilities in all cities. Moreover, the exact form of this dependence is in general nonlinear and subject to the assumptions about the joint distribution of households' unobserved preferences for location and portfolio choice. To make the estimation feasible, we consider a parsimonious, yet robust, non-parametric specification of the correction function, along the lines of the recent econometrics literature that studies selection based on multinomial logit models (e.g. Dahl (2002) and Bourguignon, Fournier, and Gurgand (2007)).

To quantify the effect of our endogenous location decision adjustment on the local bias of portfolio choices, we apply our model to a US brokerage database with roughly 11,000 households living in 58 MSAs with a population above 750K, during the period of 1991-1996. This is a widely used sample (Odean (1999), Barber and Odean (2000)) in which high income households have a significant fraction of their assets in stocks. As the investment universe, we consider stocks that belong to the Russell 1000 Index, an index that includes the largest 1000 stocks in the stock market based on market capitalization. We first run the standard censored regression of local bias: a Tobit regression of a household's portfolio weight on a stock on its demographics (e.g. income), the stock's characteristics and, notably, the distance between the household's residence city and the city in which the stock is headquartered. We find a large distance effect, in terms of both economic and statistical significance, consistent with analyses in the literature.

To correct for a potential bias of location selection, we estimate an optimal location choice model for the same households using MSA demographics data. The results are similar to what is found in the literature on optimal location decisions. Namely, the interaction of MSA demographics with household characteristics plays a crucial role in explaining location decisions and preferences. For instance, higher income, managerial, and white collar households are more likely to locate in high population centers. Older and blue collar households are more likely to locate in MSAs with high unemployment.

With the estimates of this locational choice model, we impute the probabilities with which 
each household locates in the various cities. We then plug these probabilities as additional controls in our portfolio weights regression, in line with the robust identification assumptions that we consider for our correction function. Across a wide variety of specifications, we find a large drop of around $50 \%$ in the effect of distance on the portfolio weight on a stock. This reduction is achieved with a fourth-order polynomial for the selection-bias correction function and increasing to higher orders has negligible incremental effects.

Our exclusion restriction is that these interaction terms involving MSA demographics and household characteristics, which explain location choice, do not affect portfolio choice other than through our selection/optimal location choice mechanism. We believe this exclusion restriction is a plausible one. Portfolio choice weights, of course, naturally depend on household characteristics. Typically, we do not think that portfolio choices even depend on MSA demographics such as unemployment in the area. Most companies get the revenues nationally, so the local economy of the firm headquarters has a small effect on overall revenues. Nonetheless it might be plausible, perhaps for small firms that are highly dependent on the local economy. But the interaction terms seem to us ought to be excluded. ${ }^{7}$

Our baseline analysis of household stock portfolio weights uses a Tobit specification because households do not short and their portfolios are highly sparse. But we also consider the deviation of household portfolio weights from the value-weighted market benchmark as an alternative specification. We get very similar results either way in that there is a large local bias in portfolio weights, regardless of the specification, and that using our methodology to adjust for locational selection drastically reduces this estimate. We can calculate the local bias of a hypothetical household who owns the value-weighted market portfolio. The answer is close to zero local bias that is statistically insignificant. We also reconsider our analysis by using a locational choice model that factors in each city's local investment opportunity

\footnotetext{
${ }^{7}$ The one story related to a distance-as-an-information-processing cost is that firms headquartered where a household has a high probability of locating are just easier to be informationally accessed or understood by that household. For instance, Grinblatt and Keloharju (2001) find such an effect in Finland, where some companies report their financial information in different languages. But this language effect seems implausible in the US. Moreover, we would also argue that a cost story that is highly dependent on demographic characteristics is more naturally modeled through our location choice/selection framework.
} 
sets and get similar results.

We can also apply our selection adjustment to the returns of household local versus non-local stock picks. Consistent with the literature, we find that a household's local stock picks out-perform their non-local stock picks. But once we apply our selection adjustment, distance confers no difference in the expected returns of these picks. One way to interpret our findings is that proximity does not matter much for portfolios or returns of these portfolios after accounting for selection. That is, the imputed informational advantage of proximity for portfolios is not causal but mostly driven by location selection. So, back to our thought experiment, if we were to randomly locate households and then observe their stock portfolios, their portfolios would be much less locally biased and the local stock picks would not differ in performance from their distant picks. These results establish the importance of locational preferences for stock preferences, which as far as we know is new to the literature. They support the need for theory work on asset price movements which emphasizes the importance of location. ${ }^{8}$

Our paper proceeds as follows. We elaborate on our methodology in Section 2. We describe the brokerage house and MSA demographic data in Section 3. We discuss our identification assumptions regarding the choice of the instruments and the specification of the correction function in Section 4. Our empirical findings are presented in Section 5. In Section 6, we conduct additional analysis for robustness. In Section 7, we assess the selection-corrected local bias. In Section 8, we present the results for the returns of local versus non-local stocks in household portfolios. We conclude in Section 9 with a discussion of the implications of our analysis for international home equity bias.

\footnotetext{
${ }^{8}$ Such work include the implications of Keeping up with the Joneses' preferences (Luttmer (2005), Charles, Hurst, and Roussanov (2009)) on local home or stock prices and turnover (DeMarzo, Kaniel, and Kremer (2004), Gomez, Priestley, and Zapatero (2009), Hong, Jiang, Wang, and Zhao (2014)) and more explicit models incorporating asset selection and location choices (Ortalo-Magné and Prat (2016), Hizmo (2015)). For housing only, a dynamic demand model of home ownership in which households can move is offered by Bayer, McMillan, Murphy, and Timmins (2016).
} 


\section{Model}

In this section, we present a simple framework that highlights the implications of a household's location choice on its subsequent investment decisions. We index households with $i$, stocks with $j$, and periods with $t$; overall, there are $T$ periods in each of which live $I_{t}$ households that can potentially invest in $J$ stocks. The total number of cities, throughout the years, is $C$, and we denote with $c$ the city in which household $i$ resides, and with $h$ the city in which stock $j$ is headquartered.

\subsection{Location Choice}

Since in our data households do not move, we only model their location choice in the beginning of their time series. In line with a standard discrete choice model, we decompose the utility that household $i$ derives from a city $\ell=1, \ldots, C$ into the sum of an observable component, $V_{i, \ell}$, and an unobservable idiosyncratic shock, $e_{i, \ell}$, and assume that household $i$ is a utility maximizer locating to a city $c$ satisfying the following relationship:

$$
c=\arg \max _{\ell \in\{1, \ldots, C\}}\left\{V_{i, \ell}+e_{i, \ell}\right\}
$$

Household $i$ 's observable utility from city $\ell$ is a linear combination of the city's characteristics at the time at which the location decision is made, which we group into a $K \times 1$ vector $\boldsymbol{z}_{\ell}$. In our empirical analysis, this vector consists of the city's population, unemployment rate, income per capita and house price index. On the other hand, household $i$ 's unobservable utility from city $\ell$ refers to location factors that we, as econometricians, cannot observe. For instance, such a factor could be whether household $i$ receives a job offer in that city, whether it has a relative living there or whether it likes to have residents of that city as friends. Moreover, $e_{i, \ell}$ also refers to mistakes during the location decision process.

Although households in a given period view the same city characteristics, they interpret them differently, i.e.: 


$$
V_{i, \ell}=\boldsymbol{\rho}_{i} \boldsymbol{z}_{\ell}
$$

where $\boldsymbol{\rho}_{i}$ is the vector of household $i$ 's responses. In particular, we assume observed heterogeneity in preferences through a matching structure. That is, we decompose $\boldsymbol{\rho}_{i}$ into a component that is common across all households, $\boldsymbol{\rho}$, and a component that linearly depends on household $i$ 's $M \times 1$ vector of demographics, $\boldsymbol{D}_{i}$, (through a $K \times M$ matrix of parameters П) i.e.:

$$
\rho_{i}=\rho+\Pi D_{i}
$$

The vector of household $i$ 's demographics, $\boldsymbol{D}_{i}$, that we use in our empirical analysis has as elements its total income, age, job code, gender, marital status and number of kids. By combining Equations (2) and (3), we eventually represent household $i$ 's observed utility from locating in city $\ell$ as:

$$
V_{i, \ell}=\underbrace{\sum_{k=1}^{K} \rho_{k} z_{\ell, k}}_{\delta_{\ell}}+\underbrace{\sum_{k=1}^{K} \sum_{m=1}^{M} \pi_{k, m} D_{i, m} z_{\ell, k}}_{\mu_{i, \ell}}
$$

where $\delta_{\ell}$ is the observed utility from the characteristics of city $\ell$ that is common for all households, while $\mu_{i, \ell}$ is the observed utility from the characteristics of city $\ell$ which is different across households. Equation (4) implies that once we estimate the location parameters $\boldsymbol{\theta}^{l o c} \equiv(\boldsymbol{\rho}, \boldsymbol{\Pi})$ from the data, we will have also estimated the observed utilities of household $i$ from all the available locations, $\left\{V_{i, \ell}\right\}_{\ell=1, \ldots, C}$.

Next, we define household $i$ 's maximum order statistic with respect to a city $c$ as:

$$
v_{i, c}=\max _{\ell \in\{1, \ldots, C\} / c}\left\{V_{i, \ell}-V_{i, c}+e_{i, \ell}-e_{i, c}\right\}
$$

so that household $i$ 's location rule in Equation (1) can be rewritten as: 


$$
r_{i, c}=\mathbf{1}\left[v_{i, c}<0\right]
$$

where $r_{i, c}$ denotes household $i$ 's decision to reside in city $c$ and $\mathbf{1}[\cdot]$ is an indicator function. Assuming that, conditional on the observables, household $i$ 's idiosyncratic shocks, $\left\{e_{i, \ell, t}\right\}_{\ell=1}^{C}$, are independently and identically distributed according to the extreme value type I distribution, we can calculate the probability with which it resides in city $c$ as follows:

$$
p_{i, c} \equiv \mathbb{P}\left(v_{i, c}<0 \mid\left\{V_{i, \ell}\right\}_{\ell=1}^{C}\right)=\frac{\exp \left(V_{i, c}\right)}{\sum_{\ell=1}^{C} \exp \left(V_{i, \ell}\right)}
$$

\subsection{Portfolio Choice}

To model a household's portfolio choice, we consider a simple static setting that is repeated in every period. Since we will estimate portfolio parameters for every period separately (thus allowing for time variation in households' portfolio preferences and expectations), we omit the period subscript $t$ in the discussion that follows. Specifically, we assume that household $i$, residing in city $c$, decides how much to invest in stock $j$, headquartered in city $h$, according to the following criterion:

$$
w_{i, c, h, j}=\left(\alpha+\boldsymbol{\beta} \boldsymbol{x}_{j}+\gamma \boldsymbol{D}_{i}+\delta d i s t_{i, c, h, j}+\epsilon_{i, c, h, j}\right)^{+}
$$

where $(\cdot)^{+} \equiv \max \{\cdot, 0\}$ captures both household $i$ 's extensive and intensive margin ${ }^{9}, \boldsymbol{x}_{j}$ is the vector of stock $j$ 's financial characteristics - in particular, its price, size, book-to-market ratio, turnover, momentum, volatility and industry code, $\boldsymbol{D}_{i}$ is the vector of household $i$ 's demographics exactly as in its location choice problem, while $d_{i s t} t_{i, c, h}$ is the distance between household $i$ 's ZIP-code in city $c$ and stock $j$ 's headquarters ZIP-code in city $h$. Moreover, $\epsilon_{i, c, h, j}$ is household $i$ 's idiosyncratic demand shock for stock $j$, when the former resides in city $c$ and the latter is headquartered in city $h$. For instance, it could refer to whether household

\footnotetext{
${ }^{9}$ Households do not short.
} 
$i$ thinks highly of stock $j$ due to the stock's board of directors or due to the fact that the stock belongs to a specific industry sector that household $i$ really likes (e.g. technology).

This Tobit specification, which is widely used in the literature, can be micro-founded in a number of different ways (Brandt, Santa-Clara, and Valkanov (2009), Shumway, Szefler, and Yuan (2011), Hjalmarsson and Manchev (2012), Garleanu and Pedersen (2013), Koijen and Yogo $(2016))^{10}$. In line with a Tobit model, we assume that, conditional on all observables, these errors are distributed according to the normal distribution. In the empirical analysis, we cluster standard errors at the household level. Without correcting for location selection, the conditional mean of $\epsilon_{i, c, h, j}$ is assumed to be zero. Hence, the portfolio parameters to be estimated from the data are $\boldsymbol{\theta}^{\text {port }} \equiv(\alpha, \boldsymbol{\beta}, \boldsymbol{\gamma}, \delta)$, with $\delta$ being the main parameter of interest (i.e. the coefficient on the distance variable).

\subsection{Selection Correction}

The distance between household $i$ 's ZIP-code in city $c$ and the ZIP-code of stock $j$ in city $h$ where it is headquartered can always be expressed as a function of (i) the distance between household $i$ 's ZIP-code and the central ZIP-code of city $c$ in which it resides, dist $t_{i, c}$, (ii) the distance between the central ZIP-code of city $c$ in which it resides and the central ZIP-code of city $h$ in which stock $j$ is headquartered, dist $t_{c, h}$, and (iii) the distance between the central ZIP-code of city $h$ in which stock $j$ is headquartered and stock $j$ 's headquarters ZIP-code, $d_{i s t_{h, j}}$. In short, denoting $S(\cdot)$ this function, we can write that:

$$
\operatorname{dist}_{i, c, h, j}=S\left(\operatorname{dist}_{i, c}, \operatorname{dist}_{c, h}, \operatorname{dist}_{h, j}\right)
$$

The need to correct for selection arises from the fact that the distance between the central ZIP-code of city $c$ in which household $i$ resides and the central ZIP-code of city $h$ in which stock $j$ is headquartered is the outcome of household $i$ 's location choice. That is, as long

\footnotetext{
${ }^{10}$ Koijen and Yogo (2016) explicitly highlight the link between a heterogeneous mean-variance framework (in terms of expectations or constraints) and an empirical factor model for the demand of stocks.
} 
as household $i$ is not randomly assigned to the city where it resides, the location rule in Equation (6) implies that:

$$
\operatorname{dist}_{c, h}=\sum_{\ell=1}^{C} d i s t_{\ell, h} r_{i, \ell}
$$

where every distance between the central ZIP-code of a city $\ell$ and the central ZIP-code of city $h$ in which stock $j$ is headquartered, dist $_{\ell, h}$, is multiplied by household $i$ 's respective indicator function of its decision to live there, $r_{i, \ell}=\mathbf{1}\left[v_{i, \ell}<0\right]$. Having that in mind, it is very likely that $\epsilon_{i, c, h, j}$, i.e. household $i$ 's idiosyncratic investment error when it lives in city $c$ and considers investing in stock $j$ headquartered in city $h$, is correlated with the idiosyncratic location errors, $\left\{e_{i, \ell}\right\}_{\ell=1}^{C}$ - especially $e_{i, c}$ and $e_{i, h}$ - as these are summarized by the maximum order statistic of the city $c$ where household $i$ actually resides, $v_{i, c}$. To show such a potential correlation more clearly, we decompose $\epsilon_{i, c, h, j}$ as follows:

$$
\epsilon_{i, c, h, j}=\mathbb{E}\left(\epsilon_{i, c, h, j} \mid v_{i, c}<0,\left\{V_{i, \ell}\right\}_{\ell=1}^{C}\right)+\eta_{i, c, h, j}
$$

where $\eta_{i, c, h, j}$ is an idiosyncratic stock-city investment error which, by construction, is independent of household $i$ 's location decision to reside in city $c$. That is, $\eta_{i, c, h, j}$ is mean-zero given all observables. As for the conditional expectation of the original idiosyncratic investment error, $\epsilon_{i, c, h, j}$, given household $i$ 's decision to live in city $c$ and the observed location utilities $\left\{V_{i, \ell}\right\}_{\ell=1}^{C}$, which are estimated from the location choice model in a first stage, it can be calculated as follows:

$$
\begin{aligned}
\mathbb{E}\left(\epsilon_{i, c, h, j} \mid v_{i, c}<0,\left\{V_{i, \ell}\right\}_{\ell=1}^{C}\right) & =\int_{-\infty}^{+\infty} \int_{-\infty}^{0} \frac{\epsilon_{i, c, h, j} f\left(\epsilon_{i, c, h, j}, v_{i, c} \mid\left\{V_{i, \ell}\right\}_{\ell=1}^{C}\right)}{\mathbb{P}\left(v_{i, c}<0 \mid\left\{V_{i, \ell}\right\}_{\ell=1}^{C}\right)} d v_{i, c} d \epsilon_{i, j} \\
= & \psi_{c, h}\left(\left\{V_{i, \ell}\right\}_{\ell=1}^{C}\right)
\end{aligned}
$$

where $\psi_{c, h}(\cdot)$ is an unknown correction function whose actual form depends on assumptions 
regarding the joint distribution of $\epsilon_{i, c, h, j}$ and $v_{i, c}$. The value of the correction function is in principle non-zero, unless $\epsilon_{i, c, h, j}$ and $v_{i, c}$ are independent. ${ }^{11}$ Consequently, based on Equations (9) to (12), the distance variable in the portfolio choice regression, dist $_{i, c, h, j}$, is correlated with the original investment idiosyncratic error, $\epsilon_{i, c, h, j}$, through the correction function $\psi_{c, h}(\cdot)$. Any estimation procedure that ignores this correlation is destined to yield biased estimates on the respective coefficient, $\delta$.

To avoid a selection bias in the distance coefficient, one necessarily has to restrict the structure through which the observed utilities, $\left\{V_{i, \ell}\right\}_{\ell=1}^{C}$, enter the function $\psi_{c, h}$. For instance, one could impose assumptions about the joint distribution of $\epsilon_{i, c, h, j}$ and $v_{i, c}$ as in Lee (1983) or about the conditional expectation of $\epsilon_{i, c, h, j}$ given the location idiosyncratic errors, $\left\{e_{i, \ell}\right\}_{\ell=1}^{C}$, (e.g. linearity) as in Dubin and McFadden (1984). ${ }^{12}$ Rather than following these parametric approaches, we implement a more robust non-parametric method that is very similar to the one that Dahl (2002) provides.

To this end, we invoke the monotonic relationship between household $i$ 's observed location utilities, $\left\{V_{i, \ell}\right\}_{\ell=1}^{C}$, and its location probabilities, $\left\{p_{i, \ell}\right\}_{\ell=1}^{C}$, which allows us to write:

$$
\psi_{c, h}\left(\left\{V_{i, \ell}\right\}_{\ell=1}^{C}\right)=\Psi_{c, h}\left(\left\{p_{i, \ell}\right\}_{\ell=1}^{C}\right)
$$

where now we have a new unknown correction function, namely $\Psi_{c, h}(\cdot)$, in terms of location probabilities. The probabilities, $\left\{p_{i, \ell}\right\}_{\ell=1}^{C}$, in the correction function capture the impact of unobservable location factors on subsequent investment decisions, given residence choice. ${ }^{13}$

\footnotetext{
${ }^{11}$ In that case, in the numerator of Equation (12), we have that:$$
\int_{-\infty}^{+\infty} \int_{-\infty}^{0} \epsilon_{i, c, h, j} f\left(\epsilon_{i, c}, v_{i, c} \mid\left\{V_{i, \ell}\right\}_{\ell=1}^{C}\right) d v_{i, c} d \epsilon_{i, c, h},=\int_{-\infty}^{+\infty} \epsilon_{i, c, h, j} f\left(\epsilon_{i, c, h, j} \mid\left\{V_{i, \ell}\right\}_{\ell=1}^{C}\right) d \epsilon_{i, c, h, j} \int_{-\infty}^{0} f\left(v_{i, c} \mid\left\{V_{i, \ell}\right\}_{\ell=1}^{C}\right) d v_{i, c}
$$$$
=\mathbb{E}\left(\epsilon_{i, c, h, j} \mid\left\{V_{i, \ell}\right\}_{\ell=1}^{C}\right) \mathbb{P}\left(v_{i, c}<0 \mid\left\{V_{i, \ell}\right\}_{\ell=1}^{C}\right)
$$$$
=0
$$

since the conditional mean of $\epsilon_{i, c, h, j}$, given the observables, is zero.

${ }^{12}$ Bourguignon, Fournier, and Gurgand (2007) generalize the latter approach by linearly projecting $\epsilon_{i, c, h, j}$ on monotonic transformations of $\left\{e_{i, \ell}\right\}_{\ell=1}^{C}$.

${ }^{13}$ For instance, Dubin and McFadden (1984) show that:
} 
Hence, combining Equations (8), (11), (12) and (13) yields the portfolio choice regression equation that corrects for selection based on location:

$$
w_{i, c, h, j}=\left(\alpha+\boldsymbol{\beta} \boldsymbol{x}_{j}+\boldsymbol{\gamma} \boldsymbol{D}_{i}+\delta d i s t_{i, c, h, j}+\Psi_{c, h}\left(\left\{p_{i, \ell}\right\}_{\ell=1}^{C}\right)+\eta_{i, c, h, j}\right)^{+}
$$

As in Dahl (2002), since more than one probabilities enter the correction function, the selection bias on the distance coefficient cannot be ex ante assessed. The censoring of the portfolio weights regression and the ability of a household to invest in both local and distant stocks further contribute to this. In principle, the selection correction will also affect the coefficient estimates of household demographics due to the matching structure in location choice.

\section{Data}

\subsection{MSA Demographics}

The data on the demographics (characteristics) of the Metropolitan Statistical Areas (MSAs) are gathered at a quarterly frequency from various sources. Specifically, information on the MSAs' population and unemployment rate is gathered from the Bureau of Labor Statistics (BLS), while information on their total income is collected from the Bureau of Economic Analysis (BEA). The house price index (HPI) is taken from the Federal Housing Finance Agency (FHFA). We focus on MSAs whose population at the end of 1996 was at least 750,000. As Coval and Moskowitz (1999), we also drop Alaska, Hawaii and Puerto Rico. These filters

$$
\begin{gathered}
\mathbb{E}\left(e_{i, c} \mid v_{i, c}<0,\left\{V_{i, \ell}\right\}_{\ell=1}^{C}\right)=\gamma-\log \left(p_{i, c}\right) \\
\mathbb{E}\left(e_{i, h} \mid v_{i, c}<0,\left\{V_{i, \ell}\right\}_{\ell=1}^{C}\right)=\gamma+\frac{p_{i, h} \log \left(p_{i, h}\right)}{1-p_{i, h}}
\end{gathered}
$$

where here $\gamma \approx 0.577$ denotes the Euler-Mascheroni constant. This constant is the unconditional mean of the idiosyncratic location errors, $\left\{e_{i, \ell}\right\}_{\ell=1}^{C}$, which are drawn from the extreme value type I distribution. Of course, depending on the exact form of the correction function $\Psi_{c, h}(\cdot)$, the location probabilities express also conditional variances, covariances as well as higher order moments of the unobservable location shocks. 
leave us with 57 MSAs in total.

The summary statistics of the MSA characteristics for all the quarters in the sample are presented in Panel A of Table 1. The mean population is 2.5 million with a standard deviation of 2.8 million. The mean unemployment rate is $5.8 \%$. The mean income per capita is 23.6 thousand dollars, while the mean HPI is 99.2.

\subsection{Household Demographics}

Our household investment data are drawn from the database of a national discount brokerage firm. See Barber and Odean (2000) for detailed descriptions. For our analysis, we start with an unbalanced panel of roughly 14,200 complete observations, covering the period 1990-1996 at a monthly frequency. ${ }^{14}$ The beginning and end of these households' time series in the database is in general different. Most part of the households' assets is invested in stocks and only a small fraction is allocated to mutual funds. Specifically, for every household in the database, we track the composition of its portfolio and construct its common stock portfolio weights. Every stock is identified by the corresponding CUSIP label. Moreover, every observation is accompanied by a rich list of demographic information. Specifically, we observe every household's total income, age, job code (e.g. professional, managerial, sales-services, white collar, blue collar and farmer), gender, marital status and number of kids. Since, by construction, the number of farmers who live in the selected 57 MSAs is small, we drop them from the analysis. Importantly, every household is listed with its address ZIP-code, allowing us to calculate the distances from the stocks' headquarters, as we describe below. Overall, we have 10,712 unique households with complete information on demographics and stock portfolios. These households do not move across MSAs, but stay in their original location either until the last date in the data or until they close their

\footnotetext{
${ }^{14}$ The actual total number of households in the database is about 78,000. However, many of these observations have missing information. In addition, not all households hold common stocks and some of them have multiple accounts which need to be aggregated.
} 
accounts. ${ }^{15}$ Their first time-series observations comprise the sample of our location choice model.

The summary statistics of the households' demographics are presented in Panel B of Table 1. The income of households in our sample has a mean of 82.4 thousand dollars and a median of 87.5 thousand dollars. This is to be expected since only households with sufficient income would participate in the stock market to begin with. The mean age is 47.7 years. About $55 \%$ of the households are professionals and $28 \%$ are managerial. Sales service, white collar and blue collar accounts comprise about $8 \%, 5 \%$ and $4 \%$ of the total respectively. Approximately, $93 \%$ of the households are headed by a male and $79 \%$ of the heads are married. On average, households have at most 1 kid.

\subsection{Geographical Distribution of Household Stock Holdings}

The universe of stocks that we examine is the Russell 1000 Index. We focus only on stocks located in the same 57 MSAs as above, with a complete list of financial characteristics as described below. This filter leads us to a total number of 900 different stocks for the whole period. ${ }^{16}$ Merging the financial characteristics data of these stocks with the household investment data reduces our sample to 10,594 households. ${ }^{17}$ This sample comprises the data based on which we estimate the portfolio choice model. Using the geographical coordinates of the ZIP-code of every household and the ZIP-code of the headquarters of every stock, we calculate their spherical distances, which are the key variable in our study. ${ }^{18}$

The geographical distribution of the households in our sample and the stocks in Russell 1000 is presented in Figure 1 via a map of latitude and longitude coordinates of the

\footnotetext{
${ }^{15}$ According to the US Census Bureau, the average percentage of movers during our sample period (19911996) was on average about 17\% (http://www.census.gov/newsroom/press-releases/2015/cb15-47.html). This means that, roughly, a household would be expected to change residence every $6(\approx 1 / 0.17)$ years. Given that our own sample period is six years, we expect that few households in the data did move.

${ }^{16}$ Pirinsky and Wang (2006) used Compact Disclosure to identify 118 firm relocations from 1992 to 1997. However, most of these firms were small and did not belong to the Russell 1000 index.

${ }^{17}$ Households which do not invest in any of these stocks are dropped.

${ }^{18}$ We measure distance in degrees. Multiplying by $2 \pi R / 360$ converts it to miles (kilometers), where $R \approx 3,963$ miles (6,378 kilometers).
} 
households and the stocks' headquarters. This figure depicts the geographical coordinates of the 10,594 households and the 900 stocks in Russell 1000 Index. The address ZIP-codes of households and the stocks' headquarters are converted to geographical coordinates based on the correspondence provided by the US Census Bureau. The horizontal axis is in longitude coordinate, while the vertical axis is in latitude coordinate. The blue circles indicate households, while the red squares indicate stocks. From this map of the geographical distribution of households and stocks in our sample, we can see the high numbers of households and stocks located in the New York area (latitude around 40, longitude around -75) and California (latitude around 35, longitude around -120), which is what one would expect.

The portfolio positions of households are summarized in Panel $\mathrm{C}$ of Table 1. The mean value of a household's portfolio in common stocks is about $\$ 40,000$ (averaged across time periods from 1991 to 1996$)$, while the median value is about $\$ 15,000{ }^{19}$ The standard deviation of stock holdings across our sample is $\$ 152,000$. In terms of trading, as Barber and Odean (2000) document, these households are quite active on average, buying and selling 6-7\% of their stock portfolio every month, and turning over $75 \%$ of it every year.

Furthermore, on average, a household in our sample has a portfolio weight of 11.2 bps on a Russell 1000 stock and holds 1.85 stocks. The standard deviation of the number of stocks is 1.55, indicating that most of the households in the sample are under-diversified, even as their stock holdings comprise a substantial fraction of their assets. The median number of stocks that a household holds is 1 , while the standard deviation of a portfolio weight is 0.03 . In the same panel, we also report the mean distance of a household's residence to a Russell 1000 firm headquarters, which is 17.6. The standard deviation is 11.45. These figures can be compared to the distance between California and New York, which is approximately 57 degrees. In addition, we also construct dummies indicating whether a stock is headquartered more than 250 miles and 100 miles away from a household's residence. The average percentage of

\footnotetext{
${ }^{19}$ The report by the US Census Bureau on net worth and asset ownership of households in 1998 and 2000 shows that in 1998, the median value of holdings in stocks for a typical US household is $\$ 16,800$ (https://www.census.gov/prod/2003pubs/p70-88.pdf). This information indicates that our sample is similar to the stock holding situation of US households in the ' 90 s.
} 
households that are away from a stock's headquarters according to these metrics is about $90 \% .^{20}$

\subsection{Stock Financial Characteristics}

For each stock that belonged to the Russell 1000 Index during our sample period, we gather financial characteristics from CRSP and Compustat. In particular, we generate quarterly time series for their price, market value, book-to-market ratio, turnover, past twelve-month momentum and volatility. We construct these characteristics as Gompers and Metrick (2001). We also invoke the Fama-French industry classification of stocks into 17 categories based on the four-digit SIC code, which is available from Kenneth R. French's website. ${ }^{21}$

We summarize all stock characteristics in Panel D of Table 1. The mean price of a stock in the Russell 1000 index is about $\$ 34$. The mean market capitalization is around 3.4 billion dollars. The mean book-to-market ratio is 0.43 . The mean share turnover is 0.3 . The mean past 12 -month return is 0.17 and the mean monthly return volatility is 0.18 . The industrial composition of the Russel 1000 Index is reflected by the 17 Fama-French industry classification; $26 \%$ of the stocks belong to the "Other" industry category, $16 \%$ of them are in "Finance" (referring to banks, insurance companies and other financials), while $12 \%$ belong to the "Machines" category (for machinery and business equipment).

\subsection{Summary Statistics on Local Bias of Stock Portfolios}

The summary statistics of the local bias (LB) in our household stock holdings data are given in Table 2 and are constructed as in Coval and Moskowitz (1999). Column 2 (labeled "Avg. Distance from Holdings") reports the average portfolio weighted distance of households from their stock holdings, defined as $\frac{1}{I} \sum_{i} \sum_{j} w_{j}^{i} d_{j}^{i}$, where $d_{j}^{i}$ is the ZIP-code distance between a household $i$ 's residential area and the headquarters area of a stock $j, w_{j}^{i}$ is the household $i$ 's

\footnotetext{
${ }^{20}$ The reasonable threshold of 250 miles is taken from the study of Ivkovic and Weisbenner (2005).

${ }^{21}$ http://mba.tuck.dartmouth.edu/pages/faculty/ken.french/index.html
} 
portfolio weight on stock $j$, and $I$ is the total number of households. Column 3 (labeled "Avg. Distance from Benchmark") reports the average portfolio weighted distance of households from the Russell 1000 benchmark portfolio, computed as $\frac{1}{I} \sum_{i} \sum_{j} \bar{w}_{j} d_{j}^{i}$, where $\bar{w}_{j}$ is the Russell 1000 benchmark portfolio weight on stock $j$. Row 1 has as benchmark the equally weighted portfolio, while Row 2 refers to the value-weighted portfolio. Column 5 (labeled "Difference") reports the average difference between Column 3 and Column 4, which is essentially the average local bias of households in distance units. Column 6 (labeled "\% Bias (LB)") reports the local bias (LB) measure as a percentage. Column 7 reports the $t$-statistics for the LB measure. Independent of which benchmark is used (the values are about the same), the local bias is always high in terms of both magnitude and statistical significance. Specifically, using the equally weighted portfolio, the local bias is 8.29 or $45.45 \%$, while, using the valueweighted portfolio, it is slightly decreased to 8.26 or $43.72 \% .^{22}$

\section{Identification}

\subsection{Exclusion Restriction}

As it is the case with any Heckman (1977) correction model (e.g. Puhani (2000)), to avoid identification through functional forms, an exclusion restriction is required, according to which at least one of the factors affecting location choice does not directly show up in the portfolio choice regression. Based on our location choice model, a household decides in which city to reside, taking into account the characteristics of all the available locations as well as how it matches to them through its demographics. The instruments in our portfolio choice regressions are derived through this matching process. That is, our identification assumption is that the way through which a household's demographics interact with the characteristics of a city has no direct impact on its investment decisions.

\footnotetext{
${ }^{22}$ The percentage LB is more than four times the local bias that Coval and Moskowitz (1999) report for non-index fund managers in 1995.
} 
When household $i$ residing in city $c$ considers investing in stock $j$ headquartered in city $h$, the characteristics of cities $c$ and $h$, as they are, may or may not be directly relevant. For instance, the cost of living in city $c$ may be related to household $i$ 's liquidity needs, while the cost of living in city $h$ may be related to stock $j$ 's profitability, if the operations of the latter are local. But it could also be the case that household $i$ decides to invest in stock $j$, solely based on a factor model with financial characteristics and distance (proxies for the cognitive or information costs it faces). The costs of living, in that case, would only be relevant for the cognitive or information costs it will encounter through his location choice. ${ }^{23}$ However, regardless of whether city characteristics are excluded from the portfolio choice regression or not, the way through which a household matches to them when it makes its location choice seems, a priori, to be irrelevant to the stock investments decisions that follow.

\subsection{Specification of the Correction Function}

Based on Equation (14), we need to evaluate $C^{2}$ correction functions, $\Psi_{c, h}(\cdot)$, each of which has $C$ probabilities, $\left\{p_{i, \ell}\right\}_{\ell=1}^{C}$, as arguments. This high dimensionality issue makes the estimation of the portfolio choice regression infeasible. As a first remedy, in line with Dahl (2002), we adopt the following two identification assumptions: ${ }^{24}$

Assumption 1 (Two Index Sufficiency): The correction function has only two arguments, namely the probability with which household $i$ resides in city $c$ and the probability with which it resides in city $h$ :

\footnotetext{
${ }^{23}$ Along these lines, one could have utilized an argument from the field of Industrial Organization, according to which, even if the characteristics of some cities, such as $\boldsymbol{z}_{c}$ and $\boldsymbol{z}_{h}$ do affect portfolio choice directly, it is unlikely that all the other cities' characteristics, $\left\{\boldsymbol{z}_{\ell}\right\}_{\ell \in\{1, \ldots, C\} /\{c, h\}}$ do. For example, even if house prices in cities $c$ and $h$ have a direct impact on household $i$ 's investment decision for stock $j$, the house prices in cities other than $c$ and $h$ should not be that relevant. Of course, there are exceptions that come to mind such as investments in stocks which operate in many cities.

${ }^{24}$ The difference in our context is that the location choice - portfolio choice model is more complex than the mobility-earnings model studied in Dahl (2002), since, in principle, a household can purchase stocks headquartered in any city, regardless of where it resides. On the other hand, in a mobility-earnings model, a household receives wage offers only from its own city. This extra element leads us to additionally impose Assumption 3, in order to make the estimation feasible, as we discuss in text.
} 


$$
\Psi_{c, h}\left(\left\{p_{i, \ell}\right\}_{\ell=1}^{C}\right)=\Psi_{c, h}\left(p_{i, c}, p_{i, h}\right)
$$

Assumption 2 (Residence City Independence): The form of the correction function does not depend on the residence city $c$ unless $h=c$, i.e.:

$$
\Psi_{c, h}\left(p_{i, c}, p_{i, h}\right)=\left\{\begin{array}{c}
\Psi_{c}\left(p_{i, c}\right) \text { if } h=c \\
\Psi_{h}\left(p_{i, c}, p_{i, h}\right) \text { if } h \neq c
\end{array}\right\}
$$

According to Assumption 1, only two out of $C$ probabilities are relevant for the location correction, namely the probability that household $i$ locates in the area in which it actually resides, $p_{i, c}$, and the probability that household $i$ locates in the city that has the headquarters of the stock in which it considers investing, $p_{i, h}$. However, that assumption still leaves us with $C^{2}$ correction functions. To this end, we impose Assumption 2, which reduces the total number of correction functions to its square root. In particular, it assumes that a correction function should not depend on the identity of the city in which household $i$ resides. Of course, if it happens that stock $j$ is located in the same city as household $i$ does, i.e. $h=c$, then the identity of the residence city becomes relevant again.

Lastly, because the total number of cities in our data is large, i.e. $C=58$, we are still left with a high number of correction functions to be estimated from the data. To this end, we conveniently impose the following assumption:

Assumption 3 (Homogeneity): The form of the correction function is not stock headquartered city-specific, i.e.:

$$
\begin{array}{ccc}
\Psi_{c}\left(p_{i, c}\right) & = & \Psi^{s}\left(p_{i, c}\right) \\
\Psi_{h}\left(p_{i, c}, p_{i, h}\right) & =\Psi^{d}\left(p_{i, c}, p_{i, h}\right) \quad \forall h \neq c
\end{array}
$$

Assumption 3 further reduces the correction functions to only two. In particular, the first correction function applies to the case in which household $i$ considers investing in a 
stock that is headquartered in the same city in which it resides, while the second correction function applies to the case in which the stock's headquarters are located in a different city. ${ }^{25}$ The resulting two correction functions, $\Psi^{s}(\cdot)$ and $\Psi^{d}(\cdot)$, can be flexibly estimated through a polynomial series expansion.

\section{Estimation}

\subsection{Location Choice Results}

Table 3 presents the maximum likelihood estimation results of our location choice model. This table presents two conditional logit models for household location choices. Column 1 presents the full model of location choice derived above. The choice set of households consists of the 57 MSAs. The dependent variable is an indicator variable that equals one if a household resides in a specific MSA. We use 10,712 unique households to estimate our models, which gives us roughly 610 thousand observations.

The main explanatory variables are MSA characteristics that include the log of the population number in an MSA (LogPop), the unemployment rate (Unemp), the income per

\footnotetext{
${ }^{25}$ In short, as in Dahl (2002), Assumptions 1-3 can be thought of as exclusions restrictions on the conditional joint distribution of household $i$ 's idiosyncratic investment error, $\epsilon_{i, c, h, j}$, and its maximum order statistic, $v_{i, c}$, given its observed location utilities $\left\{V_{i, \ell}\right\}_{\ell=1}^{C}$ (or equivalently, by the monotonicity, the location probabilities $\left\{p_{i, \ell}\right\}_{\ell=1}^{C}$ ), so that:

$$
f\left(\epsilon_{i, c, h, j}, v_{i, c} \mid\left\{V_{i, \ell}\right\}_{\ell=1}^{C}\right)=f\left(\epsilon_{i, c, h, j}, v_{i, c} \mid\left\{p_{i, \ell}\right\}_{\ell=1}^{C}\right)=\left\{\begin{array}{c}
f^{s}\left(\epsilon_{i, c, h, j}, v_{i, c} \mid p_{i, c}\right) \text { if } h=c \\
f^{d}\left(\epsilon_{i, c, h, j}, v_{i, c} \mid p_{i, c}, p_{i h}\right) \text { if } h \neq c
\end{array}\right\}
$$

Then, combining the above equation with Equation (12) yields that:

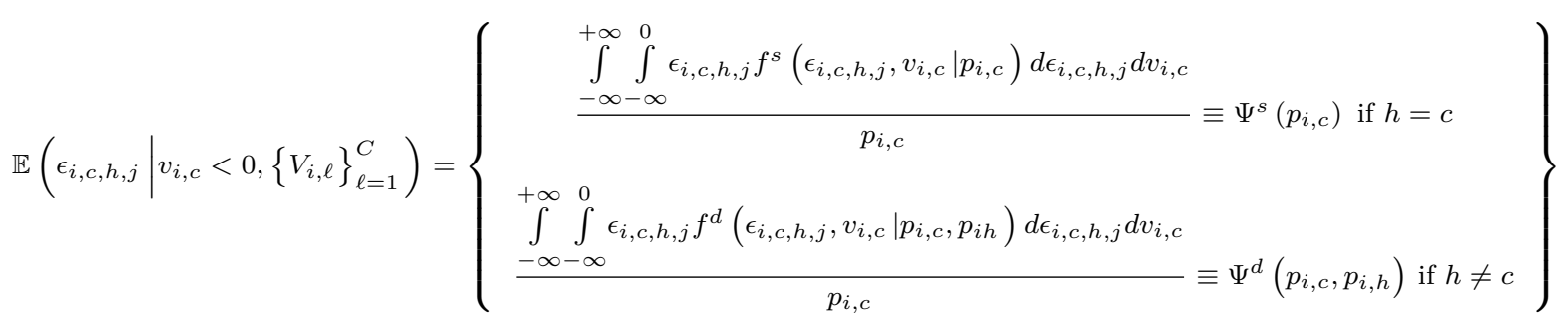


capita (Incomepc), and the log of the housing price index (LogHPI). We also include all pair-wise interaction terms between the MSA characteristics variables and the household demographics, e.g. LogIncome, LogAge, Managerial, SalesServices, WhiteCollar, BlueCollar, Male, Married, Kids (shown in Panel B of Table 1) in our main specification in Column 1.

The coefficient estimates in Column 1 have the same predicted sign as in other location choice models (e.g. Bishop (2007)). The t-statistics indicate that there is substantial observed heterogeneity in location preferences, whereby households with certain demographics (i.e. LogIncome, LogAge, etc.) are more likely to locate in MSAs with certain characteristics (i.e. LogPop, Unemp, Incomepc, LogHPI, etc.). In other words, the pairwise interaction terms involving household characteristics and MSA demographics are highly significant.

Take first LogPop, a measure of population density or urban versus rural areas. The coefficient on $\log P$ op $\times \operatorname{LogIncome~is~} 0.05$ and is marginally statistically significant with a t-statistic of 1.7. This means that higher income households are more likely to locate (i.e. prefer to live) in urban centers. Highly populated cities are also more likely to attract old households, households whose job industry is managerial instead of professional (which is the base group in our regressions), and white collar households.

Next consider MSA unemployment. The coefficient on Unemp $\times$ BlueCollar is 0.12 with a $t$-statistic of 3 . So blue collar workers are more likely to be matched with MSAs whose unemployment rate is higher than average. The coefficient on Unemp $\times$ LogAge is also statistically significant probably because older households are about to or have already exited the labor force.

Our remaining two MSA characteristics are Incompc and LogHPI. Both proxy for costs of living. The coefficient on Incomepc $\times \log$ Income is 0.05 with a $t$-statistic of 7 . Similarly, the

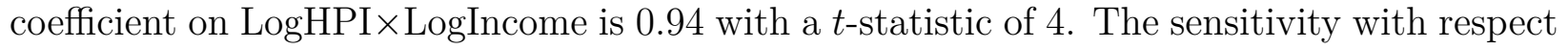
to these costs is higher for households which have low income. The same also applies for households which are older, have a family (i.e. are married or have kids) and for households which perform manual labor. 
For comparison reasons, we also estimate the location choice model without the interaction between the household demographics and the MSA characteristics. The results are shown in Column 2 of Table 3. The fit of the model is reduced as indicated by the decreased values of both the log likelihood and the pseudo $R^{2}{ }^{26}$ In addition, the coefficients of income per capita and house prices turn positive with a high statistical significance, loosing their interpretation as costs of living. Population also turns positive and becomes highly statistically significant. In short, it is important, as has been recognized in the location choice literature, that these pairwise interaction terms play a critical role in explaining location preferences.

\subsection{Portfolio Choice Results}

We next estimate a portfolio choice model but without accounting for location choice. Table 4 presents the maximum likelihood estimation results of the portfolio choice model without correcting for location selection. The portfolio regression is run separately for every month in our sample, thus flexibly allowing for time variation in the coefficients. Standard errors are clustered at the household level, taking into account part of the unobserved heterogeneity of the decision makers. For compactness, in the table, we only present the monthly averages of all the coefficients along with their monthly averaged $t$-statistics.

Whether it stands alone in the portfolio regression or is together with household demographics, financial characteristics or characteristics of the MSAs, the distance coefficient is always negative and highly statistically significant. ${ }^{27}$ In Column 1 , the distance variable by itself attracts a coefficient of -0.012 and is highly statistically significant with a $t$-statistic of -20.3 .

In Column 2, even after adding household demographics, the coefficient is virtually unchanged. Besides the expected negative effect of distance, the coefficients of household

\footnotetext{
${ }^{26}$ The nested likelihood ratio test value is 328.22 (without clustering the standard errors at the household level), i.e. higher than the $\chi^{2}(36)$ statistic at any reasonable level of statistical significance.

${ }^{27}$ Without controlling for financial characteristics, its $t$-statistic is the highest and becomes the fourth highest, when we include stock financial characteristics.
} 
demographics also have the predicted sign in their estimates. In particular, investment in a stock is more likely and is increased in magnitude if a household has a high income. The coefficient on LogIncome is 0.03 with a $t$-statistic of 2.9. The same also occurs with age. Moreover, households whose job industry code is either managerial, sales-services or blue collar are less likely to invest relative to professionals (i.e. the base group). So are households with kids under the age of eighteen.

Column 3 shows that adding stock characteristics actually increase the magnitude of the coefficient to -0.013 . As for the estimated coefficients of the financial characteristics, price enters negatively and size positively, with a high statistical significance, as anticipated. Households are not momentum traders and this is indicated by the sign of the respective coefficient. The estimated coefficient of volatility is not statistically significant. The bookto-market coefficient is estimated to be positive, showing preferences for value stocks. A high turnover ratio of a stock also makes it attractive to households.

In Column 4, we additionally control for possible, relevant MSA demographics. In particular, we add the demographics of the MSA in which household resides (which we denote with subscript $c$ ) and the demographics of the MSA of the firm headquarters (which we denote with the subscript $h$ ). The estimation results show that households are less likely to own stocks located in urban areas. Importantly, we find that adding MSA demographics increases the negative value of the distance coefficient to -0.014 . Most of the coefficients on the previous household demographics and stock financial characteristics also do not change much.

Based on our estimates in every month, we compute the average marginal effect of our main explanatory variable, Distance, on the portfolio weight. Since the Tobit model is non-linear, we first calculate the marginal effect by anchoring all of the covariates at their mean values in the sample, for each month. Then, we take the monthly average of all these marginal effects.

For our model in Column 1 of Table 4 (i.e. without any controls besides Distance), the 
marginal effect of Distance on the portfolio weight is -0.33 basis points (bps). Thus, if the Distance increases by one standard deviation (11.45 from our summary statistics Table 1), the portfolio weight of a household on a Russell 1000 stock would go down by 0.33 bps $\times 11.45=3.8$ bps. When we add in all other control variables as in Column 4 of Table 4 , the marginal effect of Distance becomes -0.16 bps, so that the economic significance of a one standard deviation increase in Distance is a 1.9 bps drop in the portfolio weight. These effects are sizable given that the average portfolio weight of a household on a Russell 1000 stock is 11.2 bps.

The complete time series evolution of the distance coefficient estimates and their $t$ statistics are depicted in Figures 2 and 3, respectively. Figure 2 documents that as years went by, the absolute value of the distance coefficient is decreased. Our sample is short, so it is difficult to make anything out of this trend. ${ }^{28}$ In any case, Figure 3 illustrates that the statistical significance of the distance coefficient is always very high during the period.

In Tables 5 and 6, we present the maximum likelihood estimation results after correcting for location selection. For exposition purposes, we first start with the simplest specification according to which portfolio weights are solely (nonlinearly) regressed on distance and the constant, $\alpha$. Such a specification allows us to clearly highlight the decreases in the absolute value of the distance coefficient as one attempts to increase the order of the polynomials approximating the correction functions. Indeed, Table 5 shows that, even with two linear correction functions in Column 1, we achieve a roughly $20 \%$ reduction. Recall that the distance coefficient was originally -0.012 with a $t$-statistic of -20.3 . The coefficient is now -0.010 with a $t$-statistic of $-17.8 .^{29}$ Notice that this reduction corresponds to the fact that

\footnotetext{
${ }^{28}$ It might possibly be driven by the technological improvements in the transmission of information across cities through the Internet (e.g. Barber and Odean (2002)), which naturally mitigates the cognitive and information costs that distance captures. Alternatively, it might be temporarily reflecting the stock-market mania of the mid-nineties. In particular, the rise of Internet stocks during this period may also be affecting the time series variation of this coefficient.

${ }^{29}$ The standard errors of the portfolio choice parameters might not be exact due to the imputation of the location probabilities from the first-stage estimation of the location choice model. This is true in any two-step estimation procedure. Of course, the estimated probabilities are consistent and the sample size in the conditional logit is quite large (10,712 households $\times 57$ MSAs). Moreover, we run the investment model separately for every month, having different households in every period. The spirit of this exercise resembles
} 
the imputed location probabilities as captured by the correction function both predict a positive portfolio weight. In other words, the higher the probability of a household locating to a given MSA, the higher are the chances of that household owning stocks which are headquartered in that MSA.

This reduction is furthered increased in Column 2, once we increase the order of the polynomial approximation. The coefficient becomes -0.008 with a $t$-statistic of -14.7 . As Column 3 of the table shows, with a 4 th order polynomial the reduction is almost $50 \%$. The coefficient is now -0.006 with a $t$-statistic of -11.1 .

In Table 6, the same percentage decreases in the distance coefficient also apply, when we control for household demographics, financial characteristics and characteristics of the MSAs. Take the first three columns. The baseline portfolio weight regression now includes, in addition to distance, the household demographics. As we move from Column 1 to Column 3 , we increase the order of the polynomial function as we did in the previous table. We see that the distance coefficient in Column 3 with the 4 th order polynomial is -0.006 , similar to before.

In Columns 4 to 6, we include both household demographics and stock characteristics in the portfolio weight regression. Again, in Column 6 with the 4th order polynomial, the coefficient is -0.007 , which is similar to the previous -0.006 coefficient. In Columns $7-9$, we additionally include the MSA characteristics in the portfolio weights regression. In Column 9 with the 4 th order polynomial, the coefficient is -0.007 . Thus, in all cases, with a 4 th order polynomial approximation of the correction function, we estimate a roughly $50 \%$ reduction on the distance coefficient.

To see the changes in economic effects when we correct for location selection biases, we again compute the marginal effects of the distance variable for the specifications in Column 3 of Table 5 and Column 9 of Table 6 (once again with a 4th order polynomial approximation of the correction function). In Column 3 of Table 5 with Distance as the only explanatory the one of a bootstrap. In any case, bootstrapped standard errors for specific cross-sections are available upon request. 
variable, the marginal effect is $-0.15 \mathrm{bps}$. Compared to the same specification without the location selection correction (Column 1 of Table 4), the marginal effect has decreased by close to $55 \%$, and the economic effect of a one standard deviation rise in Distance on portfolio weights has dropped to -1.8 bps (was -3.8 bps in Column 1 of Table 4 before). Similarly, when we include all the other control variables as in Column 9 of Table 6, the marginal effect is -0.08 bps and the associated economic effect of Distance is -0.9 bps, i.e. both go down by around $50 \%$ from the specification without the location selection correction (Column 4 of Table 4). All the aforementioned economic effects are compactly depicted in Table 7.

\section{Robustness}

\subsection{Income and Age Sub-samples}

For robustness, we repeat the estimation procedure, with and without the correction for location selection, in four sub-samples that we define based on quantiles of income and age in every month of our data. That is, we assign households to four groups, namely "Poor and Young", "Rich and Young", "Poor and Old" and "Rich and Old", depending on whether their income and age is below or above the corresponding median values. The results are shown in Table 8 and Figure 4.

Before employing our correction functions, we estimate that distance matters more for Poor and Young households (the coefficient estimate is -0.016), while it matters less for households which are Rich and Old (the coefficient estimate is -0.011). Households which are either Rich and Young or Poor and Old are in the middle of the ranking, with a coefficient estimate of -0.013 . After the selection correction, the overall ranking is preserved, with the pattern of the approximate $50 \%$ reduction in the distance coefficient being consistent across all groups. The estimate for the Rich and Old households still has the lowest value, which now is -0.006 . This is not surprising, since one would expect that with higher income and experience, information and cognitive costs for stock investments are decreased. 
The above estimation results confirm our conjecture that information and cognitive costs are reflected in a household's active location choice, irrespective of the household heterogeneity. Averaging the distance coefficient estimates across the sub-samples, before and after selection correction, yields values that approximate the estimates from the whole sample (i.e. -0.013 and -0.007 respectively).

\subsection{Higher Order Polynomials}

The above $50 \%$ reduction in the distance coefficient is achieved by approximating the two correction functions with a fourth order polynomial. In Table 9, we present additional estimation results for the distance coefficient, when the approximation order of the correction functions is furthered increased to the 5th and 6th order. Not much more reduction is achieved from higher order polynomials.

\subsection{Alternative Distance Measures}

In Appendix Table 1, we repeat the estimation of the portfolio choice model, replacing the continuous distance variable measured in degrees with dummies indicating whether the headquarters of a stock are more than a certain threshold of miles away from a household's residence. In particular, using the conservative threshold of 250 miles, the reduction in the Away coefficient is about 44\%, which is similar to the one in our baseline specification (50\%). Naturally, most firms have their headquarters away from a household's residence, so that the coefficient of Away is strengthened once the threshold decreases to 100 miles. Indeed, according to Panel $\mathrm{C}$ of Table 1, dropping the threshold from 250 miles to 100 miles results in a 5\% increase (decrease) of distant (local) stocks. Nevertheless, even in the case of 100 miles, correcting for selection still drops the coefficient of Away by $32 \%$. 


\subsection{No Income, No Job Code in the Location Model}

According to our location choice model, when households locate, they match to the characteristics of a city taking into account their income and job code. That is, we allow both income and job codes to contribute to households' observed heterogeneity in locational preferences. This assumption precludes these variables from being an outcome of the location decision; we assume perfect foresight regarding a household's ability to earn money in any city it decides to locate and treat these variables as proxies for that ability. Yet, to alleviate any concerns regarding the plausible endogeneity of income or job codes, we repeat the whole estimation exercise excluding either income or both income and job codes from the location model. The estimation results of these two alternative location models are shown in Column 1 and 2 of Appendix Table 2. The estimation results of the corresponding portfolio choice models, which are presented in Appendix Table 3, in terms of the distance coefficient estimate and the reduction due to selection correction are virtually the same. ${ }^{30}$

\subsection{Stock Characteristics in the Location Model}

We also estimate households' location choice by controlling for the financial characteristics of the stocks with headquarters in each city. In particular, given city $\ell$ and the set of stocks headquartered there $\mathcal{J}_{\ell}$, we define city $\ell$ 's financial characteristics to be the value-weighted averages of the characteristics of every stock $j \in \mathcal{J}_{\ell} \cdot{ }^{31}$ To construct city $\ell$ 's industry code, we use the mode of the industry codes of its stocks as well as a separate code if the mode is not defined.

\footnotetext{
${ }^{30}$ In more detail, with a fourth order polynomial approximation of the correction functions, the distance coefficient when the location choice model does not include income is -0.00714 , while it is -0.00702 when the location choice model does not include either income or job codes. Both are slightly lower in magnitude than the distance coefficient obtained from the baseline location choice model, which is -0.00731 .

${ }^{31}$ Equation (2) is replaced by:

$$
V_{i, \ell}=\boldsymbol{\rho}_{i} \boldsymbol{z}_{l}+\boldsymbol{b} \boldsymbol{f}_{\ell}
$$

where $\boldsymbol{f}_{\ell}$ is city $\ell$ 's vector of financial characteristics and $\boldsymbol{b}$ is the vector of the additional location parameters. Unlike the matching between household and city demographics, interactions of household demographics with financial variables have no particular meaning for a location decision. That is why we do not include them.
} 
The stock characteristics of a city comprise an additional signal for the prospects of the local economy (besides the city's demographics). In the housing equilibrium models of Ortalo-Magné and Prat (2016) and Hizmo (2015), where a household discounts future investment in its location decision, these variables could indicate the local risk to which a household will be exposed once it resides. More practically, the characterization of the type of local stocks can provide a better proxy for the employment opportunities and job offers in the area.

The estimation results of this new location choice model are presented in Column 3 of Appendix Table $2 .{ }^{32}$ The estimated coefficients of city demographics and their interactions with household demographics are similar to the ones in the baseline model. As for the estimated coefficients of the cities' financial characteristics, all of them are statistical significant and increase the pseudo $R^{2}$ by about $14 \%$. However, as Appendix Table 4 illustrates, regarding the distance coefficient estimate in portfolio choice after the selection adjustment, the new predicted location probabilities yield again the same $50 \%$ reduction.

\section{Assessing the Selection-Corrected Local Bias}

\subsection{Using Value-Weighted Portfolios as a Benchmark}

Up to this point, we have documented, under various specifications, an approximate $50 \%$ reduction in the distance coefficient $(\delta)$ of the Tobit portfolio choice model due to location selection. In particular, in the "full controls" specification, the selection corrected estimate of distance is on average -0.007 , implying an average economic effect of -0.9 bps on portfolio weight every time distance increases by one standard deviation. To assess how much of this effect is due to local bias, we consider a null hypothesis according to which households would hold value-weighted portfolios on stocks in the Russell 1000 Index. Under the

\footnotetext{
${ }^{32}$ Since cities are required to have stock headquarters, the choice set in this specification decreases by four MSAs.
} 
assumption that Russell 1000 is the market, such a hypothesis is in line with the CAPM prescription. We then proceed to estimate the portfolio parameters under this null, namely $\boldsymbol{\theta}^{o} \equiv\left(\alpha^{o}, \boldsymbol{\beta}^{o}, \boldsymbol{\gamma}^{o}, \delta^{o}\right)$, by running the following linear regression for every month in the sample period:

$$
w_{j}^{V W}=\alpha^{o}+\boldsymbol{\beta}^{o} \boldsymbol{x}_{j}+\boldsymbol{\gamma}^{o} \boldsymbol{D}_{i}+\delta^{o} d i s t_{i, c, h, j}+\Psi_{c, h}^{o}+\zeta_{i, c, h, j}
$$

where the variation in the RHS of the equation is only across stocks, with $w_{j}^{V W}$ being the Russell 1000 value-weighted portfolio on stock $j$. In the regression, we correct for location selection through the correction functions $\Psi_{c, h}^{o}$.

The estimation results of this regression (as well as of alternative specifications with fewer controls) are presented in Table 10. In Columns 1 and 2, we see that the average estimate of the distance coefficient (which here is also the average marginal effect) is -0.018 or -0.017 bps with an average $t$-statistic of -12.4 . That is, even under a CAPM null, there exist specifications in which the distance coefficient is statistically significant, since households do live near the headquarters of some stocks. Still, for these cases, the associated economic effect of a one standard deviation increase in distance is quite low (i.e. about $-0.2 \mathrm{bps}^{33}$ ). Moreover, once we control for the financial characteristics of stocks and the city demographics in Columns 3 and 4, the distance coefficient is statistically insignificant and practically zero. Therefore, the -0.9 bps estimate of the economic effect in our Tobit specification with full controls does indeed constitute an estimate of households' portfolio local bias versus the CAPM benchmark.

\subsection{Value-Weighted Portfolio Deviations}

Motivated by Brandt, Santa-Clara, and Valkanov (2009), we also explore the implications of selection correction in an alternative investment model in which households deviate from value-weighted portfolios according to a linear factor model with the same vari-

\footnotetext{
${ }^{33}$ Recall that the respective Tobit economic effect for these specifications is -3.8 bps.
} 
ables as our baseline Tobit specification. We denote the parameters of this new model $\boldsymbol{\theta}^{d e v} \equiv\left(\alpha^{d e v}, \boldsymbol{\beta}^{d e v}, \boldsymbol{\gamma}^{d e v}, \delta^{d e v}\right)$ and estimate them by running the following regression for every month in the sample period:

$$
w_{i, c, h, j}-w_{j}^{V W}=\alpha^{d e v}+\boldsymbol{\beta}^{d e v} \boldsymbol{x}_{j}+\boldsymbol{\gamma}^{d e v} \boldsymbol{D}_{i}+\delta^{d e v} d i s t_{i, c, h, j}+\Psi_{c, h}+\epsilon_{i, c, h, j}
$$

where the dependent variable in the LHS of the equation is the deviation of household $i$ 's portfolio weight on stock $j$ from the value-weighted portfolio on that stock, while $\Psi_{c, h}$ denotes the corresponding correction function. The advantage of this specification over the Tobit model is that the estimate of the distance coefficient can be directly interpreted as the estimated local bias under the same null hypothesis. On the other hand, the caveat is that the many zero portfolio weights on stocks, that motivated the use of our Tobit model in the first place, are translated to many negative deviations from the market.

The estimation results of this portfolio choice model, before and after the selection adjustment, are presented in Columns 5-8 of Table 10. Specifically, in Column 5, without correcting for selection, the distance coefficient is about -0.43 bps. As in our baseline specification, accounting for location selection drops the estimate up to 50\%, when the correction functions are approximated by a fourth order polynomial. The selection-corrected estimate of the local bias coefficient $\left(\delta^{d e v}\right)$ is about $-0.22 \mathrm{bps}$, so that the economic effect of a one standard deviation increase in distance is about -2.5 bps $(\approx-0.22 \times 11.45)$. That is, the local bias estimate of the above portfolio choice model is about three times higher than the local bias estimate of the Tobit. 


\section{Performance of Local versus Non-Local Stocks Ad- justed for Location Selection}

In the same spirit, we can consider the effect of correcting for location selection biases on the investment returns of households. To this end, we run various forms of the following regression:

$$
R_{i, j, t+1}=\alpha+\beta d i s t_{i, j, t}+\gamma^{\prime} X_{i, j, t}+\Psi_{t}+\epsilon_{i, j, t+1}
$$

where the dependent variable is $R_{i, j, t+1}=w_{i, j, t} r_{j, t+1}$, and $w_{i, j, t}$ is household $i$ 's portfolio weight on stock $j$ in month $t$ and $r_{j, t+1}$ is stock $j$ 's excess return over the market return in month $t+1 .{ }^{34}$ The key explanatory variable is $d i s t_{i, j, t}$, the distance between household $i$ 's residential zip code area and the zip code area of stock $j$ 's headquarters (in month $t$ ). Furthermore, $X_{i, j, t}$ is the vector of the same household demographics, stock characteristics, zip code area attributes and industry controls in month $t$ that are used in the portfolio choice estimations, and $\Psi_{t}$ is the correction function for location selection biases that is approximated by polynomials and the same as before in the portfolio choice estimations.

We follow the Fama and MacBeth (1973) approach and the return regressions of (20) are performed in each month. Then we use the time-series averages of the monthly coefficient estimates, and the associated $t$-statistics for the monthly estimates are based on Newey-West HAC standard errors with a lag order of 3 for all of the regressions. The estimation results are shown in Table 11.

In Columns 1, we estimate the performance regression with distance as the only independent variable. The coefficient on distance is -0.0011 with a $t$-statistic of -1.65 . This finding is consistent with those in the literature that household's local stock picks out-perform their distant stock picks. In Columns 2-5, we add in our location selection control functions as we did above for the portfolio holdings. As we increase the polynomial of the control func-

\footnotetext{
${ }^{34}$ The market return is the value-weighted return of all CRSP firms incorporated in the US and listed on the NYSE, AMEX, or NASDAQ that have a CRSP share code of 10 or 11. It is available from Kenneth R. French's website http://mba.tuck.dartmouth.edu/pages/faculty/ken.french/index.html.
} 
tions to a higher degree, the size of the coefficient in front of distance drops and becomes statistically insignificant.

In Column 6, we estimate our performance regression by including a full set of household demographics, stock characteristics, industry controls, and MSA characteristics. The mean

of the future 1-month weighted excess return $R_{i, j, t+1}=w_{i, j, t} r_{j, t+1}$ is $0.03 \mathrm{bps}$. In the full model without corrections (Column 6), a one standard deviation rise in distance is associated with a $11.45 \times 0.0017=0.020 \mathrm{bps}$ fall in the future 1 -month $R_{i, j, t+1}($ or $67 \%$ of its mean). But again, once we include our location selection control functions, the economic and statistical significance of the coefficient on distance drop.

With a 6th order correction (Column 10), the economic effect decreases to a $11.45 \times$ $0.0008=0.010$ bps fall, a $50 \%$ drop from the without corrections case. The coefficient is statistically insignificant. One way to interpret our findings is that proximity does not matter much for portfolios or returns of these portfolios after accounting for selection. That is, the imputed informational advantage of proximity for portfolios is not causal but mostly driven by location selection.

\section{Conclusion}

A long-standing puzzle in the household finance literature is that households hold undiversified stock portfolios tilted toward firms headquartered near where they reside. This puzzle is generally explained by theories that assign a causal role to proximity. The literature implicitly assumes that households locate randomly, but a household in practice optimally locates in a city depending on its preferences. In principle, it is expected that latent factors of this selection are correlated with unobservable preferences for local stocks. We use models from the literature on urban economics and real estate to account for the endogeneity of location choices and show how to correct for the potential selection effects of location choices on portfolio choices. 
Using brokerage house data over the period of 1991 to 1996, we show that accounting for location choices drastically reduces the impact of distance on household portfolios; the decrease in the distance coefficient and the associated economic effect is roughly $50 \%$. This reduction is robust across a wide range of specifications for the portfolio choice. The same is true when we apply this selection adjustment to the performance of household portfolios. The effect of distance on the performance of households' stock picks is mitigated when we control for selection. These results verify the conjecture that location choice really matters, paving the way for further work at the joint study of locational and investment decisions.

One venue for future work is to relate or extend our analysis to an international setting. While international equity home bias is not doubt driven by other factors such as trading costs, our selection bias mechanism might nonetheless naturally have a role. Some households, particularly the wealthy ones or those working in certain industries, have a choice of living abroad in cities such as London or Tokyo. To the extent we had data on households living abroad and their stock portfolios, we can integrate the international analysis into our setting and examine this issue. 


\section{References}

Agarwal, S., J. C. Driscoll, X. Gabaix, and D. Laibson, 2009, "The Age of Reason: Financial Decisions over the Life Cycle and Implications for Regulation," Brookings Papers on Economic Activity, 2009(2), 51-117.

Bajari, P., and M. E. Kahn, 2005, "Estimating Housing Demand With an Application to Explaining Racial Segregation in Cities," Journal of Business and Economic Statistics, 23(1), 20-33.

Barber, B. M., and T. Odean, 2000, "Trading Is Hazardous to Your Wealth: The Common Stock Investment Performance of Individual Investors," Journal of Finance, 55(2), 773806.

— , 2002, "Online Investors: Do the Slow Die First?," Review of Financial Studies, $15(2), 455-487$.

Bayer, P., F. Ferreira, and R. McMillan, 2007, "A Unified Framework for Measuring Preferences for Schools and Neighborhoods," Journal of Political Economy, 115(4), 588-638.

Bayer, P., R. McMillan, A. Murphy, and C. Timmins, 2016, "A Dynamic Model of Demand for Houses and Neighborhoods," Econometrica, 84(3), 893-942.

Bayer, P. J., B. D. Bernheim, and J. K. Scholz, 2009, "The Effects of Financial Education in the Workplace: Evidence from a Survey of Employers," Economic Inquiry, 47(4), 605-624.

Benartzi, S., 2001, "Excessive Extrapolation and the Allocation of 401(k) Accounts to Company Stock," Journal of Finance, 56(5), 1747-1764.

Bishop, K. C., 2007, "A Dynamic Model of Location Choice and Hedonic Valuation," Working Paper. 
Bourguignon, F., M. Fournier, and M. Gurgand, 2007, "Selection Bias Corrections Based on the Multinomial Logit Model: Monte Carlo Comparisons," Journal of Economic Surveys, 21(1), 174-205.

Brandt, W. M., P. Santa-Clara, and R. Valkanov, 2009, "Parametric Portfolio Policies: Exploiting Characteristics in the Cross-Section of Equity Returns," Review of Financial Studies, 22(9), 3411-3447.

Campbell, J. Y., 2006, "Household Finance," The Journal of Finance, 61(4), 1553-1604.

Charles, K. K., E. Hurst, and N. Roussanov, 2009, "Conspicuous Consumption and Race," The Quarterly Journal of Economics, 124(2), 425-467.

Coval, J. D., and T. J. Moskowitz, 1999, "Home Bias at Home: Local Equity Preference in Domestic Portfolios," Journal of Finance, 54(6), 2045-2073.

— , 2001, "The Geography of Investment: Informed Trading and Asset Prices," Journal of Political Economy, 109(4), 811-841.

Dahl, G. B., 2002, "Imobility and the Return to Education: Testing a Roy Model with Multiple Markets," Econometrica, 70(6), 2367-2420.

DeMarzo, P. M., R. Kaniel, and I. Kremer, 2004, "Diversification as a Public Good: Community Effects in Portfolio Choice," Journal of Finance, 59(4), 1677-1716.

Diamond, R., 2016, "The Determinants and Welfare Implications of US Workers' Diverging Location Choices by Skill: 1980-2000," American Economic Review, 106(3), 479-524.

Dubin, J. A., and D. L. McFadden, 1984, "An Econometric Analysis of Residential Electric Appliance Holdings and Consumption," Econometrica, Vol. 52(2), 345-362.

Fama, E. F., and J. D. MacBeth, 1973, "Risk, Return, and Equilibrium: Empirical Tests," Journal of Political Economy, 81(3), 607-636. 
Feng, L., and M. S. Seasholes, 2008, "Individual Investors and Gender Similarities in An Emerging Stock Market," Pacific-Basin Finance Journal, 16, 44-60.

French, K. R., and J. M. Poterba, 1991, "Investor Diversification and International Equity Markets," American Economic Review, 81(2), 222-226.

Garleanu, N., and L. H. Pedersen, 2013, "Dynamic Trading with Predictable Returns and Transaction Costs," Journal of Finance, 68(6), 2309-2340.

Gomez, J.-P., R. Priestley, and F. Zapatero, 2009, "Implications of Keeping-Up-with-theJoneses Behavior for the Equilibrium Cross Section of Stock Returns: International Evidence," Journal of Finance, 64(6), 2703-2737.

Gompers, P. A., and A. Metrick, 2001, "Institutional Investors and Equity Prices," Quarterly Journal of Economics, 116(1), 229-259.

Grinblatt, M., and M. Keloharju, 2001, "How Distance, Language, and Culture Influence Stockholdings and Trades," Journal of Finance, 56(3), 1053-1073.

Heckman, J. J., 1977, "Sample Selection Bias as a Specification Error (with an Application to the Estimation of Labor Supply Functions)," NBER Working Papers.

Hizmo, A., 2015, "Risk in Housing Markets: An Equilibrium Approach," Working Paper.

Hjalmarsson, E., and P. Manchev, 2012, "Characteristic-Based Mean-Variance Portfolio Choice," Journal of Banking and Finance, 36(5), 1392-1401.

Hong, H., W. Jiang, N. Wang, and B. Zhao, 2014, "Trading for Status," Review of Financial Studies, 27, 3171-3212.

Huberman, G., 2001, "Familiarity Breeds Investment," Review of Financial Studies, 14(3), 659-680. 
Ivković, Z., and S. Weisbenner, 2005, "Local Does as Local Is: Information Content of the Geography of Individual Investors' Common Stock Investments," The Journal of Finance, 60(1), 267-306.

Kaplan, G., and S. Schulhofer-Wohl, 2012, "Understanding the Long-Run Decline in Interstate Migration," working paper, National Bureau of Economic Research.

Keloharju, M., S. Knupfer, and E. Rantapuska, 2012, "Mutual Fund and Share Ownership in Finland," Liiketaloudellinen aikakauskirja, 2, 178-198.

Kennan, J., and J. R. Walker, 2011, "The Effect of Expected Income on Individual Migration Decisions," Econometrica, 79(1), 211-251.

Koijen, R. S., and M. Yogo, 2016, "An Equilibrium Model of Institutional Demand and Asset Prices," Working Paper.

Lee, L.-F., 1983, "Generalized Econometric Models with Selectivity," Econometrica, 51(2), $507-512$.

Lusardi, A., and O. Mitchell, 2007, "Financial Literacy and Retirement Preparedness: Evidence and Implications for Financial Education," Business economics, 42(1), 35-44.

Luttmer, E. F. P., 2005, "Neighbors as Negatives: Relative Earnings and Well-Being," The Quarterly Journal of Economics, 120(3), 963-1002.

Odean, T., 1999, "Do Investors Trade Too Much?," American Economic Review, 89(5), $1279-1298$.

Ortalo-Magné, F., and A. Prat, 2016, "Spatial Asset Pricing: A First Step," Economica, 83, $130-171$.

Pirinsky, C., and Q. Wang, 2006, "Does Corporate Headquarters Location Matter for Stock Returns?," Journal of Finance, 61(4), 1991-2015. 
Puhani, P. A., 2000, "The Heckman Correction for Sample Selection and Its Critique," Journal of Economic Surveys, 14(1), 53-68.

Sharpe, W. F., 1964, "Capital Asset Prices: A Theory of Market Equilibrium under Conditions of Risk," Journal of Finance, 19(3), 425-442.

Shumway, T., M. B. Szefler, and K. Yuan, 2011, "The Information Content of Revealed Beliefs in Portfolio Holdings," Working Paper.

Strauss-Kahn, V., and X. Vives, 2009, "Why and Where Do Headquarters Move?," Regional Science and Urban Economics, 39(2), 168-186.

Zhu, N., 2002, "The Local Bias of Individual Investors," Yale ICF working paper. 
Table 1: Summary Statistics

This table reports the summary statistics of all the variables in our sample. Panel A shows the characteristics of the 57 Metropolitan Statistical Areas (MSAs). Pop is the population number, LogPop is the log of population, Unemp is the unemployment rate, Incomepc is the income per capita, HPI is the housing price index, and LogHPI is the log of HPI. Panel B shows the demographics of the households in our sample. Income is the income level. LogIncome is the log of Income. Age is the age of the household head. LogAge is the log of Age. Professional, Managerial, SalesServices, WhiteCollar, BlueCollar, Male, Married are dummy variables that equal one if the household head has a professional-type job, managerial-type job, sales-services-type job, white collar-type job, blue collar-type job, is a male, and is married respectively. Kids is the number of kids under the age of 18 in a household. Panel $\mathrm{C}$ refers to the stock holdings of the households and their distance. Portwt is the portfolio of a household on a stock. Numst is the number of stocks that a household holds. Distance is the distance between a household's residential zip code area and the zip code area of a stock's headquarters. Away $250 \mathrm{~m}$ (Away $100 \mathrm{~m}$ ) is a dummy indicating whether a stock is headquartered more than 250 miles (100 miles) away from a household's residence. Panel D shows the characteristics of the Russell 1000 stocks. Price is the price of a stock. LogPrice is the log of Price. Size is the market capitalization. LogSize is the log of Size. BTM is the book-to-market ratio. Turnover is share turnover. Momentum is the past 12-month return. Volatility is the volatility of the monthly returns in the past 12 months. The last 17 variables of Food to Other are industry dummy variables that equal to one if a stock belongs to that particular industry. The 17 industries are defined based on the categorization of the Fama-French 17-industry portfolios. The sample is from January 1991 to November 1996.

\begin{tabular}{|c|c|c|c|c|c|}
\hline \multicolumn{6}{|c|}{ Panel A: Characteristics of 58 Metropolitan Statistical Areas (MSAs) } \\
\hline & Mean & S.D. & Median & Min & Max \\
\hline Pop (million) & 2.50 & 2.80 & 1.50 & 0.68 & 18.00 \\
\hline LogPop & 14.43 & 0.71 & 14.25 & 13.43 & 16.69 \\
\hline Unemp (\%) & 5.80 & 1.92 & 5.49 & 2.92 & 15.63 \\
\hline Incomepc ( $\$$ thousand) & 23.62 & 3.91 & 23.06 & 16.96 & 44.88 \\
\hline $\mathrm{HPI}(=100$ in $1995 \mathrm{Q} 1)$ & 99.19 & 7.85 & 100.37 & 64.57 & 123.15 \\
\hline LogHPI & 4.59 & 0.08 & 4.61 & 4.17 & 4.81 \\
\hline \multicolumn{6}{|c|}{ Panel B: Demographics of Households } \\
\hline & Mean & S.D. & Median & Min & Max \\
\hline Income ( $\$$ thousand $)$ & 82.40 & 31.69 & 87.50 & 10.00 & 125.00 \\
\hline LogIncome & 11.22 & 0.50 & 11.38 & 9.21 & 11.74 \\
\hline Age (years) & 47.73 & 10.59 & 46.00 & 24.00 & 94.00 \\
\hline LogAge & 3.84 & 0.22 & 3.83 & 3.18 & 4.54 \\
\hline Professional (\%) & 55.1 & & & & \\
\hline Managerial (\%) & 27.7 & & & & \\
\hline SalesServices (\%) & 8.4 & & & & \\
\hline WhiteCollar (\%) & 4.9 & & & & \\
\hline BlueCollar (\%) & 3.9 & & & & \\
\hline Male $(\%)$ & 92.6 & & & & \\
\hline Married (\%) & 79.2 & & & & \\
\hline Kids & 0.67 & 0.94 & 0 & 0 & 5 \\
\hline \multicolumn{6}{|c|}{ Panel C: Household Stock Holdings } \\
\hline & Mean & S.D. & Median & Min & $\operatorname{Max}$ \\
\hline Portval (\$ thousand) & 39.84 & 152.10 & 14.72 & 0.00 & $5,108.17$ \\
\hline Portwt & $11.2 \mathrm{bps}$ & 0.03 & 0 & 0 & 1 \\
\hline Numst & 1.85 & 1.55 & 1 & 1 & 24 \\
\hline Distance (degrees) & 17.60 & 11.45 & 15.66 & 0.00 & 39.72 \\
\hline Away250m (\%) & 88.2 & & & & \\
\hline Away $100 \mathrm{~m}(\%)$ & 93.6 & & & & \\
\hline
\end{tabular}


Table Cont'd: Summary Statistics

\begin{tabular}{|c|c|c|c|c|c|}
\hline \multicolumn{6}{|c|}{ Panel D: Characteristics of Russell 1000 Stocks } \\
\hline & Mean & S.D. & Median & Min & Max \\
\hline Price $(\$)$ & 33.94 & 25.06 & 29.62 & 0.03 & 684.00 \\
\hline LogPrice $(\$)$ & 3.32 & 0.69 & 3.39 & -3.51 & 6.53 \\
\hline Size ( $\$$ million) & 3455.53 & 8106.10 & 1229.75 & 0.56 & 130000.00 \\
\hline LogSize ( $\$$ million) & 7.23 & 1.25 & 7.11 & -0.57 & 11.78 \\
\hline BTM & 0.43 & 4.09 & 0.43 & -271.51 & 320.13 \\
\hline Turnover & 0.30 & 0.93 & 0.17 & 0.00 & 113.05 \\
\hline Momentum & 0.17 & 2.15 & 0.07 & -0.99 & 217.09 \\
\hline Volatility & 0.18 & 1.01 & 0.12 & 0.00 & 67.58 \\
\hline Food $(\%)$ & 4.0 & & & & \\
\hline Mines $(\%)$ & 2.0 & & & & \\
\hline Oil $(\%)$ & 6.0 & & & & \\
\hline Clths (\%) & 1.0 & & & & \\
\hline Durbl (\%) & 1.0 & & & & \\
\hline Chems $(\%)$ & 3.0 & & & & \\
\hline Cnsum (\%) & 5.0 & & & & \\
\hline Cnstr (\%) & 2.0 & & & & \\
\hline Steel (\%) & 2.0 & & & & \\
\hline FabPr $(\%)$ & 1.0 & & & & \\
\hline Machn (\%) & 12.0 & & & & \\
\hline Cars $(\%)$ & 2.0 & & & & \\
\hline Trans $(\%)$ & 3.0 & & & & \\
\hline Utils $(\%)$ & 6.0 & & & & \\
\hline Rtail (\%) & 8.0 & & & & \\
\hline Finan $(\%)$ & 16.0 & & & & \\
\hline Other (\%) & 26.0 & & & & \\
\hline
\end{tabular}


Table 2: Local Bias among Households

This table provides summary statistics for the local bias of household portfolio holdings in our data. Column 2 (Avg. Distance from Holdings) reports the average distance of households from the stocks they hold in their portfolios. The average distance in Column 2 is computed as $\frac{1}{I} \sum_{i} \sum_{j} w_{j}^{i} d_{j}^{i}$, where $d_{j}^{i}$ is the distance between household $i$ 's residential area and the headquarters area of stock $j, w_{j}^{i}$ is household $i$ 's portfolio weight on stock $j$, and $I$ is the total number of households. Column 3 (Avg. Distance from Benchmark) is computed as $\frac{1}{I} \sum_{i} \sum_{j} \bar{w}_{j} d_{j}^{i}$, where $\bar{w}_{j}$ is a benchmark Russell 1000 portfolio weight on stock $j$, and $d_{j}^{i}$ and $I$ are the same as in Column 2. In Row 1 the benchmark is the equally weighted portfolio. In Row 2 the benchmark is the value-weighted portfolio. Column 4 (Difference) reports the difference between Column 2 and Column 3, which is the local bias in distance units. Column 5 (\% Bias (LB)) reports the local bias (LB) measure as a percentage. Column 6 ( $t$-stat) reports the $t$-statistics for the LB measure. The sample period is from January 1991 to November 1996.

\begin{tabular}{lccccc}
\hline & \multicolumn{2}{c}{ Avg. Distance from } & & & \\
\cline { 2 - 3 } Weights & Holdings & Benchmark & Difference & $\%$ Bias (LB) & $t$-stat \\
\hline Equal & 9.38 & 17.67 & 8.29 & 45.45 & 52.74 \\
Value & 9.38 & 17.65 & 8.26 & 43.72 & 47.65 \\
\hline
\end{tabular}


Table 3: Conditional Logit Estimation of Household Location Choice

This table presents the results from the maximum likelihood estimation of the two conditional logit models for household location choices. $t$-statistics (shown in parentheses) are based on standard errors clustered at the household level, with *,**, *** denoting statistical significance at $10 \%, 5 \%, 1 \%$ respectively. The choice set of households consists of 57 MSAs. The dependent variable is an indicator variable that equals one if a household resides in the specific MSA. The main explanatory variables are MSA characteristics that include the log of the population number in an MSA ( $\log P o p)$, the unemployment rate (Unemp), the income per capita (Incomepc), and the log of the housing price index (LogHPI). We also include all pair-wise interaction terms between these MSA characteristics variables and the household demographics variables LogIncome, LogAge, Managerial, SalesServices, WhiteCollar, BlueCollar, Male, Married, Kids (shown in Panel B of Table 1) in our main location choice model in Column 1. For comparison, we show the estimation results from the model where the interaction terms are not included in Column 2. Log-likelihood is the estimated $\log$-likelihood value. Pseudo $R^{2}$ is the McFadden's pseudo $R^{2}$ measure based on the estimated log-likelihood value. $N$ is the number of observations.

\begin{tabular}{|c|c|c|}
\hline & $(1)$ & (2) \\
\hline LogPop & $\begin{array}{l}-0.265 \\
(-0.64)\end{array}$ & $\begin{array}{c}0.938^{* * *} \\
(71.12)\end{array}$ \\
\hline Unemp & $\begin{array}{l}-0.418 \\
(-1.51)\end{array}$ & $\begin{array}{c}-0.124^{* * *} \\
(-14.17)\end{array}$ \\
\hline Incomepc & $\begin{array}{c}-0.240^{* *} \\
(-2.42)\end{array}$ & $\begin{array}{c}0.075^{* * *} * \\
(24.00)\end{array}$ \\
\hline LogHPI & $\begin{array}{l}-3.712 \\
(-1.12)\end{array}$ & $\begin{array}{c}0.507^{* * *} \\
(4.73)\end{array}$ \\
\hline LogPop $\times$ LogIncome & $\begin{array}{l}0.051^{*} \\
(1.70)\end{array}$ & \\
\hline LogPop $\times$ LogAge & $\begin{array}{c}0.156^{* *} \\
(2.48)\end{array}$ & \\
\hline LogPop $\times$ Managerial & $\begin{array}{c}0.096^{* * *} \\
(3.07)\end{array}$ & \\
\hline LogPop $\times$ SalesServices & $\begin{array}{l}0.039 \\
(0.76)\end{array}$ & \\
\hline LogPop $\times$ WhiteCollar & $\begin{array}{c}0.210^{* * *} \\
(3.19)\end{array}$ & \\
\hline LogPop $\times$ BlueCollar & $\begin{array}{l}0.093 \\
(1.28)\end{array}$ & \\
\hline LogPop $\times$ Male & $\begin{array}{l}0.056 \\
(1.15)\end{array}$ & \\
\hline LogPop $\times$ Married & $\begin{array}{c}-0.064^{*} \\
(-1.83)\end{array}$ & \\
\hline LogPop $\times$ Kids & $\begin{array}{l}-0.012 \\
(-0.79)\end{array}$ & \\
\hline Unemp $\times$ LogIncome & $\begin{array}{l}-0.008 \\
(-0.44)\end{array}$ & \\
\hline Unemp $\times$ LogAge & $\begin{array}{c}0.094^{* *} \\
(2.18)\end{array}$ & \\
\hline Unemp $\times$ Managerial & $\begin{array}{l}0.003 \\
(0.15)\end{array}$ & \\
\hline Unemp $\times$ SalesServices & $\begin{array}{l}-0.006 \\
(-0.17)\end{array}$ & \\
\hline Unemp $\times$ WhiteCollar & $\begin{array}{l}0.058 \\
(1.41)\end{array}$ & \\
\hline Unemp $\times$ BlueCollar & $\begin{array}{c}0.118^{* * *} \\
(3.04)\end{array}$ & \\
\hline
\end{tabular}


Table Cont'd: Conditional Logit Estimation of Household Location Choice

\begin{tabular}{|c|c|c|}
\hline & (1) & $(2)$ \\
\hline Unemp $\times$ Male & $\begin{array}{l}0.013 \\
(0.34)\end{array}$ & \\
\hline Unemp $\times$ Married & $\begin{array}{l}-0.010 \\
(-0.42)\end{array}$ & \\
\hline Unemp $\times$ Kids & $\begin{array}{c}0.017^{*} \\
(1.72)\end{array}$ & \\
\hline Incomepc $\times$ LogIncome & $\begin{array}{c}0.051^{* * *} \\
(6.96)\end{array}$ & \\
\hline Incomepc $\times$ LogAge & $\begin{array}{c}-0.045^{* * *} \\
(-3.06)\end{array}$ & \\
\hline Incomepc $\times$ Managerial & $\begin{array}{l}-0.009 \\
(-1.24)\end{array}$ & \\
\hline Incomepc $\times$ SalesServices & $\begin{array}{l}-0.018 \\
(-1.48)\end{array}$ & \\
\hline Incomepc $\times$ WhiteCollar & $\begin{array}{l}-0.002 \\
(-0.09)\end{array}$ & \\
\hline Incomepc $\times$ BlueCollar & $\begin{array}{l}0.003 \\
(0.16)\end{array}$ & \\
\hline Incomepc $\times$ Male & $\begin{array}{c}-0.051^{* * *} \\
(-4.89)\end{array}$ & \\
\hline Incomepc $\times$ Married & $\begin{array}{c}-0.038^{* * *} \\
(-4.64)\end{array}$ & \\
\hline Incomepc $\times$ Kids & $\begin{array}{l}0.000 \\
(0.08)\end{array}$ & \\
\hline LogHPI $\times$ LogIncome & $\begin{array}{c}0.936^{* * *} \\
(3.96)\end{array}$ & \\
\hline LogHPI $\times$ LogAge & $\begin{array}{c}-1.186^{* *} \\
(-2.32)\end{array}$ & \\
\hline LogHPI $\times$ Managerial & $\begin{array}{l}-0.269 \\
(-1.09)\end{array}$ & \\
\hline LogHPI $\times$ SalesServices & $\begin{array}{l}-0.333 \\
(-0.86)\end{array}$ & \\
\hline LogHPI $\times$ WhiteCollar & $\begin{array}{l}0.253 \\
(0.46)\end{array}$ & \\
\hline LogHPI ×BlueCollar & $\begin{array}{c}-1.258^{* *} \\
(-2.22)\end{array}$ & \\
\hline LogHPI×Male & $\begin{array}{c}-0.777^{*} \\
(-1.67)\end{array}$ & \\
\hline LogHPI $\times$ Married & $\begin{array}{c}-0.607^{* *} \\
(-2.05)\end{array}$ & \\
\hline LogHPI $\times$ Kids & $\begin{array}{c}-0.516^{* * *} \\
(-4.20)\end{array}$ & \\
\hline Log-likelihood & -38579.5 & -38747.5 \\
\hline Pseudo $R^{2}$ & 0.109 & 0.105 \\
\hline$N$ & 610584 & 610584 \\
\hline
\end{tabular}


Table 4: Tobit Estimation of Household Portfolio Choice, No Correction for Location Selection

This table presents the maximum likelihood estimation results from our Tobit models for household portfolio choices, without any corrections for location selection biases. The results are time-series averages of the monthly coefficient estimates and their $t$-statistics (shown in parentheses) based on standard errors clustered at the household level. *, **, *** denote statistical significance at $10 \%, 5 \%, 1 \%$ respectively. The dependent variable $w_{j}^{i}$ is the portfolio weight allocated to stock $j$ by household $i$. The key explanatory variable is Distance, the distance between household $i$ 's residential zip code area and the zip code area of stock $j$ 's headquarters. Other variables include controls for household demographics, stock characteristics, and MSA characteristics. The household demographics controls are: the log of a household's income (LogIncome), the log of the age of a household head (LogAge), dummy variables for a household head's job codes (Managerial to BlueCollar), gender (Male) and marital status (Married), and the number of kids under the age of 18 a household has (Kids). The stock characteristics controls are: the log of the price (LogPrice), the log of the market capitalization (LogSize), the book-to-market ratio (BTM), the turnover ratio (Turnover), the momentum of the past 12 months (Momentum), and the volatility (Volatility). Industry controls denote 17 dummy variables for stocks belonging to the 17 Fama-French industry portfolios (the base in the regressions is the Food industry). Controls for MSA characteristics include: the log of the population number (LogPop), the unemployment rate (Unemp), the income per capita (Incomepc), the log of the housing price index (LogHPI), and the subscripts $c$ and $h$ denote household residential and stock headquarters areas respectively. The constant term and the standard deviation of the normal error term in the Tobit regression are not reported for clarity purposes. The sample period is January 1991 to November 1996.

\begin{tabular}{|c|c|c|c|c|}
\hline & \multicolumn{4}{|c|}{ Dependent Variable: Portfolio Weight $w_{j}^{i}$} \\
\hline & (1) & $(2)$ & $(3)$ & (4) \\
\hline Distance & $-0.012^{* * *}$ & $-0.012^{* * *}$ & $-0.013^{* * *}$ & $-0.014^{* * *}$ \\
\hline & $(-20.301)$ & $(-20.422)$ & $(-22.815)$ & $(-23.610)$ \\
\hline LogIncome & & $\begin{array}{c}0.034^{* * *} \\
(2.899)\end{array}$ & $\begin{array}{c}0.030 * * \\
(2.575)\end{array}$ & $\begin{array}{c}0.028^{* *} \\
(2.396)\end{array}$ \\
\hline LogAge & & $\begin{array}{c}0.086^{* * *} \\
(3.573)\end{array}$ & $\begin{array}{c}0.090^{* * *} \\
(3.796)\end{array}$ & $\begin{array}{c}0.096^{* * * *} \\
(4.039)\end{array}$ \\
\hline Managerial & & $\begin{array}{c}-0.025^{* *} \\
(-2.134)\end{array}$ & $\begin{array}{l}-0.023^{*} \\
(-1.959)\end{array}$ & $\begin{array}{l}-0.021^{*} \\
(-1.841)\end{array}$ \\
\hline SalesServices & & $\begin{array}{c}-0.043 * * * \\
(-2.631)\end{array}$ & $\begin{array}{c}-0.037^{* *} \\
(-2.296)\end{array}$ & $\begin{array}{c}-0.036^{* *} \\
(-2.208)\end{array}$ \\
\hline WhiteCollar & & $\begin{array}{c}-0.029 \\
(-1.449)\end{array}$ & $\begin{array}{c}-0.031 \\
(-1.557)\end{array}$ & $\begin{array}{c}-0.029 \\
(-1.457)\end{array}$ \\
\hline BlueCollar & & $\begin{array}{l}-0.053^{*} \\
(-1.955)\end{array}$ & $\begin{array}{l}-0.051^{*} \\
(-1.946)\end{array}$ & $\begin{array}{l}-0.049^{*} \\
(-1.844)\end{array}$ \\
\hline Male & & $\begin{array}{c}0.019 \\
(1.065)\end{array}$ & $\begin{array}{c}0.025 \\
(1.413)\end{array}$ & $\begin{array}{c}0.028 \\
(1.604)\end{array}$ \\
\hline Married & & $\begin{array}{c}-0.019 \\
(-1.363)\end{array}$ & $\begin{array}{c}-0.016 \\
(-1.159)\end{array}$ & $\begin{array}{c}-0.015 \\
(-1.078)\end{array}$ \\
\hline Kids & & $\begin{array}{c}-0.013^{* *} \\
(-2.318)\end{array}$ & $\begin{array}{c}-0.014^{* *} \\
(-2.491)\end{array}$ & $\begin{array}{c}-0.013^{* *} \\
(-2.359)\end{array}$ \\
\hline LogPrice & & & $\begin{array}{c}-0.376^{* * *} \\
(-29.959)\end{array}$ & $\begin{array}{c}-0.381 \text { *** } \\
(-29.896)\end{array}$ \\
\hline LogSize & & & $\begin{array}{c}0.429^{* * *} \\
(53.107)\end{array}$ & $\begin{array}{c}0.429^{* * *} \\
(52.566)\end{array}$ \\
\hline BTM & & & $\begin{array}{c}0.099^{* * *} \\
(6.373)\end{array}$ & $\begin{array}{c}0.100^{* * *} \\
(6.483)\end{array}$ \\
\hline Turnover & & & $\begin{array}{c}0.396^{* * *} \\
(29.004)\end{array}$ & $\begin{array}{c}0.376^{* * *} \\
(27.120)\end{array}$ \\
\hline Momentum & & & $\begin{array}{c}-0.035^{* *} \\
(-2.390)\end{array}$ & $\begin{array}{c}-0.036^{* *} \\
(-2.383)\end{array}$ \\
\hline Volatility & & & $\begin{array}{c}0.020 \\
(1.192)\end{array}$ & $\begin{array}{c}0.004 \\
(0.854)\end{array}$ \\
\hline $\operatorname{LogPop}_{c}$ & & & & $\begin{array}{c}-0.020 * * * \\
(-2.614)\end{array}$ \\
\hline $\mathrm{Unemp}_{c}$ & & & & $\begin{array}{c}0.001 \\
(0.078)\end{array}$ \\
\hline Incomepc $_{c}$ & & & & $\begin{array}{c}0.002 \\
(1.111)\end{array}$ \\
\hline $\operatorname{LogHPI}{ }_{c}$ & & & & $\begin{array}{c}-0.356 \\
(0.963)\end{array}$ \\
\hline $\operatorname{LogPop}_{h}$ & & & & $\begin{array}{c}-0.029 * * * \\
(-3.625)\end{array}$ \\
\hline Unemp $_{h}$ & & & & $\begin{array}{c}0.010 \\
(1.394)\end{array}$ \\
\hline Incomepc $_{h}$ & & & & $\begin{array}{c}0.004^{* * *} \\
(2.662)\end{array}$ \\
\hline $\operatorname{LogHPI}_{h}$ & & & & $\begin{array}{l}-0.687 \\
(0.755)\end{array}$ \\
\hline Industry controls & $\mathrm{NO}$ & $\mathrm{NO}$ & YES & YES \\
\hline
\end{tabular}


Table 5: Tobit Estimation of Household Portfolio Choice, with Correction for Location Selection

This table shows the results from the Tobit regressions of our household portfolio choice model with corrections for location selection biases. The results are time-series averages of the monthly coefficient estimates and their $t$-statistics (shown in parentheses) based on standard errors clustered at the household level. *, **, *** denote statistical significance at $10 \%, 5 \%$, $1 \%$ respectively. The dependent variable $w_{j}^{i}$ is the portfolio weight allocated to stock $j$ by household $i$. The key explanatory variable is Distance, the distance between household $i$ 's zip code area and the zip code area of stock $j$ 's headquarters. The correction functions $\Psi^{s}\left(p_{i, c}\right)$ and $\Psi^{d}\left(p_{i, h}, p_{i, c}\right)$ for location selections are approximated by polynomials. The approximation order is 1, 2 and 4. We do not include other control variables besides Distance in these Tobit regressions. The constant term and the standard deviation of the normal error term in the Tobit regression are not reported for clarity purposes. The sample period is from January 1991 to November 1996.

\begin{tabular}{|c|c|c|c|}
\hline & \multicolumn{3}{|c|}{ Dependent Variable: Portfolio Weight $w_{j}^{i}$} \\
\hline & (1) & $(2)$ & $(3)$ \\
\hline Distance & $-0.010^{* * *}$ & $-0.008^{* * *}$ & $-0.006^{* * *}$ \\
\hline & $(-17.794)$ & $(-14.698)$ & $\begin{array}{l}(-11.068) \\
61141 * * *\end{array}$ \\
\hline$p_{c}^{s}$ & $\begin{array}{c}3.122^{* * *} \\
(17.670)\end{array}$ & $\begin{array}{c}14.558^{* * * *} \\
(14.732)\end{array}$ & $\begin{array}{c}61.141^{* * *} \\
(16.171)\end{array}$ \\
\hline$p_{h}^{d}$ & $\begin{array}{c}1.167^{* * *} \\
(9.577)\end{array}$ & $\begin{array}{c}-0.402 \\
(-0.884)\end{array}$ & $\begin{array}{c}9.133^{* * *} \\
(4.336)\end{array}$ \\
\hline$p_{c}^{d}$ & $\begin{array}{c}-0.889^{* * *} \\
(-6.013)\end{array}$ & $\begin{array}{c}-3.507^{* * *} \\
(-7.908)\end{array}$ & $\begin{array}{c}-19.156^{* * *} \\
(-9.249)\end{array}$ \\
\hline$\left(p_{c}^{s}\right)^{2}$ & & $\begin{array}{r}-0.880^{* * *} \\
(-10.726)\end{array}$ & $\begin{array}{c}-14.106^{* * *} \\
(-12.590)\end{array}$ \\
\hline$\left(p_{h}^{d}\right)^{2}$ & & $\begin{array}{c}0.062^{* *} \\
(2.546)\end{array}$ & $\begin{array}{c}-2.799^{* * *} \\
(-6.012)\end{array}$ \\
\hline$p_{h}^{d} p_{c}^{d}$ & & $\begin{array}{c}0.284^{* * *} \\
(8.208)\end{array}$ & $\begin{array}{c}3.816^{* * *} \\
(7.422)\end{array}$ \\
\hline$\left(p_{c}^{d}\right)^{2}$ & & $\begin{array}{c}0.135^{* * *} \\
(5.366)\end{array}$ & $\begin{array}{c}3.013^{* * *} \\
(7.430)\end{array}$ \\
\hline$\left(p_{c}^{s}\right)^{3}$ & & & $\begin{array}{c}103.173^{* * *} \\
(10.037)\end{array}$ \\
\hline$\left(p_{h}^{d}\right)^{3}$ & & & $\begin{array}{c}24.822 * * * \\
(6.241)\end{array}$ \\
\hline$\left(p_{h}^{d}\right)^{2} p_{c}^{d}$ & & & $\begin{array}{c}-0.262^{* * *} \\
(-5.986)\end{array}$ \\
\hline$p_{h}^{d}\left(p_{c}^{d}\right)^{2}$ & & & $\begin{array}{c}-0.246^{* * *} \\
(-6.437)\end{array}$ \\
\hline$\left(p_{c}^{d}\right)^{3}$ & & & $\begin{array}{c}-18.787^{* * *} \\
(-6.252)\end{array}$ \\
\hline$\left(p_{c}^{s}\right)^{4}$ & & & $\begin{array}{c}-236.548^{* * *} \\
(-8.186)\end{array}$ \\
\hline$\left(p_{h}^{d}\right)^{4}$ & & & $\begin{array}{c}-64.993^{* * *} \\
(-5.849)\end{array}$ \\
\hline$\left(p_{h}^{d}\right)^{3} p_{c}^{d}$ & & & $\begin{array}{c}0.633^{* * *} \\
(4.528)\end{array}$ \\
\hline$\left(p_{h}^{d}\right)^{2}\left(p_{c}^{d}\right)^{2}$ & & & $\begin{array}{c}0.006^{* * *} \\
(3.863)\end{array}$ \\
\hline$p_{h}^{d}\left(p_{c}^{d}\right)^{3}$ & & & $\begin{array}{c}0.498^{* * *} \\
(4.985)\end{array}$ \\
\hline$\left(p_{c}^{d}\right)^{4}$ & & & $\begin{array}{c}39.799^{* * *} \\
(5.670)\end{array}$ \\
\hline
\end{tabular}


Table 6: Tobit Estimation of Household Portfolio Choice with Correction for Location Selection, Full Controls

This table presents the results from the Tobit regressions of our household portfolio choice model with corrections for location selection bias, and with controls for household demographics, stock characteristics, industries and MSA characteristics included. The results are time-series averages of the monthly coefficient estimates and their $t$-statistics (shown in parentheses) based on standard errors clustered at the household level. *, **, *** denote statistical significance at $10 \%, 5 \%, 1 \%$ respectively. The dependent variable $w_{j}^{i}$ is the portfolio weight allocated to stock $j$ by household $i$. The key explanatory variable is Distance, the distance between household $i$ 's residential zip code area and the zip code area of stock $j$ 's headquarters. The household demographics controls LogIncome to Kids, the stock characteristics controls LogPrice to Volatility, the industry controls, and the MSA characteristics controls $\log \mathrm{Pop}_{c}$ to $\operatorname{LogHPI}_{h}$ are the same as those shown in Table $4 . \Psi^{1 s t}$ to $\Psi^{4 t h}$ denote the orders of the polynomials used for approximating the correction functions $\Psi^{s}\left(p_{i, c}\right)$ and $\Psi^{d}\left(p_{i, h}, p_{i, c}\right)$ for location selections. The constant term and the standard deviation of the normal error term in the Tobit regression are not reported for clarity purposes. The sample period is January 1991 to November 1996.

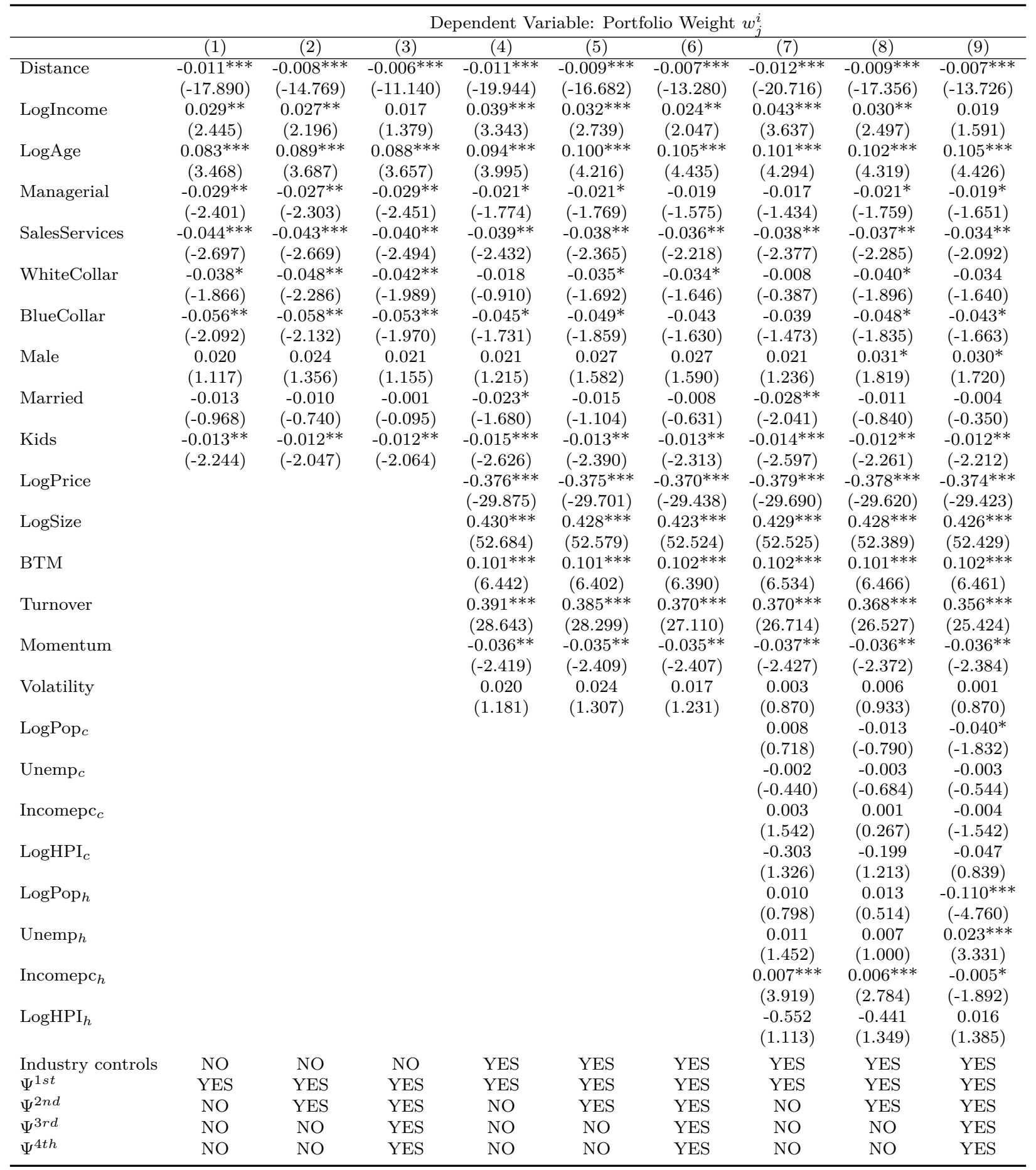


Table 7: Economic Effects of Distance on Household Portfolio Weights

This table shows the economic effect of a one standard deviation increase in Distance on the portfolio weight of a household on a stock, from different specifications of our household portfolio choice model. The economic effect is calculated based on the marginal effect of Distance on the portfolio weight from the Tobit estimation, with all other control variables anchored at their mean levels. The marginal effect is computed in each monthly estimation and then averaged across all months. Corrections denote whether the 4 th order correction function for location selection bias is included, and Full Controls denote whether the full set of controls for household demographics, stock characteristics, industry and MSA characteristics are included. The sample period is January 1991 to November 1996.

\begin{tabular}{|c|c|c|c|}
\hline & Full Controls & No & Yes \\
\hline \multicolumn{4}{|c|}{ Corrections } \\
\hline No & & $-3.8 \mathrm{bps}$ & $-1.9 \mathrm{bps}$ \\
\hline Yes & & $-1.8 \mathrm{bps}$ & $-0.9 \mathrm{bps}$ \\
\hline
\end{tabular}


Table 8: Tobit Estimation of Household Portfolio Choice with Correction for Location Selection, Full Controls, Sub-samples based on Income and Age

This table presents the results from the Tobit regressions of our household portfolio choice model with corrections for location selection biases, and with controls for household demographics, stock characteristics, industries and MSA characteristics included. The sub-samples are defined based on the median household income and age (i.e. using the cartesian product of their values below and above) in every month. The results are time-series averages of the monthly coefficient estimates and their $t$-statistics (shown in parentheses) based on standard errors clustered at the household level. $*,{ }^{* *}, * * *$ denote statistical significance at $10 \%, 5 \%, 1 \%$ respectively. The dependent variable $w_{j}^{i}$ is the portfolio weight allocated to stock $j$ by household $i$. The key explanatory variable is Distance, the distance between household $i$ 's residential zip code area and the zip code area of stock $j$ 's headquarters. The household demographics controls LogIncome to Kids, the stock characteristics controls LogPrice to Volatility, the industry controls, and the controls for MSA characteristics LogPop $\mathrm{P}_{\mathrm{H}}$ to $\operatorname{LogHPI}$ are the same as those shown in Table 4. $\Psi^{1 s t}$ to $\Psi^{4 t h}$ denote the orders of the polynomials used for approximating the correction functions $\Psi^{s}\left(p_{i, c}\right)$ and $\Psi^{d}\left(p_{i, h}, p_{i, c}\right)$ for location selections. The constant term and the standard deviation of the normal error term in the Tobit regression are not reported for clarity purposes. The sample period is January 1991 to November 1996.

\begin{tabular}{|c|c|c|c|c|c|c|c|c|}
\hline & \multicolumn{4}{|c|}{ Poor and Young } & \multicolumn{4}{|c|}{ Rich and Young } \\
\hline & $(1)$ & $(2)$ & $(3)$ & $(4)$ & $(5)$ & $(6)$ & $(7)$ & $(8)$ \\
\hline \multirow[t]{2}{*}{ Distance } & $-0.016^{* * *}$ & $-0.014^{* * *}$ & $-0.011^{* * *}$ & $-0.008^{* * *}$ & $-0.013^{* * *}$ & $-0.011^{* * *}$ & $-0.009^{* * *}$ & $-0.007^{* * *}$ \\
\hline & $(-14.449)$ & $(-12.701)$ & $(-10.336)$ & $(-8.103)$ & $(-10.380)$ & $(-9.161)$ & $(-7.713)$ & $(-6.257)$ \\
\hline \multirow[t]{2}{*}{ LogIncome } & 0.014 & 0.031 & 0.011 & -0.002 & 0.130 & 0.145 & 0.108 & 0.053 \\
\hline & $(0.663)$ & $(1.476)$ & $(0.490)$ & $(-0.143)$ & $(0.642)$ & $(0.717)$ & $(0.537)$ & $(0.276)$ \\
\hline \multirow[t]{2}{*}{ LogAge } & 0.092 & 0.098 & 0.095 & 0.095 & 0.106 & 0.108 & 0.112 & 0.122 \\
\hline & $(1.214)$ & $(1.298)$ & $(1.260)$ & $(1.267)$ & $(1.204)$ & $(1.243)$ & $(1.285)$ & $(1.404)$ \\
\hline \multirow[t]{2}{*}{ Managerial } & -0.010 & -0.004 & -0.007 & -0.007 & -0.011 & -0.003 & -0.007 & -0.004 \\
\hline & $(-0.439)$ & $(-0.186)$ & $(-0.349)$ & $(-0.315)$ & $(-0.550)$ & $(-0.212)$ & $(-0.394)$ & $(-0.271)$ \\
\hline \multirow[t]{2}{*}{ SalesServices } & -0.027 & -0.030 & -0.030 & -0.027 & -0.053 & $-0.059^{*}$ & -0.052 & -0.045 \\
\hline & $(-1.110)$ & $(-1.222)$ & $(-1.251)$ & $(-1.130)$ & $(-1.495)$ & $(-1.681)$ & $(-1.445)$ & $(-1.251)$ \\
\hline \multirow[t]{2}{*}{ WhiteCollar } & -0.013 & 0.013 & -0.031 & -0.021 & -0.032 & 0.003 & -0.034 & -0.026 \\
\hline & $(-0.389)$ & $(0.407)$ & $(-0.929)$ & $(-0.631)$ & $(-0.490)$ & $(0.068)$ & $(-0.522)$ & $(-0.324)$ \\
\hline \multirow[t]{2}{*}{ BlueCollar } & 0.007 & 0.019 & 0.006 & 0.015 & $-0.146^{* * *}$ & $-0.133^{* * *}$ & $-0.148^{* * *}$ & $-0.135 * * *$ \\
\hline & $(0.175)$ & $(0.414)$ & $(0.164)$ & $(0.343)$ & $(-3.004)$ & $(-2.700)$ & $(-3.026)$ & $(-2.838)$ \\
\hline \multirow[t]{2}{*}{ Male } & 0.005 & -0.005 & 0.005 & 0.003 & 0.046 & 0.037 & 0.051 & 0.051 \\
\hline & $(0.166)$ & $(-0.149)$ & $(0.164)$ & $(0.103)$ & (1.339) & $(1.084)$ & (1.444) & (1.423) \\
\hline \multirow[t]{2}{*}{ Married } & -0.025 & $-0.040^{*}$ & -0.022 & -0.015 & 0.020 & 0.001 & 0.027 & 0.033 \\
\hline & $(-1.140)$ & $(-1.766)$ & $(-0.955)$ & $(-0.668)$ & $(0.524)$ & $(-0.015)$ & (0.688) & $(0.822)$ \\
\hline \multirow[t]{2}{*}{ Kids } & -0.015 & $-0.017^{*}$ & -0.015 & -0.014 & -0.016 & -0.017 & -0.015 & -0.015 \\
\hline & $(-1.591)$ & $(-1.754)$ & $(-1.616)$ & $(-1.507)$ & $(-1.285)$ & $(-1.450)$ & $(-1.242)$ & $(-1.179)$ \\
\hline \multirow[t]{2}{*}{ LogPrice } & $-0.420^{* * *}$ & $-0.419 * * *$ & $-0.416^{* * *}$ & $-0.412^{* * *}$ & $-0.377^{*} * *$ & $-0.374^{* * *}$ & $-0.373^{* * *}$ & $-0.372^{* * *}$ \\
\hline & $(-16.937)$ & $(-16.832)$ & $(-16.738)$ & $(-16.658)$ & $(-13.758)$ & $(-13.617)$ & $(-13.604)$ & $(-13.614)$ \\
\hline \multirow[t]{2}{*}{ LogSize } & $0.487^{* * *}$ & $0.487 * * *$ & $0.485^{* * *}$ & $0.482^{* * *}$ & $0.433^{* * *}$ & $0.433^{* * *}$ & $0.432 * * *$ & $0.431^{* * *}$ \\
\hline & $(31.793)$ & $(31.775)$ & $(31.712)$ & $(31.685)$ & $(24.755)$ & $(24.713)$ & $(24.730)$ & $(24.780)$ \\
\hline \multirow[t]{2}{*}{ ВTM } & $0.103^{* * *}$ & $0.106^{* * *}$ & $0.104^{* * *}$ & $0.106^{* * *}$ & $0.073^{* *}$ & $0.074 * *$ & $0.073^{* *}$ & $0.073^{* *}$ \\
\hline & $(3.511)$ & $(3.561)$ & $(3.520)$ & $(3.526)$ & $(2.088)$ & $(2.101)$ & $(2.041)$ & $(2.018)$ \\
\hline \multirow[t]{2}{*}{ Turnover } & $0.448^{* * *}$ & $0.442^{* * *}$ & $0.437 * * *$ & $0.426^{* * *}$ & $0.402^{* * *}$ & $0.395^{* * *}$ & $0.392^{* * *}$ & $0.380 * * *$ \\
\hline & $(17.407)$ & $(17.168)$ & $(17.001)$ & $(16.422)$ & $(13.421)$ & $(13.196)$ & (13.039) & $(12.463)$ \\
\hline \multirow[t]{2}{*}{ Momentum } & $-0.054^{* *}$ & $-0.054^{* *}$ & $-0.053^{*}$ & $-0.053^{*}$ & $-0.065^{* *}$ & $-0.066^{* *}$ & $-0.065^{* *}$ & $-0.064^{* *}$ \\
\hline & $(-1.963)$ & $(-1.966)$ & $(-1.935)$ & $(-1.912)$ & $(-2.153)$ & $(-2.190)$ & $(-2.157)$ & $(-2.131)$ \\
\hline Volatility & 0.094 & 0.093 & 0.098 & 0.091 & 0.069 & 0.069 & 0.068 & 0.062 \\
\hline & $(1.517)$ & (1.530) & (1.589) & $(1.516)$ & (1.004) & (1.017) & $(1.034)$ & $(1.002)$ \\
\hline $\operatorname{LogPop}_{c}$ & $-0.025^{*}$ & 0.010 & 0.011 & -0.019 & -0.013 & 0.027 & -0.013 & -0.003 \\
\hline & $(-1.827)$ & $(0.454)$ & $(0.446)$ & $(-0.468)$ & $(-0.916)$ & $(1.084)$ & $(-0.354)$ & $(-0.023)$ \\
\hline Unemp $_{c}$ & 0.005 & 0.000 & -0.003 & -0.003 & -0.002 & -0.003 & -0.003 & -0.005 \\
\hline & $(0.179)$ & $(-0.287)$ & $(-0.614)$ & $(-0.497)$ & $(-0.249)$ & $(-0.346)$ & $(-0.339)$ & $(-0.546)$ \\
\hline Incomepc $_{c}$ & 0.003 & 0.004 & 0.002 & -0.004 & 0.002 & 0.005 & 0.000 & 0.001 \\
\hline & $(1.002)$ & $(1.146)$ & $(0.638)$ & $(-0.828)$ & $(0.484)$ & $(1.200)$ & $(0.038)$ & $(0.063)$ \\
\hline $\operatorname{LogHPI}_{c}$ & -0.242 & -0.174 & 0.092 & 0.174 & -0.368 & -0.244 & 0.032 & 0.303 \\
\hline & $(0.594)$ & $(0.887)$ & (1.087) & $(0.769)$ & $(0.349)$ & $(0.640)$ & $(0.551)$ & $(0.418)$ \\
\hline $\operatorname{LogPop}_{h}$ & $-0.030^{*}$ & 0.012 & -0.004 & $-0.102^{* *}$ & -0.026 & 0.024 & 0.054 & $-0.091^{*}$ \\
\hline & $(-1.746)$ & $(0.565)$ & $(-0.129)$ & $(-2.288)$ & $(-1.453)$ & $(0.866)$ & (1.091) & $(-1.735)$ \\
\hline Unemp $_{h}$ & 0.011 & 0.010 & 0.009 & 0.021 & 0.008 & 0.009 & 0.003 & 0.019 \\
\hline & $(0.666)$ & $(0.579)$ & $(0.471)$ & $(1.373)$ & $(0.579)$ & $(0.599)$ & $(0.300)$ & $(1.347)$ \\
\hline Incomepc $_{h}$ & 0.002 & 0.005 & 0.001 & -0.009 & 0.005 & $0.010^{* *}$ & $0.011^{*}$ & -0.006 \\
\hline & $(0.889)$ & (1.601) & $(0.543)$ & $(-1.579)$ & $(1.412)$ & $(2.292)$ & $(1.954)$ & $(-0.918)$ \\
\hline $\operatorname{LogHPI}_{h}$ & -0.566 & -0.410 & -0.049 & $0.463^{*}$ & -0.719 & -0.563 & -0.546 & -0.259 \\
\hline & $(1.143)$ & $(1.349)$ & (1.637) & $(1.758)$ & $(0.562)$ & $(0.814)$ & $(0.845)$ & $(0.502)$ \\
\hline Industry controls & YES & YES & YES & YES & YES & YES & YES & YES \\
\hline & $\mathrm{NO}$ & YES & YES & YES & $\mathrm{NO}$ & YES & YES & YES \\
\hline$\Psi^{2 n d}$ & NO & NO & YES & YES & $\mathrm{NO}$ & $\mathrm{NO}$ & YES & YES \\
\hline$\Psi^{3 r d}$ & $\mathrm{NO}$ & $\mathrm{NO}$ & NO & YES & $\mathrm{NO}$ & $\mathrm{NO}$ & $\mathrm{NO}$ & YES \\
\hline$\Psi^{4 t h}$ & $\mathrm{NO}$ & $\mathrm{NO}$ & $\mathrm{NO}$ & YES & $\mathrm{NO}$ & NO & NO & YES \\
\hline
\end{tabular}


Table Cont'd: Tobit Estimation of Household Portfolio Choice with Correction for Location Selection, Full Controls, Sub-samples based on Income and Age

\begin{tabular}{|c|c|c|c|c|c|c|c|c|}
\hline & \multicolumn{4}{|c|}{ Poor and Old } & \multicolumn{4}{|c|}{ Rich and Old } \\
\hline & $(9)$ & $(10)$ & (11) & $(12)$ & (13) & $(14)$ & (15) & $(16)$ \\
\hline Distance & $\begin{array}{c}-0.013^{* * *} \\
(-12.655)\end{array}$ & $\begin{array}{c}-0.011^{* * *} \\
(-11.193)\end{array}$ & $\begin{array}{c}-0.009^{* * *} \\
(-9.474)\end{array}$ & $\begin{array}{c}-0.007 * * * \\
(-7.593)\end{array}$ & $\begin{array}{c}-0.011^{* * *} \\
(-9.444)\end{array}$ & $\begin{array}{c}-0.009^{* * *} \\
(-7.981)\end{array}$ & $\begin{array}{c}-0.007 * * * \\
(-6.654)\end{array}$ & $\begin{array}{c}-0.006^{* * *} \\
(-5.226)\end{array}$ \\
\hline LogIncome & $\begin{array}{c}0.000 \\
(0.037)\end{array}$ & $\begin{array}{c}0.012 \\
(0.586)\end{array}$ & $\begin{array}{c}-0.002 \\
(-0.051)\end{array}$ & $\begin{array}{c}-0.014 \\
(-0.608)\end{array}$ & $\begin{array}{c}0.072 \\
(0.320)\end{array}$ & $\begin{array}{c}0.084 \\
(0.375)\end{array}$ & $\begin{array}{c}0.060 \\
(0.254)\end{array}$ & $\begin{array}{c}0.009 \\
(0.009)\end{array}$ \\
\hline LogAge & $\begin{array}{c}0.100 \\
(1.325)\end{array}$ & $\begin{array}{c}0.106 \\
(1.403)\end{array}$ & $\begin{array}{c}0.106 \\
(1.417)\end{array}$ & $\begin{array}{c}0.103 \\
(1.395)\end{array}$ & $\begin{array}{c}-0.025 \\
(-0.277)\end{array}$ & $\begin{array}{c}-0.014 \\
(-0.156)\end{array}$ & $\begin{array}{c}-0.009 \\
(-0.094)\end{array}$ & $\begin{array}{c}-0.017 \\
(-0.185)\end{array}$ \\
\hline Managerial & $\begin{array}{l}-0.023 \\
(-1.055)\end{array}$ & $\begin{array}{l}-0.020 \\
(-0.915)\end{array}$ & $\begin{array}{l}-0.024 \\
(-1.118)\end{array}$ & $\begin{array}{c}-0.023 \\
(-1.058)\end{array}$ & $\begin{array}{l}-0.042^{*} \\
(-1.768)\end{array}$ & $\begin{array}{l}-0.036 \\
(-1.524)\end{array}$ & $\begin{array}{l}-0.040^{*} \\
(-1.717)\end{array}$ & $\begin{array}{l}-0.043^{*} \\
(-1.819)\end{array}$ \\
\hline SalesServices & $\begin{array}{c}-0.027 \\
(-0.891)\end{array}$ & $\begin{array}{c}-0.028 \\
(-0.949)\end{array}$ & $\begin{array}{c}-0.028 \\
(-0.964)\end{array}$ & $\begin{array}{c}-0.028 \\
(-0.971)\end{array}$ & $\begin{array}{c}-0.039 \\
(-1.014)\end{array}$ & $\begin{array}{c}-0.042 \\
(-1.107)\end{array}$ & $\begin{array}{c}-0.039 \\
(-1.023)\end{array}$ & $\begin{array}{c}-0.035 \\
(-0.933)\end{array}$ \\
\hline WhiteCollar & $\begin{array}{c}-0.034 \\
(-1.095)\end{array}$ & $\begin{array}{l}-0.020 \\
(-0.641)\end{array}$ & $\begin{array}{c}-0.046 \\
(-1.400)\end{array}$ & $\begin{array}{c}-0.044 \\
(-1.335)\end{array}$ & $\begin{array}{c}-0.063 \\
(-1.211)\end{array}$ & $\begin{array}{c}-0.039 \\
(-0.747)\end{array}$ & $\begin{array}{c}-0.086 \\
(-1.509)\end{array}$ & $\begin{array}{c}-0.068 \\
(-1.176)\end{array}$ \\
\hline BlueCollar & $\begin{array}{c}-0.078^{* *} \\
(-2.387)\end{array}$ & $\begin{array}{c}-0.070^{* *} \\
(-2.163)\end{array}$ & $\begin{array}{c}-0.079^{* *} \\
(-2.420)\end{array}$ & $\begin{array}{c}-0.078^{* *} \\
(-2.427)\end{array}$ & $\begin{array}{c}-0.096 \\
(-1.588)\end{array}$ & $\begin{array}{c}-0.082 \\
(-1.372)\end{array}$ & $\begin{array}{c}-0.096 \\
(-1.477)\end{array}$ & $\begin{array}{c}-0.084 \\
(-1.256)\end{array}$ \\
\hline Male & $\begin{array}{c}0.045 \\
(1.526)\end{array}$ & $\begin{array}{c}0.041 \\
(1.394)\end{array}$ & $\begin{array}{c}0.054^{*} \\
(1.826)\end{array}$ & $\begin{array}{c}0.049 \\
(1.628)\end{array}$ & $\begin{array}{c}0.047 \\
(1.069)\end{array}$ & $\begin{array}{c}0.042 \\
(0.965)\end{array}$ & $\begin{array}{c}0.046 \\
(1.113)\end{array}$ & $\begin{array}{c}0.048 \\
(1.076)\end{array}$ \\
\hline Married & $\begin{array}{c}0.002 \\
(0.059)\end{array}$ & $\begin{array}{l}-0.010 \\
(-0.417)\end{array}$ & $\begin{array}{c}0.007 \\
(0.289)\end{array}$ & $\begin{array}{c}0.014 \\
(0.614)\end{array}$ & $\begin{array}{c}-0.047 \\
(-1.264)\end{array}$ & $\begin{array}{l}-0.062^{*} \\
(-1.653)\end{array}$ & $\begin{array}{l}-0.045 \\
(-1.165)\end{array}$ & $\begin{array}{c}-0.034 \\
(-0.886)\end{array}$ \\
\hline Kids & $\begin{array}{c}-0.010 \\
(-0.782)\end{array}$ & $\begin{array}{c}-0.011 \\
(-0.833)\end{array}$ & $\begin{array}{c}-0.009 \\
(-0.749)\end{array}$ & $\begin{array}{c}-0.010 \\
(-0.757)\end{array}$ & $\begin{array}{c}-0.005 \\
(-0.360)\end{array}$ & $\begin{array}{c}-0.007 \\
(-0.499)\end{array}$ & $\begin{array}{c}-0.004 \\
(-0.317)\end{array}$ & $\begin{array}{l}-0.005 \\
(-0.382)\end{array}$ \\
\hline LogPrice & $\begin{array}{c}-0.405^{* * *} \\
(-17.552)\end{array}$ & $\begin{array}{c}-0.404^{* * * *} \\
(-17.534)\end{array}$ & $\begin{array}{c}-0.403 * * * \\
(-17.501)\end{array}$ & $\begin{array}{c}-0.399 * * * \\
(-17.378)\end{array}$ & $\begin{array}{c}-0.282^{* * * *} \\
(-11.101)\end{array}$ & $\begin{array}{c}-0.278^{* * *} \\
(-10.913)\end{array}$ & $\begin{array}{c}-0.278^{* * *} \\
(-10.899)\end{array}$ & $\begin{array}{c}-0.275^{* * *} \\
(-10.850)\end{array}$ \\
\hline LogSize & $\begin{array}{c}0.416^{* * *} \\
(27.612)\end{array}$ & $\begin{array}{c}0.416^{* * *} \\
(27.641)\end{array}$ & $\begin{array}{c}0.416^{* * *} \\
(27.484)\end{array}$ & $\begin{array}{c}0.413^{* * *} \\
(27.586)\end{array}$ & $\begin{array}{c}0.356^{* * *} \\
(21.833)\end{array}$ & $\begin{array}{c}0.356^{* * *} \\
(21.801)\end{array}$ & $\begin{array}{c}0.355^{* * *} \\
(21.823)\end{array}$ & $\begin{array}{c}0.352^{* * *} \\
(21.851)\end{array}$ \\
\hline ВTM & $\begin{array}{c}0.119^{* * *} \\
(4.314)\end{array}$ & $\begin{array}{c}0.121^{* * *} \\
(4.343)\end{array}$ & $\begin{array}{c}0.119^{* * *} \\
(4.295)\end{array}$ & $\begin{array}{c}0.121^{* * *} \\
(4.285)\end{array}$ & $\begin{array}{c}0.091^{* * *} * \\
(2.927)\end{array}$ & $\begin{array}{c}0.093^{* * *} * \\
(2.951)\end{array}$ & $\begin{array}{c}0.093^{* * *} * \\
(2.946)\end{array}$ & $\begin{array}{c}0.094^{* * *} \\
(2.959)\end{array}$ \\
\hline Turnover & $\begin{array}{c}0.330^{* * *} \\
(12.793)\end{array}$ & $\begin{array}{c}0.325^{* * *} \\
(12.650)\end{array}$ & $\begin{array}{c}0.323^{* * *} \\
(12.578)\end{array}$ & $\begin{array}{c}0.312^{* * *} * \\
(12.060)\end{array}$ & $\begin{array}{c}0.302^{* * *} \\
(10.547)\end{array}$ & $\begin{array}{c}0.295^{* * *} * \\
(10.275)\end{array}$ & $\begin{array}{c}0.293^{* * *} * \\
(10.227)\end{array}$ & $\begin{array}{c}0.281^{* * *} \\
(9.709)\end{array}$ \\
\hline Momentum & $\begin{array}{c}0.001 \\
(0.356)\end{array}$ & $\begin{array}{c}0.001 \\
(0.332)\end{array}$ & $\begin{array}{c}0.002 \\
(0.364)\end{array}$ & $\begin{array}{c}0.001 \\
(0.326)\end{array}$ & $\begin{array}{c}-0.039 \\
(-1.236)\end{array}$ & $\begin{array}{l}-0.040 \\
-1.275)\end{array}$ & $\begin{array}{l}-0.039 \\
(-1.260)\end{array}$ & $\begin{array}{l}-0.039 \\
(-1.249)\end{array}$ \\
\hline Volatility & $\begin{array}{l}-0.139 \\
(-1.102)\end{array}$ & $\begin{array}{l}-0.140 \\
(-1.105)\end{array}$ & $\begin{array}{c}-0.137 \\
(-1.068)\end{array}$ & $\begin{array}{l}-0.141 \\
(-1.102)\end{array}$ & $\begin{array}{c}0.005 \\
(0.275)\end{array}$ & $\begin{array}{c}0.006 \\
(0.294)\end{array}$ & $\begin{array}{c}0.006 \\
(0.300)\end{array}$ & $\begin{array}{l}-0.001 \\
(0.292)\end{array}$ \\
\hline $\operatorname{LogPop}_{c}$ & $\begin{array}{l}-0.019 \\
(-1.247)\end{array}$ & $\begin{array}{l}-0.003 \\
(-0.137)\end{array}$ & $\begin{array}{l}-0.026 \\
(-0.806)\end{array}$ & $\begin{array}{l}-0.074 * \\
(-1.764)\end{array}$ & $\begin{array}{l}-0.018 \\
(-1.089)\end{array}$ & $\begin{array}{c}0.009 \\
(0.354)\end{array}$ & $\begin{array}{l}-0.035 \\
(-0.930)\end{array}$ & $\begin{array}{l}-0.080 \\
(-1.314)\end{array}$ \\
\hline Unemp $_{c}$ & $\begin{array}{c}0.002 \\
(0.180)\end{array}$ & $\begin{array}{c}0.000 \\
(-0.074)\end{array}$ & $\begin{array}{c}-0.002 \\
(-0.229)\end{array}$ & $\begin{array}{c}0.001 \\
(0.068)\end{array}$ & $\begin{array}{c}-0.002 \\
(-0.294)\end{array}$ & $\begin{array}{c}-0.004 \\
(-0.496)\end{array}$ & $\begin{array}{c}-0.003 \\
(-0.384)\end{array}$ & $\begin{array}{c}0.001 \\
(-0.026)\end{array}$ \\
\hline Incomepc $_{c}$ & $\begin{array}{c}0.005 \\
(1.408)\end{array}$ & $\begin{array}{c}0.005 \\
(1.313)\end{array}$ & $\begin{array}{c}0.003 \\
(0.813)\end{array}$ & $\begin{array}{c}-0.003 \\
(-0.855)\end{array}$ & $\begin{array}{c}-0.004 \\
(-0.969)\end{array}$ & $\begin{array}{c}-0.002 \\
(-0.587)\end{array}$ & $\begin{array}{c}-0.005 \\
(-1.259)\end{array}$ & $\begin{array}{l}-0.010^{*} \\
(-1.675)\end{array}$ \\
\hline $\operatorname{LogHPI}_{c}$ & $\begin{array}{l}-0.373 \\
(0.549)\end{array}$ & $\begin{array}{l}-0.355 \\
(0.628)\end{array}$ & $\begin{array}{l}-0.312 \\
(0.630)\end{array}$ & $\begin{array}{l}-0.147 \\
(0.644)\end{array}$ & $\begin{array}{c}-0.372 \\
(0.486)\end{array}$ & $\begin{array}{l}-0.344 \\
(0.647)\end{array}$ & $\begin{array}{l}-0.362 \\
(0.244)\end{array}$ & $\begin{array}{c}-0.142 \\
(0.070)\end{array}$ \\
\hline $\operatorname{LogPop}_{h}$ & $\begin{array}{c}-0.031^{* *} \\
(-2.160)\end{array}$ & $\begin{array}{c}0.001 \\
(0.071)\end{array}$ & $\begin{array}{c}-0.007 \\
(-0.261)\end{array}$ & $\begin{array}{c}-0.154^{* * * *} \\
(-3.489)\end{array}$ & $\begin{array}{l}-0.027^{*} \\
(-1.732)\end{array}$ & $\begin{array}{c}0.020 \\
(0.747)\end{array}$ & $\begin{array}{c}0.068 \\
(1.467)\end{array}$ & $\begin{array}{l}-0.107^{*} \\
(-1.815)\end{array}$ \\
\hline Unemp $_{h}$ & $\begin{array}{c}0.009 \\
(0.670)\end{array}$ & $\begin{array}{c}0.010 \\
(0.742)\end{array}$ & $\begin{array}{c}0.007 \\
(0.537)\end{array}$ & $\begin{array}{c}0.025^{* *} \\
(2.106)\end{array}$ & $\begin{array}{c}0.010 \\
(0.844)\end{array}$ & $\begin{array}{c}0.012 \\
(0.979)\end{array}$ & $\begin{array}{c}0.005 \\
(0.454)\end{array}$ & $\begin{array}{c}0.023^{*} \\
(1.858)\end{array}$ \\
\hline Incomepc $_{h}$ & $\begin{array}{c}0.003 \\
(1.225)\end{array}$ & $\begin{array}{c}0.005^{*} \\
(1.683)\end{array}$ & $\begin{array}{c}0.004 \\
(1.107)\end{array}$ & $\begin{array}{l}-0.005 \\
(-1.177)\end{array}$ & $\begin{array}{l}0.006^{*} \\
(1.905)\end{array}$ & $\begin{array}{c}0.010^{* * *} \\
(2.691)\end{array}$ & $\begin{array}{c}0.013^{* * *} \\
(2.835)\end{array}$ & $\begin{array}{l}-0.002 \\
(-0.341)\end{array}$ \\
\hline $\operatorname{LogHPI}_{h}$ & $\begin{array}{l}-0.792 \\
(0.167)\end{array}$ & $\begin{array}{l}-0.676 \\
(0.286)\end{array}$ & $\begin{array}{l}-0.593 \\
(0.387)\end{array}$ & $\begin{array}{l}-0.135 \\
(0.444)\end{array}$ & $\begin{array}{c}-0.688 \\
(-0.520)\end{array}$ & $\begin{array}{c}-0.527 \\
(-0.286)\end{array}$ & $\begin{array}{c}-0.534 \\
(-0.012)\end{array}$ & $\begin{array}{c}-0.187 \\
(-0.201)\end{array}$ \\
\hline $\begin{array}{l}\text { Industry controls } \\
\Psi^{1 s t}\end{array}$ & YES & $\begin{array}{l}\text { YES } \\
\text { YES }\end{array}$ & $\begin{array}{l}\text { YES } \\
\text { YES }\end{array}$ & $\begin{array}{l}\text { YES } \\
\text { YES }\end{array}$ & YES & $\begin{array}{l}\text { YES } \\
\text { YES }\end{array}$ & $\begin{array}{l}\text { YES } \\
\text { YES }\end{array}$ & $\begin{array}{l}\text { YES } \\
\text { YES }\end{array}$ \\
\hline$\Psi^{2 n d}$ & NO & NO & YES & YES & NO & $\mathrm{NO}$ & YES & YES \\
\hline$\Psi^{3 r d}$ & NO & NO & NO & YES & NO & NO & $\mathrm{NO}$ & YES \\
\hline$\Psi^{4 t h}$ & $\mathrm{NO}$ & $\mathrm{NO}$ & NO & YES & $\mathrm{NO}$ & $\mathrm{NO}$ & NO & YES \\
\hline
\end{tabular}


Table 9: Tobit Estimation of Household Portfolio Choice, Using Higher Order Polynomials to Approximate Correction Functions

This table presents the results from the Tobit regressions of our household portfolio choice model with corrections for location selection biases, where the correction functions for location selections are approximated by high order polynomials from the 5 th order to the 6 th order. The regressions control for household demographics, stock characteristics and MSA characteristics. The results are time-series averages of the monthly coefficient estimates and their $t$-statistics (shown in parentheses) based on standard errors clustered at the household level. *, **, *** denote statistical significance at $10 \%, 5 \%, 1 \%$ respectively. The dependent variable $w_{j}^{i}$ is the portfolio weight allocated to stock $j$ by household $i$. The key explanatory variable is Distance, the distance between household $i$ 's residential zip code area and the zip code area of stock $j$ 's headquarters. For clarity purposes, we only show the coefficient estimates and their $t$-statistics for the Distance variable. The Polynomial Order 5 to 6 on the left denotes the order of the approximating polynomials used (from the 5th order to the 6th order), and Household demographics, Stock characteristics, Industry controls and Zip code area characteristics denote whether controls for these variables are included respectively. The sample period is January 1991 to November 1996.

\begin{tabular}{lccc}
\hline & \multicolumn{3}{c}{ Dependent Variable: Portfolio Weight $w_{j}^{i}$} \\
\hline Polynomial Order & \multicolumn{2}{c}{ Coef Estimate and $t$-stat of } & Distance \\
\hline \multirow{3}{*}{5} & $(1)$ & $(2)$ & $(3)$ \\
& $-0.0062^{* * *}$ & $-0.0068^{* * *}$ & $-0.0069^{* * *}$ \\
6 & $(-11.330)$ & $(-12.701)$ & $(-12.906)$ \\
& $-0.0059^{* * *}$ & $-0.0065^{* * *}$ & $-0.0066^{* * *}$ \\
& $(-10.822)$ & $(-12.152)$ & $(-12.270)$ \\
Household demographics & YES & YES & YES \\
Stock characteristics & NO & YES & YES \\
Industry controls & NO & YES & YES \\
MSA characteristics & NO & NO & YES \\
\hline
\end{tabular}


Table 10: Regressions of Value-weighted Market Portfolio Weights and Households' Portfolio Weight Deviations from the Market

This table shows the results from linear regressions of value-weighted market portfolio weights and households' portfolio weight deviations from the market on our set of explanatory variables. The results are time-series averages of the monthly coefficient estimates and their $t$-statistics (shown in parentheses) based on standard errors clustered at the household level. *, **, *** denote statistical significance at $10 \%, 5 \%, 1 \%$ respectively. The dependent variable in columns (1) to (4) is the value-weighted market portfolio (Russell 1000) weight, and in columns (5) to (8) is the deviation of a household's portfolio weight from the market. The explanatory variables are the same as before, which include the key variable Distance, the household demographics controls LogIncome to Kids, the stock characteristics controls LogPrice to Volatility, the industry controls, and the controls for MSA characteristics $\operatorname{LogPop} \mathrm{P}_{\mathrm{H}}$ to $\operatorname{LogHPI}$ S that are the same as those shown in Table $4 . \Psi^{1 s t}$ to $\Psi^{4 t h}$ denote the orders of the polynomials used for approximating the correction functions $\Psi^{s}\left(p_{i, c}\right)$ and $\Psi^{d}\left(p_{i, h}, p_{i, c}\right)$ for location selections. The constant term in the linear regression is not reported for clarity purposes. All of the coefficient estimates are in basis points. The sample period is January 1991 to November 1996.

\begin{tabular}{|c|c|c|c|c|c|c|c|c|}
\hline & \multicolumn{8}{|c|}{ Coefficient Estimates in bps } \\
\hline & \multicolumn{4}{|c|}{ VW Market Port Weight } & \multicolumn{4}{|c|}{ Deviation from VW Market Port Weight } \\
\hline & (1) & $(2)$ & (3) & $(4)$ & $(5)$ & (6) & $(7)$ & $(8)$ \\
\hline \multirow[t]{2}{*}{ Distance } & $-0.018^{* * *}$ & $-0.017^{* * *}$ & $0.002^{*}$ & 0.002 & $-0.429^{* * *}$ & $-0.354^{* * *}$ & $-0.289^{* * *}$ & $-0.217^{* * *}$ \\
\hline & $(-12.381)$ & $(-12.434)$ & $(1.826)$ & $(0.367)$ & $(-25.565)$ & $(-22.139)$ & $(-18.658)$ & $(-14.522)$ \\
\hline \multirow[t]{2}{*}{ LogIncome } & & $-0.656^{* * *}$ & $-0.222^{* * *}$ & $-0.258^{* * *}$ & -0.181 & $0.394^{* *}$ & 0.007 & $-0.295^{*}$ \\
\hline & & $(-60.060)$ & $(-87.025)$ & $(-65.718)$ & $(-1.111)$ & $(2.380)$ & $(0.036)$ & $(-1.732)$ \\
\hline \multirow[t]{2}{*}{ LogAge } & & $-0.379 * * *$ & $-0.068^{* * *}$ & $-0.029 * * *$ & $-1.025 * * *$ & $-0.792^{* *}$ & $-0.826^{* *}$ & $-0.726^{* *}$ \\
\hline & & $(-14.744)$ & $(-10.600)$ & $(-5.645)$ & $(-2.974)$ & $(-2.373)$ & $(-2.484)$ & $(-2.186)$ \\
\hline \multirow[t]{2}{*}{ Managerial } & & $-0.324 * * *$ & $-0.080 * * *$ & $-0.075^{* * *}$ & $-0.316^{*}$ & -0.095 & -0.244 & -0.238 \\
\hline & & $(-33.055)$ & $(-36.036)$ & $(-35.809)$ & $(-1.861)$ & $(-0.587)$ & $(-1.463)$ & $(-1.433)$ \\
\hline \multirow[t]{2}{*}{ SalesServices } & & $0.058^{* * *}$ & $0.027 * * *$ & $0.042^{* * *}$ & 0.130 & 0.051 & 0.089 & 0.178 \\
\hline & & $(5.225)$ & $(9.889)$ & $(12.433)$ & $(0.422)$ & $(0.140)$ & $(0.285)$ & $(0.630)$ \\
\hline \multirow[t]{2}{*}{ WhiteCollar } & & $-0.563 * * *$ & $-0.192^{* * *}$ & $-0.276^{* * *}$ & 0.447 & $1.317^{* * *}$ & 0.507 & 0.349 \\
\hline & & $(-13.171)$ & $(-21.326)$ & $(-33.165)$ & $(1.415)$ & $(4.018)$ & $(1.492)$ & $(1.053)$ \\
\hline \multirow[t]{2}{*}{ BlueCollar } & & $-0.433 * * *$ & $-0.119 * * *$ & $-0.126^{* * *}$ & 0.225 & 0.616 & 0.388 & 0.428 \\
\hline & & $(-16.629)$ & $(-18.557)$ & $(-19.380)$ & $(0.591)$ & (1.639) & (1.033) & $(1.173)$ \\
\hline \multirow[t]{2}{*}{ Male } & & $0.064^{*}$ & $0.070^{* * *}$ & $0.146^{* * *}$ & $-0.654^{* *}$ & $-0.907 * * *$ & $-0.665^{* *}$ & $-0.581^{* *}$ \\
\hline & & $(1.799)$ & $(10.952)$ & $(20.540)$ & $(-2.357)$ & $(-3.308)$ & $(-2.408)$ & $(-2.091)$ \\
\hline \multirow{2}{*}{ Married } & & $0.533^{* * *}$ & $0.174^{* * *}$ & $0.229 * * *$ & 0.057 & $-0.495^{* *}$ & -0.020 & 0.249 \\
\hline & & $(26.265)$ & $(40.284)$ & $(50.343)$ & $(0.208)$ & $(-2.475)$ & $(-0.152)$ & (1.098) \\
\hline \multirow[t]{2}{*}{ Kids } & & $0.068^{* * *}$ & $0.036^{* * *}$ & $0.054^{* * *}$ & 0.027 & -0.025 & 0.034 & 0.042 \\
\hline & & $(14.682)$ & $(34.210)$ & $(42.950)$ & $(0.385)$ & $(-0.238)$ & $(0.504)$ & $(0.623)$ \\
\hline \multirow[t]{2}{*}{ LogPrice } & & & $-8.472^{* * *}$ & $-8.476 * * *$ & $-1.734^{* * *}$ & $-1.638 * * *$ & $-1.635^{* * *}$ & $-1.530 * * *$ \\
\hline & & & $(-11704)$ & $(-11883)$ & $(-6.342)$ & $(-6.035)$ & $(-6.021)$ & $(-5.629)$ \\
\hline \multirow[t]{2}{*}{ LogSize } & & & $20.336^{* * *}$ & $20.335^{* * *}$ & $-5.820 * * *$ & $-5.818 * * *$ & $-5.825 * * *$ & $-5.836 * * *$ \\
\hline & & & $(23682)$ & $(39585)$ & $(-25.436)$ & $(-25.441)$ & $(-25.506)$ & $(-25.592)$ \\
\hline \multirow[t]{2}{*}{ BTM } & & & $1.361^{* * *}$ & $1.381^{* * *}$ & $0.806^{* * *}$ & $0.786^{* * *}$ & $0.768^{* * *}$ & $0.767^{* * *}$ \\
\hline & & & $(1046)$ & $(1152)$ & $(11.274)$ & $(10.886)$ & $(10.856)$ & $(10.629)$ \\
\hline \multirow[t]{2}{*}{ Turnover } & & & $-1.403 * * *$ & $-1.500 * * *$ & $10.600^{* * *}$ & $10.355^{* * *}$ & $10.238^{* * *}$ & $9.858^{* * *}$ \\
\hline & & & $(-583)$ & $(-702)$ & $(19.254)$ & $(18.890)$ & $(18.672)$ & $(17.999)$ \\
\hline Momentum & & & $0.916^{* * *}$ & $0.947^{* * *}$ & $-1.536 * * *$ & $-1.579 * * *$ & $-1.563 * * *$ & $-1.582^{* * *}$ \\
\hline & & & $(2230)$ & $(1856)$ & $(-5.892)$ & $(-6.050)$ & $(-6.009)$ & $(-6.078)$ \\
\hline Volatility & & & $0.477^{* * *}$ & $0.435^{* * *}$ & 1.127 & 1.112 & 1.167 & 1.229 \\
\hline & & & (1088) & (1168) & $(1.310)$ & (1.348) & (1.414) & $(1.527)$ \\
\hline $\operatorname{LogPop}_{c}$ & & & & 0.013 & $-1.200^{* * *}$ & -0.119 & -0.172 & $-0.588^{*}$ \\
\hline & & & & (1.397) & $(-9.190)$ & $(-0.674)$ & $(-0.761)$ & $(-1.724)$ \\
\hline $\mathrm{Unemp}_{c}$ & & & & $-0.008^{* * *}$ & $0.377^{* * *}$ & $0.275^{* * *}$ & 0.130 & 0.143 \\
\hline & & & & $(-3.520)$ & $(4.054)$ & $(2.898)$ & $(1.126)$ & $(1.068)$ \\
\hline Incomepc $_{c}$ & & & & -0.001 & $0.179 * * *$ & $0.206^{* * *}$ & $0.194^{* * *}$ & $0.133^{* * *}$ \\
\hline & & & & $(-1.532)$ & (6.165) & $(6.876)$ & $(6.239)$ & $(3.524)$ \\
\hline $\operatorname{LogHPI}_{c}$ & & & & $0.236^{* * *}$ & $-11.397 * * *$ & $-9.432^{* * *}$ & $-10.494^{* * *}$ & $-4.941 * * *$ \\
\hline & & & & $(4.270)$ & $(5.443)$ & $(5.867)$ & $(5.395)$ & $(4.982)$ \\
\hline $\operatorname{LogPop}_{h}$ & & & & $2.232^{* * *}$ & $-1.517^{* * *}$ & 0.333 & 0.756 & $-3.014^{* * *}$ \\
\hline & & & & $(65.767)$ & $(-5.911)$ & $(1.129)$ & $(1.187)$ & $(-3.992)$ \\
\hline Unemp $_{h}$ & & & & $-0.870^{* * *}$ & $0.813^{* * *}$ & $0.775^{* * *}$ & $0.588^{* * *}$ & $1.106^{* * *}$ \\
\hline & & & & $(-214)$ & $(4.223)$ & $(3.882)$ & $(2.854)$ & $(5.236)$ \\
\hline Incomepc $_{h}$ & & & & $0.055^{* * *}$ & $0.236^{* * *}$ & $0.354^{* * *}$ & $0.347^{* * *}$ & 0.064 \\
\hline & & & & $(26.338)$ & $(4.872)$ & $(6.712)$ & $(6.043)$ & $(0.558)$ \\
\hline $\operatorname{LogHPI} I_{h}$ & & & & $7.746^{* * *}$ & $-35.526^{* *}$ & $-31.756^{*}$ & -31.079 & -9.755 \\
\hline & & & & $(250)$ & $(-1.991)$ & $(-1.654)$ & $(-1.255)$ & $(-1.018)$ \\
\hline Industry controls & $\mathrm{NO}$ & $\mathrm{NO}$ & YES & YES & YES & YES & YES & YES \\
\hline$\Psi^{1 s t}$ & YES & YES & YES & YES & NO & YES & YES & YES \\
\hline$\Psi^{2 n d}$ & YES & YES & YES & YES & $\mathrm{NO}$ & $\mathrm{NO}$ & YES & YES \\
\hline$\Psi^{3 r d}$ & YES & YES & YES & YES & $\mathrm{NO}$ & $\mathrm{NO}$ & $\mathrm{NO}$ & YES \\
\hline$\Psi^{4 t h}$ & YES & YES & YES & YES & $\mathrm{NO}$ & $\mathrm{NO}$ & $\mathrm{NO}$ & YES \\
\hline
\end{tabular}



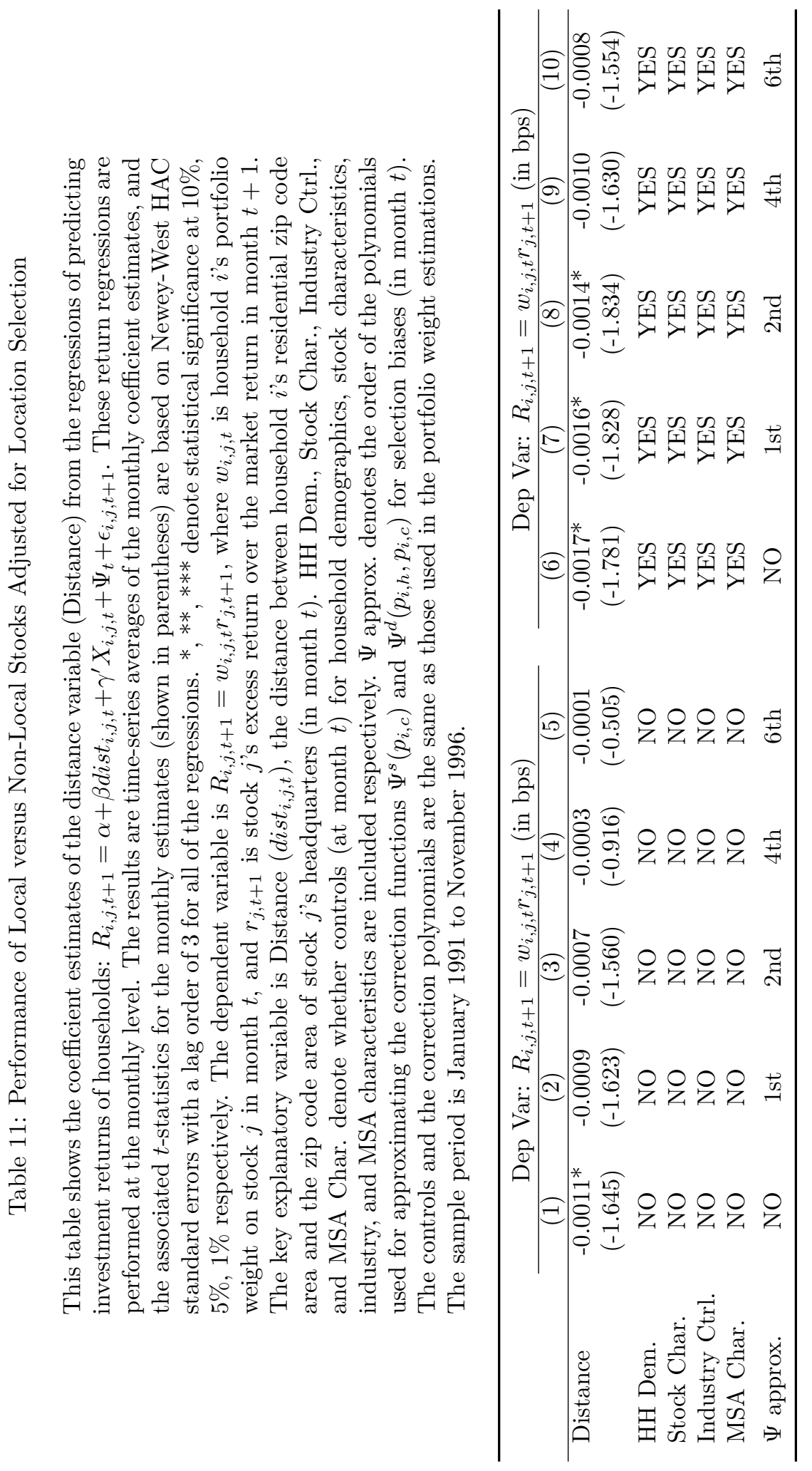
Figure 1: Geographical Distribution of Households and Russell 1000 Stocks

This figure depicts the geographical coordinates of the 10,594 households and the 900 stocks in the Russell 1000 Index. The address ZIP-codes of households and the stocks' headquarters are converted to geographical coordinates based on the correspondence provided by the US Census Bureau. The horizontal axis is in longitude coordinates, while the vertical axis is in latitude coordinates. The blue circles indicate households, while the red squares indicate stocks. The sample period is from January 1991 to November 1996.

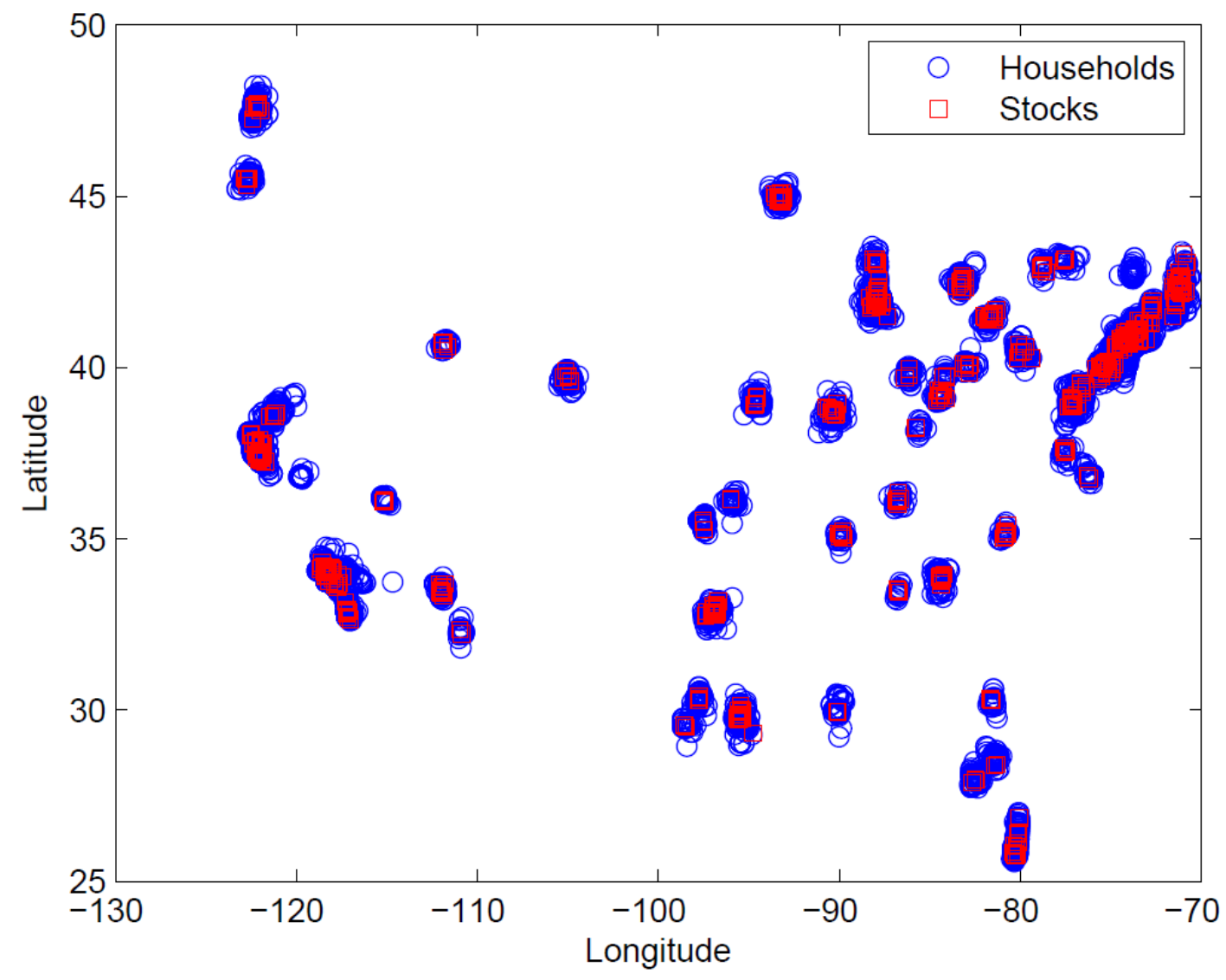


Figure 2: Coefficient Estimates of Distance across Time from Various Portfolio Choice Regressions with Full Controls

This figure depicts the coefficient estimates of our key explanatory variable Distance across the time periods from various portfolio choice regressions with full household demographics, stock characteristics, industry and MSA characteristics controls. The vertical axis shows the values of the estimates. The horizontal axis shows the time periods (year-month). The blue line represents the estimates from the regression without any correction for location selection biases, while the green dotted line, the orange dashed line and the red dash-dotted line represent regressions with correction functions for location selections approximated by polynomials of order 1, 2 and 4 respectively. The sample period is from January 1991 (199101) to November 1996 (199611).

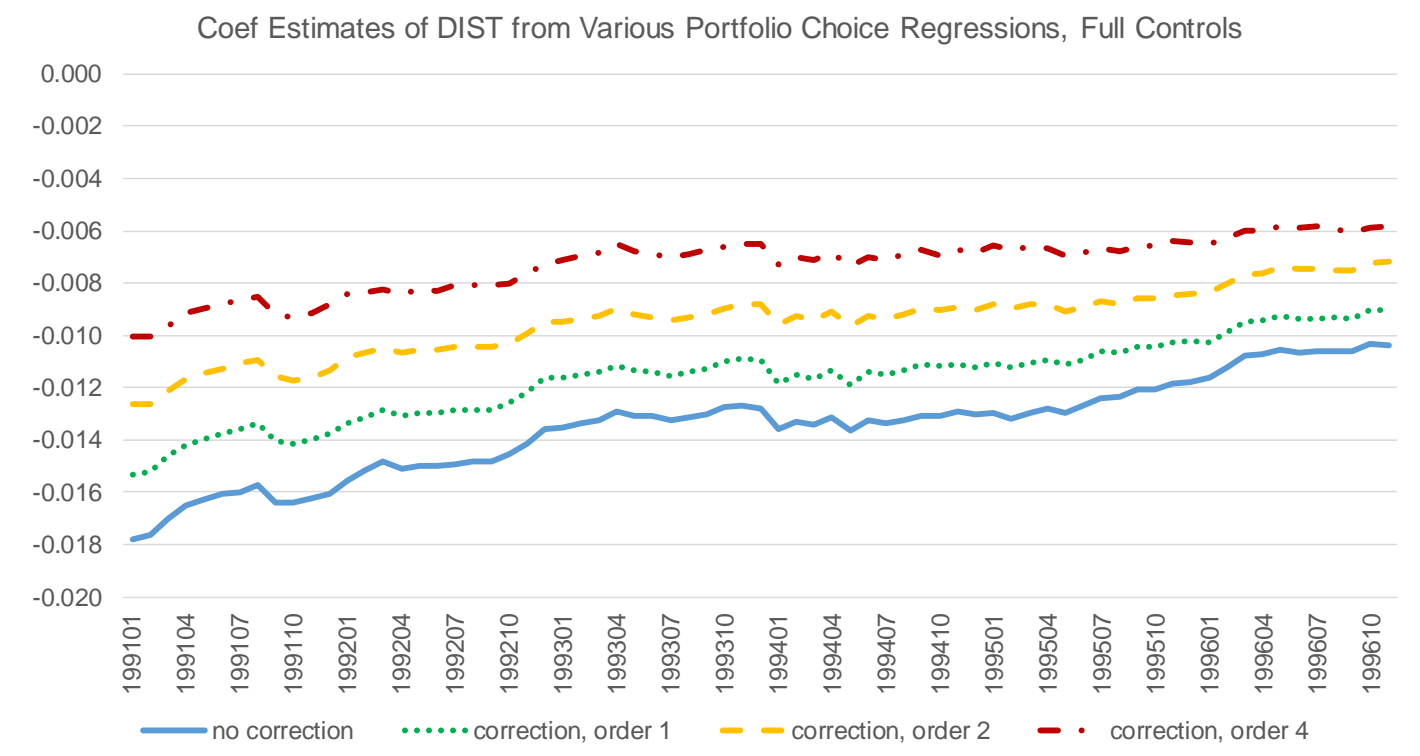


Figure 3: $t$-Statistics of Distance Estimates across Time from Various Portfolio Choice Regressions with Full Controls

This figure depicts the $t$-statistics (based on the standard errors clustered at the household level) of the coefficient estimates of our key explanatory variable Distance across the time periods from various portfolio choice regressions with full household demographics, stock characteristics, industry and MSA characteristics controls. The vertical axis shows the values of the $t$-statistics. The horizontal axis shows the time periods (year-month). The blue line represents the $t$-statistics from the regression without any correction for location selection biases, while the green dotted line, the orange dashed line and the red dash-dotted line represent regressions with correction functions for location selections approximated by polynomials of order 1,2 and 4 respectively. The sample period is from January 1991 (199101) to November 1996 (199611).

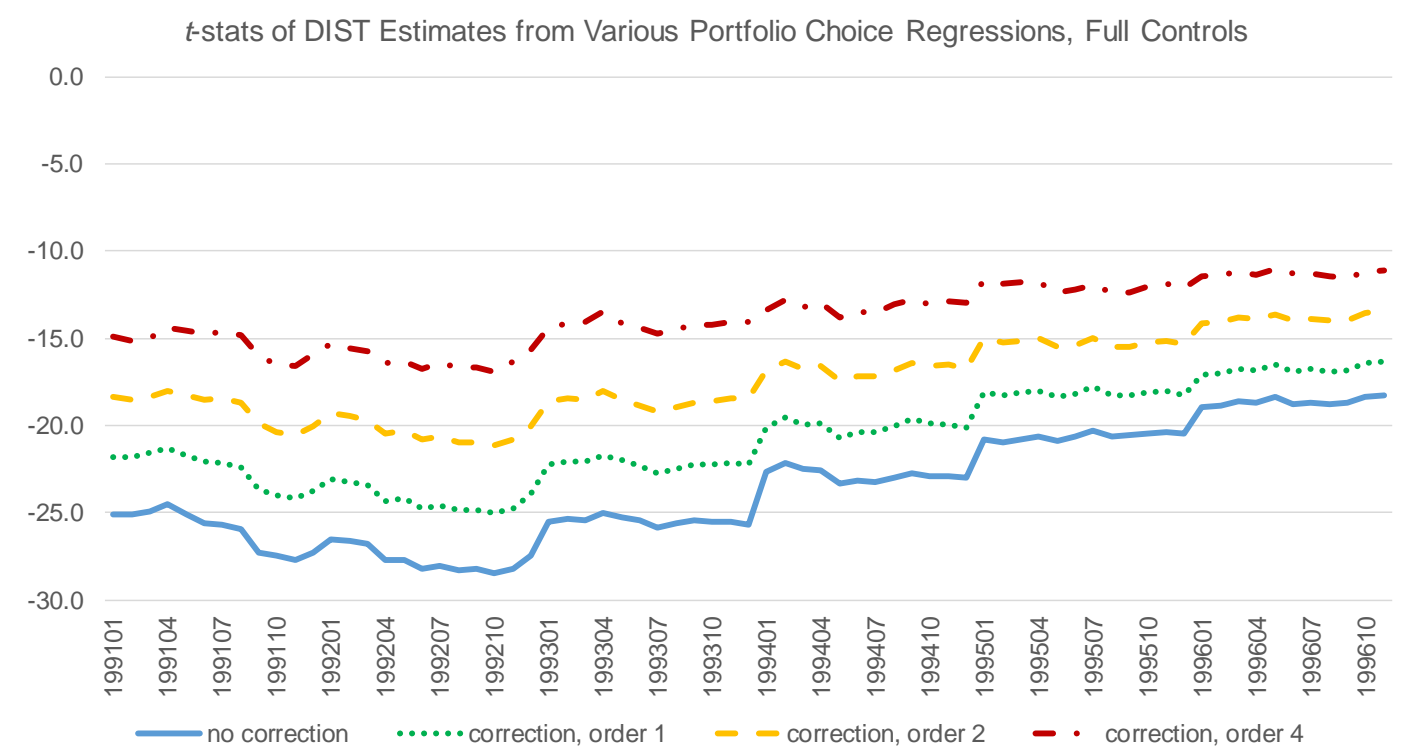


Figure 4: Coefficient Estimates of Distance in Sub-samples

This figure depicts the coefficient estimates of our key explanatory variable Distance, averaged across the time periods, in the four sub-samples based on quantiles of income and age. We assign households to four groups, namely "Poor and Young", "Rich and Young", "Poor and Old" and "Rich and Old", depending on whether their income and age is below or above the corresponding median values. The group average ("Group Average") and the whole sample ("Whole Sample") results are also shown. The solid blue bars represent the average estimates from regressions without any correction for location selection biases, while the dashed orange bars represent those from regressions with correction functions for location selections approximated by polynomials of order 4. The sample period is from January 1991 (199101) to November 1996 (199611).

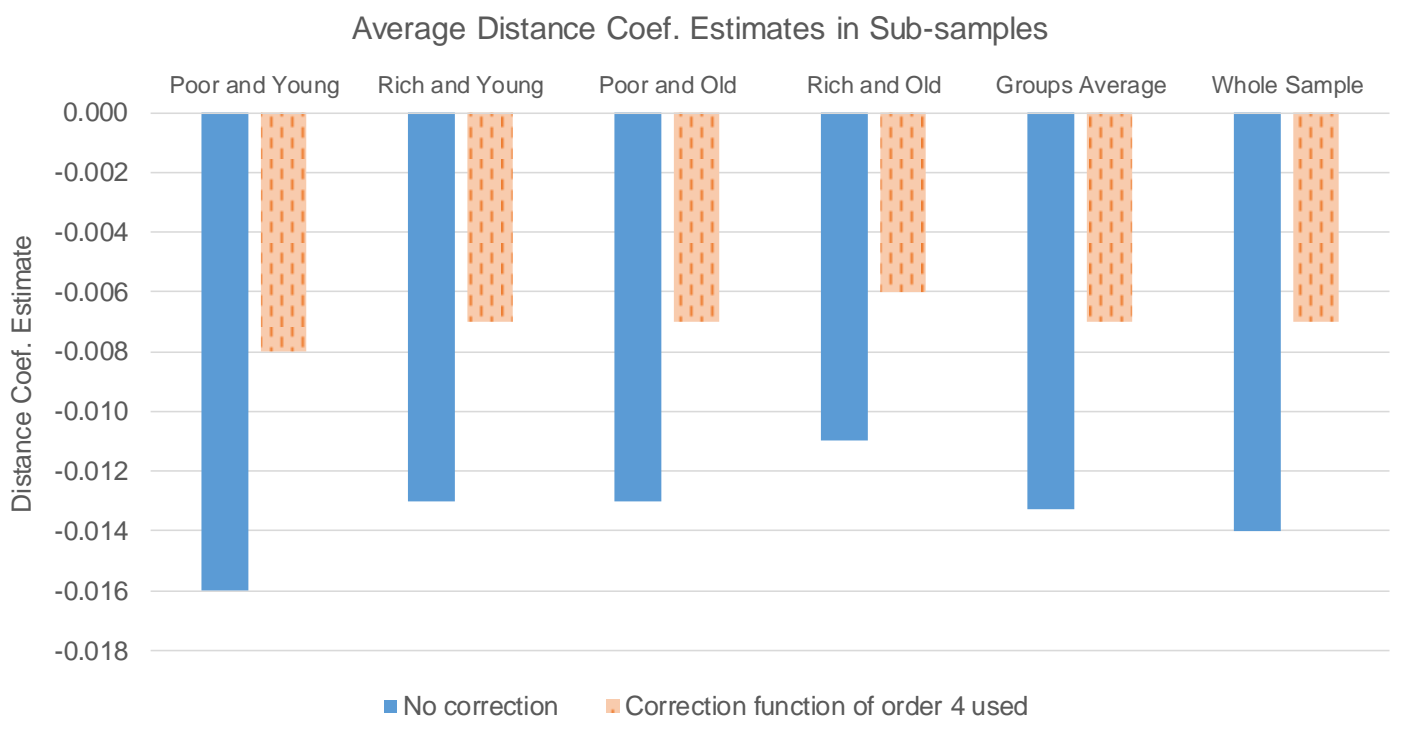




\section{Internet Appendix For Online Publication Only}


Appendix Table 1: Tobit Estimation of Household Portfolio Choice with Correction for Location Selection, Full Controls, with Distance Indicator Variables

This table presents the results from the Tobit regressions of our household portfolio choice model with corrections for location selection bias, and with controls for household demographics, stock characteristics, industries and MSA characteristics included. The results are time-series averages of the monthly coefficient estimates and their $t$-statistics (shown in parentheses) based on standard errors clustered at the household level. *,**,*** denote statistical significance at $10 \%, 5 \%, 1 \%$ respectively. The dependent variable $w_{j}^{i}$ is the portfolio weight allocated to stock $j$ by household $i$. The key explanatory variable is Away, an indicator variable that equals one if the distance between household $i$ 's residential zip code area and the zip code area of stock $j$ 's headquarters is greater than a specific threshold value. In columns (1) to (2), the distance (away) threshold is 100 miles, and in columns (3) to (4) it is 250 miles. The household demographics controls LogIncome to Kids, the stock characteristics controls LogPrice to Volatility, the industry controls, and the MSA characteristics controls $\log \operatorname{Pop}_{c}$ to $\operatorname{LogHPI}_{h}$ are the same as those shown in Table $4 . \Psi^{1 s t}$ to $\Psi^{4 t h}$ denote the orders of the polynomials used for approximating the correction functions $\Psi^{s}\left(p_{i, c}\right)$ and $\Psi^{d}\left(p_{i, h}, p_{i, c}\right)$ for location selections. The constant term and the standard deviation of the normal error term in the Tobit regression are not reported for clarity purposes. The sample period is January 1991 to November 1996.

\begin{tabular}{|c|c|c|c|c|}
\hline & \multicolumn{2}{|c|}{100 Miles Away } & \multicolumn{2}{|c|}{250 Miles Away } \\
\hline & (1) & $(2)$ & $(3)$ & $(4)$ \\
\hline \multirow[t]{2}{*}{ Away } & $-0.629^{* * *}$ & $-0.429^{* * *}$ & $-0.479^{* * *}$ & $-0.266^{* * *}$ \\
\hline & $(-33.743)$ & $(-18.130)$ & $(-30.970)$ & $(-15.941)$ \\
\hline \multirow{2}{*}{ LogIncome } & $0.027^{* *}$ & 0.020 & $0.026^{* *}$ & $0.021 *$ \\
\hline & $(2.287)$ & $(1.609)$ & $(2.230)$ & $(1.725)$ \\
\hline \multirow[t]{2}{*}{ LogAge } & $0.106^{* * *}$ & $0.109 * * *$ & $0.099^{* * *}$ & $0.107^{* * *}$ \\
\hline & $(4.512)$ & $(4.637)$ & $(4.198)$ & $(4.527)$ \\
\hline \multirow[t]{2}{*}{ Managerial } & $-0.021^{*}$ & -0.019 & -0.019 & -0.016 \\
\hline & $(-1.809)$ & $(-1.583)$ & $(-1.598)$ & $(-1.398)$ \\
\hline \multirow{2}{*}{ SalesServices } & $-0.036^{* *}$ & $-0.034^{* *}$ & $-0.034^{* *}$ & $-0.033^{* *}$ \\
\hline & $(-2.214)$ & $(-2.091)$ & $(-2.111)$ & $(-2.067)$ \\
\hline \multirow[t]{2}{*}{ WhiteCollar } & -0.029 & -0.033 & -0.029 & -0.031 \\
\hline & $(-1.453)$ & $(-1.596)$ & $(-1.460)$ & $(-1.479)$ \\
\hline \multirow[t]{2}{*}{ BlueCollar } & -0.041 & -0.039 & -0.041 & -0.038 \\
\hline & $(-1.563)$ & $(-1.498)$ & $(-1.574)$ & $(-1.446)$ \\
\hline \multirow[t]{2}{*}{ Male } & $0.033^{*}$ & $0.033^{*}$ & $0.029^{*}$ & $0.029^{*}$ \\
\hline & $(1.947)$ & (1.930) & $(1.668)$ & $(1.702)$ \\
\hline \multirow[t]{2}{*}{ Married } & -0.012 & -0.005 & -0.014 & -0.007 \\
\hline & $(-0.884)$ & $(-0.378)$ & $(-1.006)$ & $(-0.530)$ \\
\hline \multirow[t]{2}{*}{ Kids } & $-0.010^{*}$ & $-0.011^{*}$ & $-0.012^{* *}$ & $-0.012^{* *}$ \\
\hline & $(-1.870)$ & $(-1.907)$ & $(-2.139)$ & $(-2.129)$ \\
\hline \multirow[t]{2}{*}{ LogPrice } & $-0.380^{* * *}$ & $-0.374^{* * *}$ & $-0.381 * * *$ & $-0.374^{* * *}$ \\
\hline & $(-29.864)$ & $(-29.402)$ & $(-29.872)$ & $(-29.410)$ \\
\hline \multirow[t]{2}{*}{ LogSize } & $0.428^{* * *}$ & $0.426 * * *$ & $0.428^{* * *}$ & $0.426^{* * *}$ \\
\hline & $(52.441)$ & $(52.381)$ & $(52.466)$ & $(52.390)$ \\
\hline \multirow[t]{2}{*}{ BTM } & $0.099^{* * *}$ & $0.101^{* * *}$ & $0.098^{* * *}$ & $0.101^{* * *}$ \\
\hline & $(6.407)$ & $(6.426)$ & $(6.347)$ & $(6.405)$ \\
\hline \multirow[t]{2}{*}{ Turnover } & $0.357 * * *$ & $0.348^{* * *}$ & $0.364^{* * *}$ & $0.351^{* * *}$ \\
\hline & $(25.582)$ & $(24.808)$ & $(26.343)$ & $(25.125)$ \\
\hline \multirow[t]{2}{*}{ Momentum } & $-0.034^{* *}$ & $-0.035^{* *}$ & $-0.035^{* *}$ & $-0.035^{* *}$ \\
\hline & $(-2.171)$ & $(-2.297)$ & $(-2.229)$ & $(-2.322)$ \\
\hline \multirow[t]{2}{*}{ Volatility } & -0.002 & -0.005 & -0.008 & -0.006 \\
\hline & $(0.719)$ & $(0.756)$ & $(0.600)$ & $(0.728)$ \\
\hline \multirow[t]{2}{*}{$\operatorname{LogPop}_{c}$} & -0.005 & -0.023 & -0.001 & -0.027 \\
\hline & $(-0.594)$ & $(-1.006)$ & $(-0.105)$ & $(-1.190)$ \\
\hline $\mathrm{Unemp}_{c}$ & $-0.016^{* * *}$ & $-0.011^{* *}$ & $-0.011^{* *}$ & -0.008 \\
\hline & $(-3.118)$ & $(-2.076)$ & $(-2.178)$ & $(-1.502)$ \\
\hline Incomepc $_{c}$ & $-0.012^{* * *}$ & $-0.010 * * *$ & $-0.009 * * *$ & $-0.008^{* * *}$ \\
\hline & $(-6.212)$ & $(-3.756)$ & $(-4.650)$ & $(-3.284)$ \\
\hline $\operatorname{LogHPI}_{c}$ & -0.183 & 0.015 & -0.414 & -0.075 \\
\hline & $(-0.815)$ & $(-0.429)$ & $(-1.624)$ & $(-0.511)$ \\
\hline $\operatorname{LogPop}_{h}$ & $-0.021 * *$ & $-0.094^{* * *}$ & $-0.025 * * *$ & $-0.111^{* * *}$ \\
\hline & $(-2.502)$ & $(-4.148)$ & $(-3.088)$ & $(-4.815)$ \\
\hline Unemp $_{h}$ & -0.004 & $0.015^{* *}$ & -0.004 & $0.017^{* *}$ \\
\hline & $(-0.908)$ & $(2.187)$ & $(-0.896)$ & $(2.500)$ \\
\hline Incomepc $_{h}$ & $-0.008^{* * *}$ & $-0.010^{* * *}$ & $-0.005^{* *}$ & $-0.010^{* * *}$ \\
\hline & $(-3.494)$ & $(-3.734)$ & $(-2.309)$ & $(-3.519)$ \\
\hline $\log \mathrm{HPI}_{h}$ & -0.422 & 0.066 & -0.740 & -0.047 \\
\hline & $(-0.055)$ & $(0.703)$ & $(-0.584)$ & $(0.615)$ \\
\hline Industry controls & YES & YES & YES & YES \\
\hline$\Psi^{1 s t}$ & $\mathrm{NO}$ & YES & $\mathrm{NO}$ & YES \\
\hline$\Psi^{2 n d}$ & NO & YES & NO & YES \\
\hline$\Psi^{3 r d}$ & $\mathrm{NO}$ & YES & $\mathrm{NO}$ & YES \\
\hline$\Psi^{4 t h}$ & $\mathrm{NO}$ & YES & $\mathrm{NO}$ & YES \\
\hline
\end{tabular}


Appendix Table 2: Conditional Logit Estimation of Household Location Choice, Alternative Location-Choice Models

This table presents the results from the maximum likelihood estimation of three alternative conditional logit models for household location choices. $t$-statistics (shown in parentheses) are based on standard errors clustered at the household level, with $*, * *, * * *$ denoting statistical significance at $10 \%, 5 \%, 1 \%$ respectively. The choice set of households in Columns 1 and 2 consists of 57 MSAs, while in Column 3 of 53 MSAs. The dependent variable is an indicator variable that equals one if a household resides in the specific MSA. In Column 1, we exclude household income (and its interactions with MSA demographics) from the explanatory variables. In Column 2, we exclude household income and job codes (and their interactions with MSA demographics) from the explanatory variables. In Column 3, we include the financial characteristics of the stocks with headquarters in each city as additional explanatory variables. All other explanatory variables are the same as in Table 3. Log-likelihood is the estimated log-likelihood value. Pseudo $R^{2}$ is the McFadden's pseudo $R^{2}$ measure based on the estimated log-likelihood value. $N$ is the number of observations.

\begin{tabular}{|c|c|c|c|}
\hline & (1) & (2) & (3) \\
\hline LogPop & $\begin{array}{l}0.323 \\
(1.33)\end{array}$ & $\begin{array}{l}0.349 \\
(1.44)\end{array}$ & $\begin{array}{l}-0.672 \\
(-1.55)\end{array}$ \\
\hline Unemp & $\begin{array}{c}-0.512^{* * *} \\
(-3.03)\end{array}$ & $\begin{array}{c}-0.514^{* * *} \\
(-3.04)\end{array}$ & $\begin{array}{l}-0.070 \\
(-0.25)\end{array}$ \\
\hline Incomepc & $\begin{array}{c}0.322^{* * *} \\
(5.78)\end{array}$ & $\begin{array}{c}0.316^{* * *} \\
(5.70)\end{array}$ & $\begin{array}{c}-0.249^{* *} \\
(-2.21)\end{array}$ \\
\hline LogHPI & $\begin{array}{c}6.831^{* * *} \\
(3.41)\end{array}$ & $\begin{array}{c}6.857^{* * *} \\
(3.43)\end{array}$ & $\begin{array}{l}-4.636 \\
(-1.34)\end{array}$ \\
\hline LogPrice_MSA & & & $\begin{array}{c}-0.446^{* * *} \\
(-8.87)\end{array}$ \\
\hline LogSize_MSA & & & $\begin{array}{c}0.140^{* * * *} \\
(8.84)\end{array}$ \\
\hline BTM_MSA & & & $\begin{array}{c}-0.484^{* * *} \\
(-5.31)\end{array}$ \\
\hline Turnover_MSA & & & $\begin{array}{c}1.790^{* * *} \\
(17.46)\end{array}$ \\
\hline Momentum_MSA & & & $\begin{array}{c}-0.308^{* * *} \\
(-4.08)\end{array}$ \\
\hline Volatility_MSA & & & $\begin{array}{c}-1.792^{* * *} \\
(-5.61)\end{array}$ \\
\hline LogPop $\times$ LogIncome & & & $\begin{array}{c}0.083^{* * *} \\
(2.64)\end{array}$ \\
\hline LogPop $\times$ LogAge & $\begin{array}{c}0.147^{* *} \\
(2.35)\end{array}$ & $\begin{array}{c}0.155^{* *} \\
(2.47)\end{array}$ & $\begin{array}{c}0.173^{* * *} \\
(2.61)\end{array}$ \\
\hline LogPop $\times$ Managerial & $\begin{array}{c}0.099^{* * *} \\
(3.18)\end{array}$ & & $\begin{array}{c}0.081^{* *} \\
(2.47)\end{array}$ \\
\hline LogPop $\times$ SalesServices & $\begin{array}{c}0.035 \\
(0.70)\end{array}$ & & $\begin{array}{l}0.043 \\
(0.81)\end{array}$ \\
\hline LogPop $\times$ WhiteCollar & $\begin{array}{c}0.195^{* * *} \\
(2.99)\end{array}$ & & $\begin{array}{c}0.218^{* * * *} \\
(3.16)\end{array}$ \\
\hline LogPop $\times$ BlueCollar & $\begin{array}{l}0.069 \\
(0.96)\end{array}$ & & $\begin{array}{l}0.062 \\
(0.80)\end{array}$ \\
\hline LogPop $\times$ Male & $\begin{array}{l}0.061 \\
(1.25)\end{array}$ & $\begin{array}{l}0.048 \\
(1.00)\end{array}$ & $\begin{array}{l}0.032 \\
(0.63)\end{array}$ \\
\hline LogPop $\times$ Married & $\begin{array}{l}-0.046 \\
(-1.37)\end{array}$ & $\begin{array}{l}-0.047 \\
(-1.39)\end{array}$ & $\begin{array}{c}-0.062^{*} \\
(-1.67)\end{array}$ \\
\hline LogPop $\times$ Kids & $\begin{array}{l}-0.012 \\
(-0.78)\end{array}$ & $\begin{array}{l}-0.013 \\
(-0.83)\end{array}$ & $\begin{array}{l}-0.014 \\
(-0.88)\end{array}$ \\
\hline
\end{tabular}


Table Cont'd: Conditional Logit Estimation of Household Location Choice, Alternative Location-Choice Models

\begin{tabular}{|c|c|c|c|}
\hline & $(1)$ & $(2)$ & $(3)$ \\
\hline Unemp $\times$ LogIncome & & & $\begin{array}{c}-0.044^{* *} \\
(-2.30)\end{array}$ \\
\hline Unemp $\times$ LogAge & $\begin{array}{c}0.095^{* *} \\
(2.21)\end{array}$ & $\begin{array}{c}0.099^{* *} \\
(2.29)\end{array}$ & $\begin{array}{c}0.100^{* *} \\
(2.27)\end{array}$ \\
\hline Unemp $\times$ Managerial & $\begin{array}{l}0.002 \\
(0.11)\end{array}$ & & $\begin{array}{l}0.021 \\
(1.01)\end{array}$ \\
\hline Unemp $\times$ SalesServices & $\begin{array}{l}-0.005 \\
(-0.15)\end{array}$ & & $\begin{array}{l}-0.005 \\
(-0.14)\end{array}$ \\
\hline Unemp $\times$ WhiteCollar & $\begin{array}{l}0.060 \\
(1.49)\end{array}$ & & $\begin{array}{c}0.070^{*} \\
(1.65)\end{array}$ \\
\hline Unemp $\times$ BlueCollar & $\begin{array}{c}0.121^{* * *} \\
(3.17)\end{array}$ & & $\begin{array}{c}0.154^{* * *} \\
(3.51)\end{array}$ \\
\hline Unemp $\times$ Male & $\begin{array}{l}0.012 \\
(0.32)\end{array}$ & $\begin{array}{l}0.011 \\
(0.30)\end{array}$ & $\begin{array}{c}0.050 \\
(1.31)\end{array}$ \\
\hline Unemp $\times$ Married & $\begin{array}{l}-0.012 \\
(-0.54)\end{array}$ & $\begin{array}{l}-0.015 \\
(-0.67)\end{array}$ & $\begin{array}{l}-0.017 \\
(-0.68)\end{array}$ \\
\hline Unemp $\times$ Kids & $\begin{array}{c}0.018^{*} \\
(1.72)\end{array}$ & $\begin{array}{c}0.017^{*} \\
(1.65)\end{array}$ & $\begin{array}{c}0.018^{*} \\
(1.77)\end{array}$ \\
\hline Incomepc $\times$ LogIncome & & & $\begin{array}{c}0.054^{* * *} \\
(6.57)\end{array}$ \\
\hline Incomepc $\times$ LogAge & $\begin{array}{c}-0.048^{* * *} \\
(-3.27)\end{array}$ & $\begin{array}{c}-0.048^{* * *} \\
(-3.27)\end{array}$ & $\begin{array}{c}-0.056^{* * *} \\
(-3.28)\end{array}$ \\
\hline Incomepc $\times$ Managerial & $\begin{array}{l}-0.006 \\
(-0.83)\end{array}$ & & $\begin{array}{l}-0.012 \\
(-1.36)\end{array}$ \\
\hline Incomepc $\times$ SalesServices & $\begin{array}{c}-0.021^{*} \\
(-1.68)\end{array}$ & & $\begin{array}{l}-0.018 \\
(-1.26)\end{array}$ \\
\hline Incomepc $\times$ WhiteCollar & $\begin{array}{l}-0.016 \\
(-0.98)\end{array}$ & & $\begin{array}{l}-0.005 \\
(-0.27)\end{array}$ \\
\hline Incomepc $\times$ BlueCollar & $\begin{array}{l}-0.020 \\
(-1.13)\end{array}$ & & $\begin{array}{l}0.000 \\
(0.01)\end{array}$ \\
\hline Incomepc $\times$ Male & $\begin{array}{c}-0.047^{* * * *} \\
(-4.51)\end{array}$ & $\begin{array}{c}-0.046^{* * *} \\
(-4.42)\end{array}$ & $\begin{array}{c}-0.059 * * * \\
(-4.66)\end{array}$ \\
\hline Incomepc $\times$ Married & $\begin{array}{c}-0.022^{* * *} \\
(-2.80)\end{array}$ & $\begin{array}{c}-0.022^{* * *} * \\
(-2.75)\end{array}$ & $\begin{array}{c}-0.042^{* * *} \\
(-4.43)\end{array}$ \\
\hline Incomepc $\times$ Kids & $\begin{array}{l}0.001 \\
(0.22)\end{array}$ & $\begin{array}{c}0.001 \\
(0.26)\end{array}$ & $\begin{array}{l}0.000 \\
(0.05)\end{array}$ \\
\hline LogHPI $\times$ LogIncome & & & $\begin{array}{c}1.045^{* * *} \\
(4.23)\end{array}$ \\
\hline LogHPI $\times$ LogAge & $\begin{array}{c}-1.281^{* *} \\
(-2.50)\end{array}$ & $\begin{array}{c}-1.321^{* * *} \\
(-2.58)\end{array}$ & $\begin{array}{c}-1.117^{* *} \\
(-2.09)\end{array}$ \\
\hline LogHPI $\times$ Managerial & $\begin{array}{l}-0.199 \\
(-0.81)\end{array}$ & & $\begin{array}{l}-0.221 \\
(-0.86)\end{array}$ \\
\hline LogHPI $\times$ SalesServices & $\begin{array}{l}-0.391 \\
(-1.01)\end{array}$ & & $\begin{array}{l}-0.314 \\
(-0.76)\end{array}$ \\
\hline LogHPI $\times$ WhiteCollar & $\begin{array}{l}-0.026 \\
(-0.05)\end{array}$ & & $\begin{array}{l}0.395 \\
(0.69)\end{array}$ \\
\hline LogHPI × BlueCollar & $\begin{array}{c}-1.691 * * * \\
(-3.03)\end{array}$ & & $\begin{array}{c}-1.221^{* *} \\
(-2.08)\end{array}$ \\
\hline LogHPI $\times$ Male & $\begin{array}{l}-0.694 \\
(-1.50)\end{array}$ & $\begin{array}{l}-0.744 \\
(-1.61)\end{array}$ & $\begin{array}{l}-0.756 \\
(-1.53)\end{array}$ \\
\hline LogHPI $\times$ Married & $\begin{array}{l}-0.308 \\
(-1.06)\end{array}$ & $\begin{array}{l}-0.285 \\
(-0.99)\end{array}$ & $\begin{array}{c}-0.678^{* *} \\
(-2.19)\end{array}$ \\
\hline LogHPI $\times$ Kids & $\begin{array}{c}-0.509^{* * *} \\
(-4.14)\end{array}$ & $\begin{array}{c}-0.508^{* * *} \\
(-4.14)\end{array}$ & $\begin{array}{c}-0.529^{* * *} \\
(-4.10)\end{array}$ \\
\hline MSA industry controls & NO & NO & YES \\
\hline $\begin{array}{l}\text { Log-likelihood } \\
\text { Pseudo } R^{2}\end{array}$ & $\begin{array}{c}-38650.4 \\
0.1076\end{array}$ & $\begin{array}{c}-38679.2 \\
0.1069\end{array}$ & $\begin{array}{c}-36268.2 \\
0.1247\end{array}$ \\
\hline$N$ & 610584 & 610584 & 553108 \\
\hline
\end{tabular}


Appendix Table 3: Tobit Estimation of Household Portfolio Choice with Correction for Location Selection, Full Controls, No Income or No Income and Job Code in the Location Model

This table presents the results from the Tobit regressions of our household portfolio choice model with corrections for location selection biases, and with controls for household demographics, stock characteristics, industries and MSA characteristics included. We exclude either the income of a household or the income and job code of a household from the explanatory variables in our location choice estimation (first-stage conditional logit estimation). No Income refers to the case in which we exclude household income, while No Income and Job Code refers to the case in which we exclude household income and job code in our location choice estimation. The results are time-series averages of the monthly coefficient estimates and their $t$-statistics (shown in parentheses) based on standard errors clustered at the household level from our portfolio choice estimation. ${ }^{*}, * *, * * *$ denote statistical significance at $10 \%, 5 \%, 1 \%$ respectively. The dependent variable $w_{j}^{i}$ is the portfolio weight allocated to stock $j$ by household $i$. The key explanatory variable is Distance, the distance between household $i$ 's residential zip code area and the zip code area of stock $j$ 's headquarters. The household demographics controls LogIncome to Kids, the stock characteristics controls LogPrice to Volatility, the industry controls, and the controls for MSA characteristics $\log \operatorname{Pop}_{\mathrm{c}}$ to $\log \mathrm{HPI}_{\mathrm{h}}$ are the same as those shown in Table 4. $\Psi^{1 s t}$ to $\Psi^{4 t h}$ denote the orders of the polynomials used for approximating the correction functions $\Psi^{s}\left(p_{i, c}\right)$ and $\Psi^{d}\left(p_{i, h}, p_{i, c}\right)$ for location selections. The constant term and the standard deviation of the normal error term in the Tobit regression are not reported for clarity purposes. The sample period is January 1991 to November 1996.

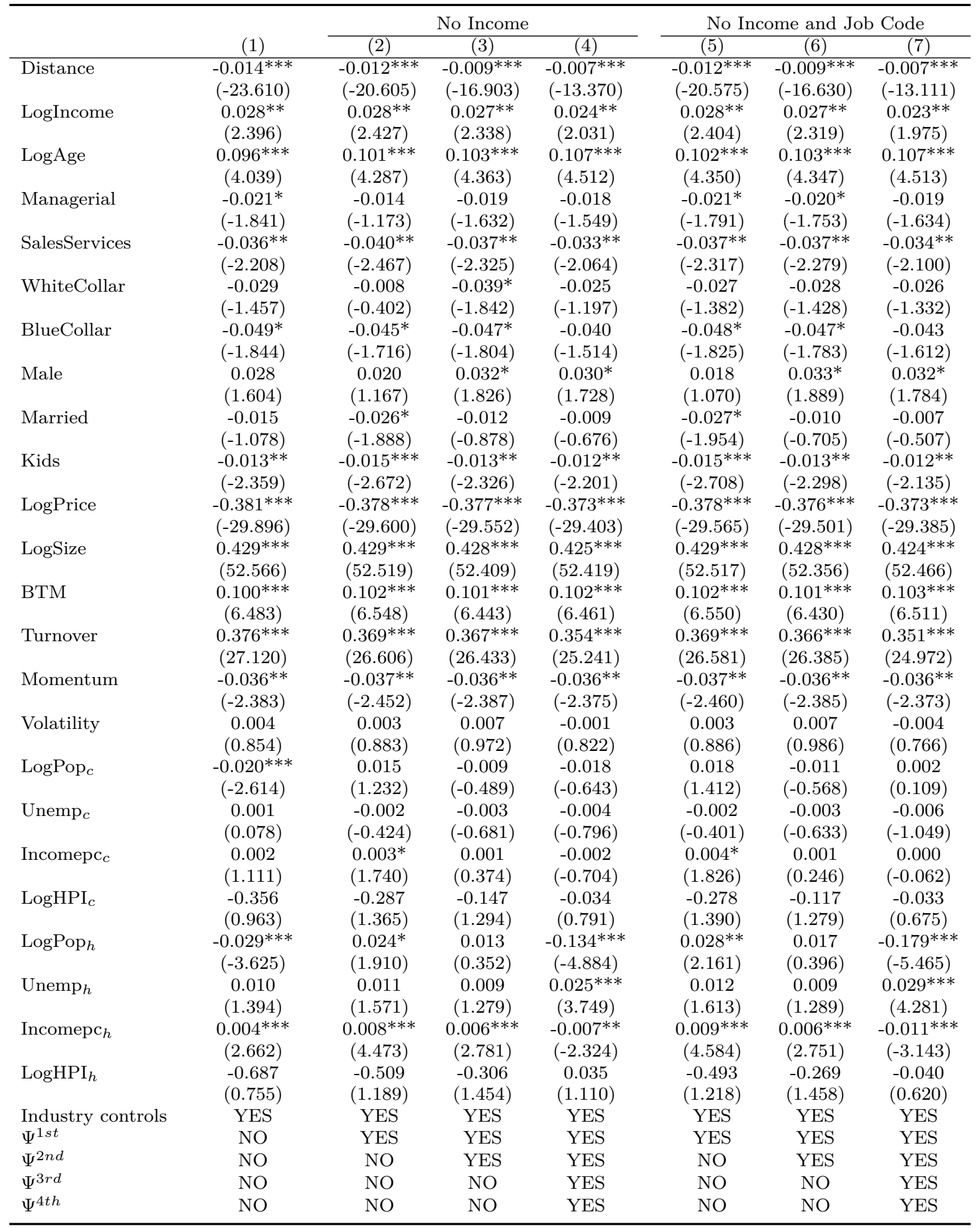


Appendix Table 4: Tobit Estimation of Household Portfolio Choice with Correction for Location Selection, Full Controls, with Stock Characteristics in the Location Model

This table presents the results from the Tobit regressions of our household portfolio choice model with corrections for location selection biases, and with controls for household demographics, stock characteristics, industries and MSA characteristics included. We control for the financial characteristics of the stocks with headquarters in each city in the explanatory variables in our location choice estimation (first-stage conditional logit estimation). The results are time-series averages of the monthly coefficient estimates and their $t$-statistics (shown in parentheses) based on standard errors clustered at the household level from our portfolio choice estimation. ${ }^{*}, * *, * * *$ denote statistical significance at $10 \%, 5 \%, 1 \%$ respectively. The dependent variable $w_{j}^{i}$ is the portfolio weight allocated to stock $j$ by household $i$. The key explanatory variable is Distance, the distance between household $i$ 's residential zip code area and the zip code area of stock $j$ 's headquarters. The household demographics controls LogIncome to Kids, the stock characteristics controls LogPrice to Volatility, the industry controls, and the controls for MSA characteristics $\operatorname{LogPop}_{c}$ to $\operatorname{LogHPI} h$ are the same as those shown in Table $4 . \Psi^{1 s t}$ to $\Psi^{4 t h}$ denote the orders of the polynomials used for approximating the correction functions $\Psi^{s}\left(p_{i, c}\right)$ and $\Psi^{d}\left(p_{i, h}, p_{i, c}\right)$ for location selections. The constant term and the standard deviation of the normal error term in the Tobit regression are not reported for clarity purposes. The sample period is January 1991 to November 1996.

\begin{tabular}{|c|c|c|c|c|}
\hline & \multicolumn{4}{|c|}{ Dependent Variable: Portfolio Weight $w_{j}^{i}$} \\
\hline & $(1)$ & $(2)$ & $(3)$ & $(4)$ \\
\hline \multirow[t]{2}{*}{ Distance } & $-0.014^{* * *}$ & $-0.011^{* * *}$ & $-0.009 * * *$ & $-0.007 * * *$ \\
\hline & $(-23.547)$ & $(-19.741)$ & $(-16.063)$ & $(-12.813)$ \\
\hline \multirow[t]{2}{*}{ LogIncome } & $0.029 * *$ & $0.035^{* * *}$ & $0.030 * *$ & $0.024^{*}$ \\
\hline & $(2.485)$ & $(2.909)$ & $(2.459)$ & $(1.953)$ \\
\hline \multirow[t]{2}{*}{ LogAge } & $0.092^{* * *}$ & $0.092 * * *$ & $0.104^{* * *}$ & $0.101^{* * *}$ \\
\hline & $(3.853)$ & $(3.844)$ & $(4.310)$ & $(4.225)$ \\
\hline \multirow[t]{2}{*}{ Managerial } & $-0.020^{*}$ & $-0.020^{*}$ & -0.017 & -0.018 \\
\hline & $(-1.741)$ & $(-1.692)$ & $(-1.475)$ & $(-1.559)$ \\
\hline \multirow{2}{*}{ SalesServices } & $-0.036^{* *}$ & $-0.037 * *$ & $-0.036 * *$ & $-0.036^{* *}$ \\
\hline & $(-2.218)$ & $(-2.304)$ & $(-2.223)$ & $(-2.226)$ \\
\hline \multirow{2}{*}{ WhiteCollar } & -0.026 & -0.020 & -0.024 & -0.028 \\
\hline & $(-1.330)$ & $(-0.986)$ & $(-1.137)$ & $(-1.361)$ \\
\hline \multirow[t]{2}{*}{ BlueCollar } & $-0.044^{*}$ & -0.041 & -0.041 & -0.036 \\
\hline & $(-1.656)$ & $(-1.543)$ & $(-1.533)$ & $(-1.340)$ \\
\hline \multirow[t]{2}{*}{ Male } & 0.026 & 0.023 & $0.030 *$ & 0.023 \\
\hline & $(1.500)$ & $(1.303)$ & $(1.718)$ & $(1.345)$ \\
\hline \multirow[t]{2}{*}{ Married } & -0.015 & -0.020 & -0.015 & -0.011 \\
\hline & $(-1.089)$ & $(-1.443)$ & $(-1.100)$ & $(-0.777)$ \\
\hline \multirow[t]{2}{*}{ Kids } & $-0.013^{* *}$ & $-0.013^{* *}$ & $-0.012^{* *}$ & $-0.012^{* *}$ \\
\hline & $(-2.275)$ & $(-2.381)$ & $(-2.160)$ & $(-2.208)$ \\
\hline \multirow[t]{2}{*}{ LogPrice } & $-0.380 * * *$ & $-0.381 * * *$ & $-0.375^{* * *}$ & $-0.369 * * *$ \\
\hline & $(-29.624)$ & $(-29.726)$ & $(-29.310)$ & $(-28.910)$ \\
\hline \multirow[t]{2}{*}{ LogSize } & $0.428^{* * *}$ & $0.429^{* * *}$ & $0.425^{* * *}$ & $0.419^{* * *}$ \\
\hline & $(52.080)$ & $(51.987)$ & $(51.794)$ & $(51.684)$ \\
\hline \multirow[t]{2}{*}{ BTM } & $0.098 * * *$ & $0.098 * * *$ & $0.098^{* * *}$ & $0.101^{* * *}$ \\
\hline & $(6.325)$ & (6.333) & $(6.318)$ & $(6.386)$ \\
\hline \multirow[t]{2}{*}{ Turnover } & $0.376 * * *$ & $0.376^{* * *}$ & $0.358 * * *$ & $0.340^{* * *}$ \\
\hline & $(26.820)$ & $(26.731)$ & $(24.865)$ & $(23.328)$ \\
\hline \multirow[t]{2}{*}{ Momentum } & $-0.037^{* *}$ & $-0.036^{* *}$ & $-0.035^{* *}$ & $-0.035^{* *}$ \\
\hline & $(-2.386)$ & $(-2.300)$ & $(-2.276)$ & $(-2.316)$ \\
\hline \multirow[t]{2}{*}{ Volatility } & 0.005 & 0.005 & 0.011 & 0.003 \\
\hline & $(0.854)$ & $(0.830)$ & $(1.012)$ & $(0.918)$ \\
\hline \multirow[t]{2}{*}{$\operatorname{LogPop}_{c}$} & $-0.023^{* * *}$ & -0.002 & 0.000 & 0.003 \\
\hline & $(-2.753)$ & $(-0.126)$ & $(0.009)$ & $(0.276)$ \\
\hline \multirow[t]{2}{*}{ Unemp $_{c}$} & 0.002 & -0.001 & -0.004 & -0.004 \\
\hline & $(0.116)$ & $(-0.372)$ & $(-0.899)$ & $(-0.880)$ \\
\hline Incomepc $_{c}$ & 0.002 & 0.003 & 0.001 & 0.000 \\
\hline & $(1.024)$ & $(1.422)$ & $(0.244)$ & $(0.096)$ \\
\hline $\operatorname{LogHPI}_{c}$ & -0.299 & -0.322 & -0.136 & -0.098 \\
\hline & $(1.232)$ & $(1.274)$ & (1.399) & (1.171) \\
\hline $\operatorname{LogPop}_{h}$ & $-0.030 * * *$ & $-0.036 * * *$ & $-0.086 * * *$ & $-0.114^{* * *}$ \\
\hline & $(-3.736)$ & $(-3.258)$ & $(-6.517)$ & $(-8.205)$ \\
\hline Unemp $_{h}$ & 0.010 & 0.006 & 0.009 & $0.019 * * *$ \\
\hline & $(1.417)$ & $(0.832)$ & $(1.158)$ & $(2.591)$ \\
\hline Incomepc $_{h}$ & $0.004^{* * *}$ & $0.003^{*}$ & -0.004 & $-0.007 * * *$ \\
\hline & $(2.792)$ & $(1.727)$ & $(-1.611)$ & $(-2.649)$ \\
\hline $\operatorname{LogHPI}_{h}$ & -0.693 & -0.716 & -0.183 & 0.325 \\
\hline & $(0.807)$ & $(0.892)$ & $(1.286)$ & $(1.599)$ \\
\hline Industry controls & YES & YES & YES & YES \\
\hline$\Psi^{1 s t}$ & NO & YES & YES & YES \\
\hline$\Psi^{2 n d}$ & $\mathrm{NO}$ & $\mathrm{NO}$ & YES & YES \\
\hline$\Psi^{3 r d}$ & $\mathrm{NO}$ & $\mathrm{NO}$ & $\mathrm{NO}$ & YES \\
\hline$\Psi^{4 t h}$ & $\mathrm{NO}$ & $\mathrm{NO}$ & $\mathrm{NO}$ & YES \\
\hline
\end{tabular}

